\title{
Integrative Taxonomy of New Zealand Stenopodidea (Crustacea: Decapoda) with New Species and Records for the Region
}

\author{
Kareen E. Schnabel ${ }^{1, *} \mathbb{0}$, Qi Kou ${ }^{2,3}$ and Peng $\mathrm{Xu}^{4}$ \\ 1 Coasts and Oceans Centre, National Institute of Water \& Atmospheric Research, Private Bag 14901 Kilbirnie, \\ Wellington 6241, New Zealand \\ 2 Institute of Oceanology, Chinese Academy of Sciences, Qingdao 266071, China; kouqi@qdio.ac.cn \\ 3 College of Marine Science, University of Chinese Academy of Sciences, Beijing 100049, China \\ 4 Key Laboratory of Marine Ecosystem Dynamics, Second Institute of Oceanography, \\ Ministry of Natural Resources, Hangzhou 310012, China; xupeng@sio.org.cn \\ * Correspondence: kareen.schnabel@niwa.co.nz; Tel.: +64-4-386-0862
}

check for

updates

Citation: Schnabel, K.E.; Kou, Q.; Xu, P. Integrative Taxonomy of New Zealand Stenopodidea (Crustacea: Decapoda) with New Species and Records for the Region. Diversity 2021, 13, 343. https://doi.org/10.3390/ d13080343

Academic Editors: Michael Wink, Patricia Briones-Fourzán and Michel E. Hendrickx

Received: 24 June 2021

Accepted: 11 July 2021

Published: 27 July 2021

Publisher's Note: MDPI stays neutral with regard to jurisdictional claims in published maps and institutional affiliations.

Copyright: (c) 2021 by the authors. Licensee MDPI, Basel, Switzerland. This article is an open access article distributed under the terms and conditions of the Creative Commons Attribution (CC BY) license (https:/ / creativecommons.org/licenses/by/ $4.0 /)$.

\begin{abstract}
The New Zealand fauna of the crustacean infraorder Stenopodidea, the coral and sponge shrimps, is reviewed using both classical taxonomic and molecular tools. In addition to the three species so far recorded in the region, we report Spongicola goyi for the first time, and formally describe three new species of Spongicolidae. Following the morphological review and DNA sequencing of type specimens, we propose the synonymy of Spongiocaris yaldwyni with S. neocaledonensis and review a proposed broad Indo-West Pacific distribution range of Spongicoloides novaezelandiae. New records for the latter at nearly $54^{\circ}$ South on the Macquarie Ridge provide the southernmost record for stenopodidean shrimp known to date.
\end{abstract}

Keywords: sponge shrimp; coral cleaner shrimp; taxonomy; cytochrome oxidase 1; 16S ribosomal RNA; association; southwest Pacific Ocean

\section{Introduction}

The unique group of coral shrimp and Venus or sponge shrimp, united in the infraorder Stenopodidea Spence Bate, 1888 [1], is a small group of marine decapod crustaceans with 92 species, 13 genera and three families currently recognized [2]. While the infraorder is well-defined considering shared morphological synapomorphies [3], the placement of the Stenopodidea within the Decapoda remains unresolved [4-6]. Similarly, the internal classification remains in flux with a recently erected family [7], four new genera [7-10] and over one-third of the current species diversity described since 2006, e.g., [11-14].

The Stenopodidea currently contains three families: (1) The shallow-water, free-living Macromaxillocarididae Alvarez, Iliffe \& Villalobos, 2006 [7] that includes the anchialine species Macromaxillocaris bahamaensis Alvarez, Iliffe \& Villalobos, 2006 [7,10]; (2) the Stenopodidae, as defined presently, include the colorful and popular ornamental shrimps in the aquarium trade $[3,15]$ and are almost exclusively free-living shallow-water taxa inhabiting coral reefs down to about $50 \mathrm{~m}$; (3) the more diverse Spongicolidae represent primarily deep-water taxa, typically associated with hexactinellid sponges or octocorals, which can extend beyond $2300 \mathrm{~m}$ depth $[3,8,12,16]$. Comparative morphology and molecular phylogenetics more recently called for internal taxonomic revisions, e.g., a molecular phylogeny provided by Chen et al. [17] refuted both the family and genus level classification and the authors suggested to unite all species in a single family Stenopodidae. More recently, Bochini et al. [10] provided additional molecular evidence and hypotheses of current taxonomic delimitations. Work is underway to increase taxon sampling and to settle the classification for this group by e.g., Kou and Goy with colleagues (unpubl.).

Stenopodidean shrimps inhabit all oceans, with an overall pan-tropical distribution and the highest diversity centered in the Indo-West Pacific [3]. The most northern record 
was provided by Hansen [18] off Iceland, in the Atlantic, the most northern record in the Pacific is Japan, while South Africa, Tasmania and New Zealand represent the southern latitudinal boundaries of this group [12,19-21]. However, the New Zealand stenopodideans have historically received limited attention. The known fauna currently only comprises three species: the first record was provided by Yaldwyn [22] for the banded coral shrimp Stenopus hispidus Olivier, 1911 [23] from northern New Zealand, followed by Spongiocaris yaldwyni Bruce \& Baba, 1973 [21] from the Bay of Plenty off the central North Island, which remained the only specimen record of this species to date (gene sequences were for one sample were recently presented by Chen et al. [17] from Tonga), and Spongicoloides novaezelandiae Baba, 1979 [20] from the Chatham Rise off the South Island. The latter species was recently reported by Goy [13] with a broad Indo-Pacific distribution, but records are either referred to other species or called into doubt in this study.

Here, we review historical and new specimens of stenopodidean shrimps collected in the New Zealand region by combining DNA sequencing and morphological classification. We provide evidence of a higher diversity for the region than previously reported, with one new record and three new species presented, including the most southern record known to date.

\section{Materials and Methods}

\subsection{Specimen Collections}

The primary study area encompasses the New Zealand charting area [24] which includes portions of the Australian Exclusive Economic Zone that surround Norfolk, Lord Howe and Macquarie Islands (Figure 1). Samples were collected between the years of 1962-2017 and from depths ranging from 0-1998 m. Most of the recent samples were provided by the following RV Tangaroa surveys: the 2003 NORFANZ voyage (TAN0308); 2008 "MacRidge 2" Macquarie Ridge voyage (TAN0803); two “Impact of resource use on vulnerable deep-sea communities" project voyages (TAN1104 and TAN1206); the 2016 "Biodiversity of the Kermadec Islands and offshore waters of the Kermadec Ridge-a coastal, marine mammal and deep-sea survey" (TAN1612); and the 2017 PoribacNewZ voyage using the ROV KIEL 6000 on the German RV Sonne (voyage SO254). Please see the Acknowledgments section for details. Specimens examined are deposited at the National Institute of Water \& Atmospheric Research, Wellington (NIWA), Museum of New Zealand Te Papa Tongarewa, Wellington (NMNZ) and Tāmaki Paenga Hira Auckland War Memorial Museum, Auckland (AWMM).

\subsection{Morphological Examination}

Morphological terminology and measurements follow Goy [3]. Measurements of specimens are given in millimeters $(\mathrm{mm})$. Postrostral carapace length (PCL) is measured along the dorsal midline, from the posterior end of the orbit to the posterior margin of the carapace; total carapace length (CL) is measured from the anterior end of the rostrum to the posterior end of the carapace; total body length (TL) is measured from the tip of the rostrum to the posterior end of the telson. Specimens were measured and illustrated using a MZ9.5 (KS, Leica, Heerbrugg, Switzerland) and SteREO Discovery V8 (QK Zeiss, Oberkochen, Germany) stereomicroscope. Line drawings and color plates were made using a Intuous Pro Graphics Tablet (WACOM, Saitama, Japan), Adobe Illustrator CS6 and Adobe Photoshop 2020 (KS) and CS4 (QK) (Adobe, San Jose, CA, USA); sample records were mapped using ArcGIS Pro version 2.6.1 (ESRI, Redlands, CA, USA) and a NIWA Basemap (Mercator 41 Projection, NIWA 2018) using maps based on NIWA Regional Bathymetry data (https: / / niwa.co.nz/our-science/oceans/bathymetry/download-the-data (accessed on 12 July 2021)).

\subsection{DNA Extraction and Analysis}

DNA was extracted from muscle or branchial tissue of recently collected specimens. Extraction using the DNeasy Blood \& Tissue Kit (QIAGEN, Germantown, MD, USA) fol- 
lowed the manufacturer's protocols. Genomic DNA was eluted in $50 \mu \mathrm{L}$ of sterile distilled $\mathrm{H}_{2} \mathrm{O}$ (RNase free) and stored at $-20{ }^{\circ} \mathrm{C}$ until processed further. A partial sequence of the mitochondrial cytochrome c oxidase I (COI) gene was amplified using the universal primer pairs LCO1490/HCO2198 [25] or the newly-designed stenopodidean-specific primer pairs: COI-stenF ( $5^{\prime}$-TTTATTTTYGGWRCWTGARSAGG- $\left.3^{\prime}\right)$ and COI-stenR $\left(5^{\prime}\right.$ TAACTGAYCGWAATMTTAAYACTTC- $3^{\prime}$ ). The $16 \mathrm{~S}$ ribosomal RNA gene was amplified using the universal primer pair 16S-arL/brH [26] or the newly-designed stenopodideanspecific primer pairs: $16 \mathrm{~S}$-stenF ( $5^{\prime}$-TTGAYGARARATADTCTGTC- $\left.3^{\prime}\right)$ and 16S-stenR $\left(5^{\prime}\right.$ CGGTBTGAACTCAAATCAT- ${ }^{\prime}$ ). Polymerase chain reaction (PCR) amplifications were performed in a reaction mix containing $25 \mu \mathrm{L}$ of Premix Taq ${ }^{\mathrm{TM}}$ (Takara, Otsu, Shiga, Japan), 2-5 $\mu \mathrm{L}$ of template DNA, $1 \mu \mathrm{L}$ of each primer $(10 \mathrm{mM})$, and sterile distilled $\mathrm{H}_{2} \mathrm{O}$ to a total volume of $50 \mu \mathrm{L}$. The PCR protocol was run on a 2720 Thermal Cycler (Applied Biosystems, Waltham, MA, USA) as follows: the reactions were processed with an initial denaturation step $\left(95^{\circ} \mathrm{C}, 3 \mathrm{~min}\right)$, followed by 35 cycles of denaturation $\left(95^{\circ} \mathrm{C}, 30 \mathrm{~s}\right)$, annealing $\left(48^{\circ} \mathrm{C}\right.$, $30 \mathrm{~s})$ and extension $\left(72{ }^{\circ} \mathrm{C}, 45 \mathrm{~s}\right)$, with a final extension of $5 \mathrm{~min}$ at $72^{\circ} \mathrm{C}$. $\mathrm{PCR}$ products were assessed by agarose gel electrophoresis, cleaned using ExoSAP-IT reagent (USB, Cleveland, $\mathrm{OH}, \mathrm{USA}$ ) and commercially sequenced (Macrogen Inc., Seoul, Korea) using the same primers used for the PCR.

The $16 \mathrm{~S}$ rRNA and COI gene sequence chromatograms were checked using CHROMAS 2.23 (Technelysium Pty Ltd., Brisbane, Australia) by eye. The forward and reverse sequence fragments were assembled by CONTIG EXPRESS (a component of Vector NTI Suite 6.0, Life Technologies, Carlsbad, CA, USA). Sequences were checked for potential contamination using the Basic Local Alignment Search Tool (BLAST) through GenBank. The homologous sequence alignment was conducted with MAFFT version 7 webserver [27] using the default parameters, and manually trimmed to the same length. The Kimura's 2-parameter genetic distances of COI and 16S rRNA genes were calculated using MEGA 6.06 [28].

The 16S phylogenetic tree was reconstructed using maximum likelihood (ML) method. The best-fit nucleotide substitution model was selected by ModelFinder [29] implemented in IQ-TREE 2.1.2 [30]. Then the ML analysis was conducted using IQ-TREE 2.1.2 and the node supports were evaluated by performing Bayesian-like transformation of aLRT (aBayes) test [31], as well as SH-like approximate likelihood ratio test (SH-aLRT) [32] and ultrafast bootstrap (UFBoot) with 1000 replicates [33]. The phylogenetic trees were visualized using FigTree 1.4.3 [34] and annotated with Adobe Photoshop CS4 ${ }^{\circledR}$. Finally, all the new sequences were submitted to the GenBank database (Table 1). 


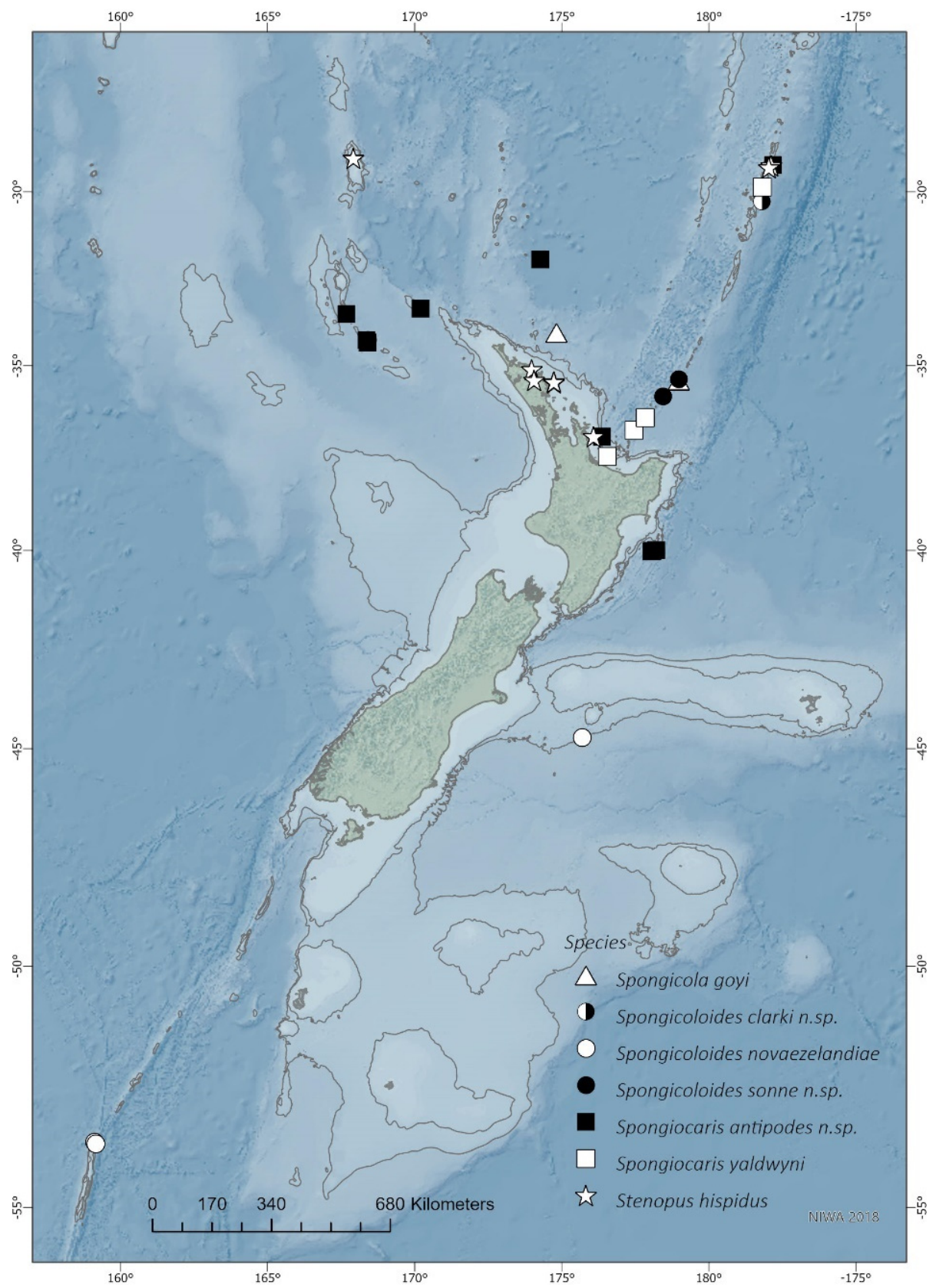

Figure 1. Map of the New Zealand region showing sampling locations for New Zealand Stenopodidea. 1000 and $2000 \mathrm{~m}$ bathymetric contours are highlighted. 


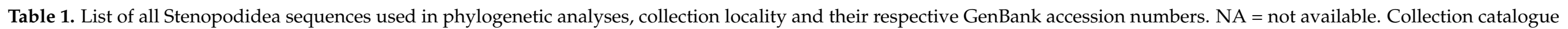
numbers in bold indicate misidentified specimens. GenBank accession numbers in bold indicate new sequences presented in this study.

\begin{tabular}{|c|c|c|c|c|c|c|c|}
\hline Family & Genus & Species & Collection Cat. No. & Collection Locality & CO1 & 16S rRNA & $\begin{array}{l}\text { Sequence } \\
\text { References }\end{array}$ \\
\hline \multirow[t]{4}{*}{ Macromaxillocarididae } & Chicosciencea & Chicosciencea pernambucensis & DZ/UFRGS-6779 & Pernambuco, Brazil & $\mathrm{NA}$ & MN482688 & [10] \\
\hline & Macromaxillocaris & Macromaxillocaris bahamaensis & ULLZ-11769 & Eleuthera, Bahamas & NA & KX086378 & [17] \\
\hline & Microprosthema & Microprosthema semilaeve & MNHN-IU-2013-4307 & Guadeloupe & NA & KX086382 & [17] \\
\hline & & Microprosthema takedai & MNHN-IU-2014-6693 & Vanuatu & NA & KX086404 & [17] \\
\hline \multirow[t]{17}{*}{ Spongicolidae } & Engystenopus & Engystenopus palmipes & NTOU-M01900 & The Philippines & NA & KX086379 & {$[17]$} \\
\hline & Paraspongicola & Paraspongicola inflatus & MNHN-IU-2014-12066 & New Caledonia & NA & KX086392 & [17] \\
\hline & Spongicola & Spongicola andamanicus & NTOU-M01903 & South China Sea & $\mathrm{NA}$ & KX086415 & [17] \\
\hline & & Spongicola goyi & NIWA-127123 & New Zealand & MZ539859 & MZ531909 & this study \\
\hline & & & NTOU-M01905 & South China Sea & NA & KX086426 & [17] \\
\hline & & Spongicola levigatus & NTOU-M01876 & South China Sea & KU188325 \# & KU188325 \# & [5] \\
\hline & & Spongicola robustus & MNHN-IU-2010-85 & Madagascar & NA & KX086395 & [17] \\
\hline & & Spongicoloides corbitellus & MBM-286006 & $\begin{array}{c}\text { Seamount near the } \\
\text { Mariana Trench }\end{array}$ & MG386936 & MG429776 & [35] \\
\hline & & Spongicoloides iheyaensis & NTOU-M01908 & Taiwan & NA & KX086424 & [17] \\
\hline & & Spongicoloides novaezelandiae & NMNZ-CR.1889 & New Zealand & MZ539861 & MZ531911 & This study \\
\hline & & & NIWA-40567 & New Zealand & MZ539862 & MZ531912 & This study \\
\hline & & & NIWA-40638 & New Zealand & MZ539863 & MZ531913 & This study \\
\hline & & & MNHN-IU-2013-19488 & New Caledonia & MZ539867 & MZ531918 & This study \\
\hline & & & MNHN-IU-2013-19622 & Vanuatu & NA & MZ531917 & This study \\
\hline & & & MNHN-IU-2013-19625 & New Caledonia & NA & MZ531919 & This study \\
\hline & & & MNHN-IU-2013-19627 & New Caledonia & NA & MZ531920 & This study \\
\hline & & & MNHN-IU-2013-19630 & New Caledonia & NA & MZ53192 & This study \\
\hline
\end{tabular}


Table 1. Cont.

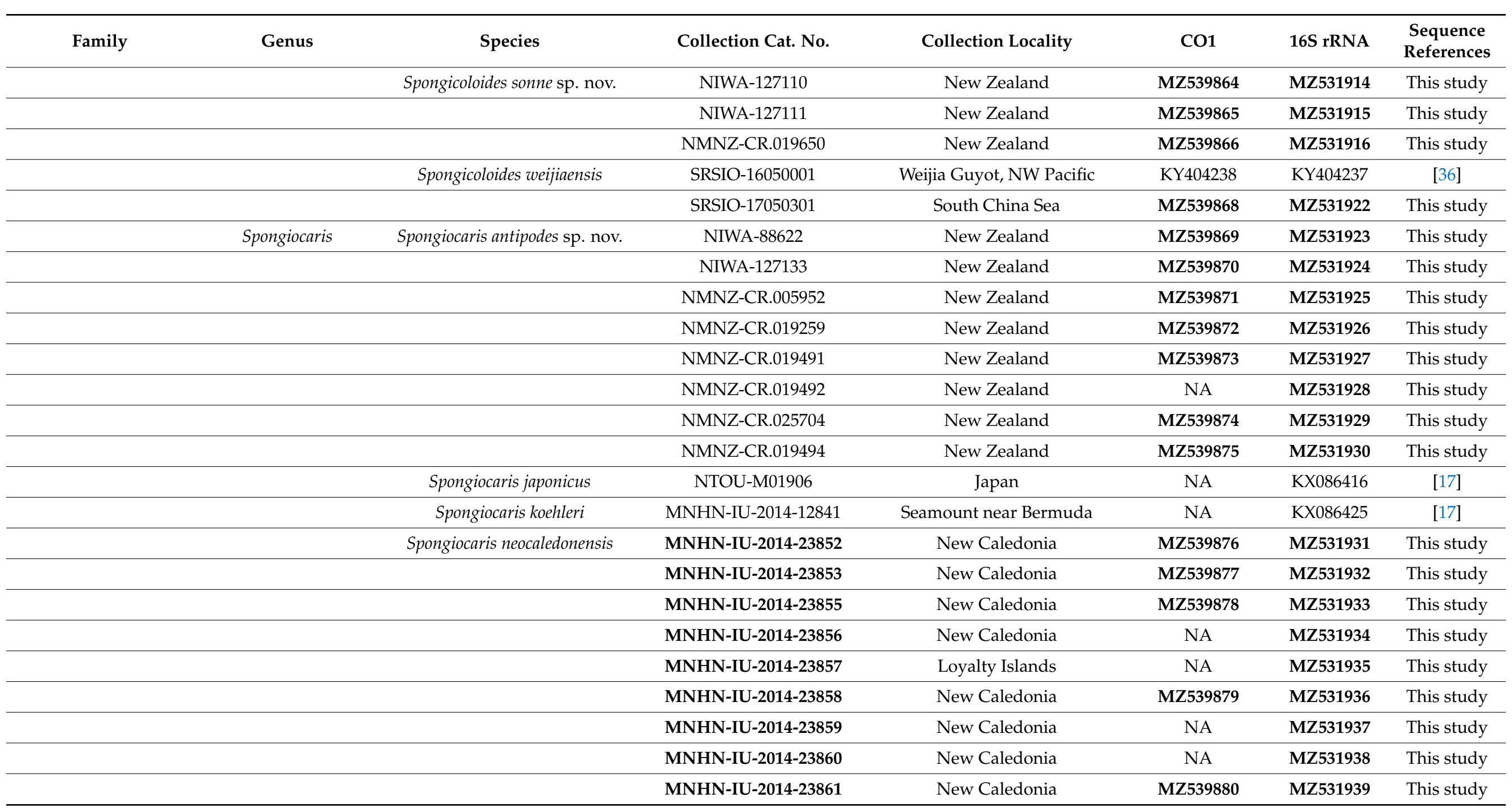


Table 1. Cont.

\begin{tabular}{|c|c|c|c|c|c|c|c|}
\hline Family & Genus & Species & Collection Cat. No. & Collection Locality & $\mathrm{CO} 1$ & 16S rRNA & $\begin{array}{l}\text { Sequence } \\
\text { References }\end{array}$ \\
\hline & & Spongiocaris panglao & NTOU-M01909 & The Philippines & NA & KX086429 & [17] \\
\hline & & & Sun et al. (2018) * & Seamount near the Yap Trench & MG812382 \# & MG812382 \# & [37] \\
\hline & & Spongiocaris yaldwyni & NMNZ-CR.1888 & New Zealand & NA & MZ531940 & This study \\
\hline & & & NIWA-82821 & New Zealand & MZ539881 & MZ531941 & This study \\
\hline & & & NIWA-83102 & New Zealand & MZ539882 & MZ531942 & This study \\
\hline \multirow[t]{12}{*}{ Stenopodidae } & Juxtastenopus & Juxtastenopus spinulatus & MNHN-IU-2014-6692 & Vanuatu & NA & KX086403 & [17] \\
\hline & Odontozona & Odontozona meloi & MNHN-IU-2013-2887 & French Guinea & NA & KX086387 & [17] \\
\hline & Richardina & Richardina spinicincta & MNHN-IU-2013-19177 & Guadeloupe & NA & KX086442 & [17] \\
\hline & Stenopus & Stenopus goyi & NTOU-M01912 & The Philippines & NA & KX086422 & [17] \\
\hline & & Stenopus hispidus & NIWA-118168 & New Zealand & NA & MZ531943 & This study \\
\hline & & & AM-MA-168313 & New Zealand & MZ539883 & MZ531944 & This study \\
\hline & & & MNHN-IU-2013-233 & Papua New Guinea & NA & KX086420 & [17] \\
\hline & & Stenopus pyrsonotus & MNHN-IU-2011-8952 & French Polynesia & NA & KX086431 & [17] \\
\hline & & Stenopus scutellatus & MNHN-IU-2013-4378 & Guadeloupe & NA & KX086432 & [17] \\
\hline & & Stenopus spinosus & CCDB-1525 & Sao Paulo, Brazil & MF490042 & MF490145 & [38] \\
\hline & & Stenopus tenuirostris & MNHN-IU-2013-10246 & Papua New Guinea & NA & KX086434 & [17] \\
\hline & & Stenopus zanzibaricus & MNHN-IU-2013-10243 & Papua New Guinea & NA & KX086441 & [17] \\
\hline \multirow[t]{4}{*}{ Outgroups } & & Alvinocaris chelys & NTOU-M01671 & Taiwan & NA & KX086443 & [17] \\
\hline & & Gnathophyllum americanum & MSLKHC-CA02 & Aquarium shop, Hong Kong & NA & KX086444 & [17] \\
\hline & & Palaemon serratus & MSLKHC-CA98 & Hawaii & NA & KX086445 & [17] \\
\hline & & Procaris hawaiiana & OUMNH.ZC.2010-13-007 & Hawaii & NA & KX086446 & [17] \\
\hline
\end{tabular}

* Collection catalogue number was not provided. " Sequences are extracted from complete mitochondrial genome sequence. 


\section{Results}

\subsection{Molecular Taxonomy}

A total of $32 \mathrm{CO} 1$ and $7016 \mathrm{~S}$ rRNA sequences were included in our analyses. The final CO1 and 16S rRNA dataset for phylogeny inference were trimmed to the same length after the alignments and consisted of $590 \mathrm{bp}$ and $390 \mathrm{bp}$, respectively. The best-fit models for $16 \mathrm{~S}$ rRNA dataset selected by ModelFinder is TIM3 + F + I + G4. The Kimura's 2-parameter pair-wise genetic distances between individuals for the CO1 and 16S rRNA datasets are shown in Tables S1 and S2.

For the $\mathrm{CO} 1$ dataset, the inter-generic genetic divergences of Stenopodidea ranged from $8.5 \%$ (between Spongiocaris yaldwyni and Spongicoloides sonne sp. nov.) to $26.6 \%$ (between Spongicola goyi and Spongicoloides sonne sp. nov.). The intra-generic genetic divergences ranged from $3.8 \%$ (between Spongicoloides novaezelandiae and S. clarki sp. nov.) to 16.8\% (between Stenopus hispidus and S. spinosus). The intra-specific genetic divergences ranged from $0.0 \%$ to $4.2 \%$ (between MNHN-IU-2014-23855 and NIWA-83102 in Spongiocaris yaldwyni). These high levels of intraspecific divergences represent substantial internal genetic structure and may warrant further investigation.

For the 16S rRNA dataset, the inter-generic genetic divergences of Stenopodidea ranged from $4.0 \%$ (between Juxtastenopus spinulatus and Stenopus goyi) to $27.5 \%$ (between Microprosthema takedai and Spongicola levigatus). The intra-generic genetic divergences ranged from 0.6\% (between Spongiocaris japonica and S. panglao) to 17.1\% (between Spongicoloides iheyaensis and $S$. sonne sp. nov.). The intra-specific genetic divergences ranged from $0.0 \%$ to 2.6\% (between MNHN-IU-2014-12842 and MNHN-IU-2014-23855, in Spongiocaris yaldwyni).

The phylogenetic trees inferred from ML analysis was generally well supported (Figure 2). Our findings show the ingroup (Stenopodidea) was recognized as a monophyletic group with high support values. At the familial level, Macromaxillocarididae was at the basal position and monophyletic, but with weak support. The monophyly of the other two families, Spongicolidae and Stenopodidae was not supported, as the spongicolid genus Globospongicola Komai \& Saito, 2006 [8] was embedded in the Stenopodidae clade. At the generic level, Stenopus, Spongicola, Spongiocaris and Spongicoloides were suggested to be non-monophyletic, which was generally in accord with the results of previous phylogenetic studies [10,17]. Specifically, Stenopus, Spongicola and Spongiocaris are paraphyletic, while the species of Spongicoloides formed a polyphyletic assemblage. At the specific level, all the species were well separated. Significantly, our tree suggested that Spongiocaris neocaledonensis should be the synonym of $S$. yaldwyni, and some specimens previously identified as Spongicoloides novaezelandiae in Goy [13] are actually S. weijiaensis $\mathrm{Xu}$, Zhou \& Wang, 2017 [36] or S. sonne sp. nov. These findings are discussed further under the species below.

\subsection{Systematics}

Order DECAPODA Latreille, 1802 [39]

Infraorder STENOPODIDEA Spence Bate, 1888 [1]

Family SPONGICOLIDAE Schram, 1986 [40]

Genus Spongicola de Haan, 1844 [41]

\subsubsection{Spongicola goyi Saito \& Komai, 2008}

In (Figures 1-4). Spongicola goyi Saito \& Komai, 2008 [12]: 107.—Goy 2010 [3]: 224.—De Grave \& Fransen 2011 [42]: 251.-Goy 2015 [13]: 307.

Material examined. Northland. $1 \mathrm{M}$ (PCL: $5.7 \mathrm{~mm}$ ); Seamount \#441, 34.043 ${ }^{\circ} \mathrm{S}$, $174.817^{\circ}$ E, 880-792 m; 19 Apr 2002; R/V Kaharoa Stn. KAH0204/47; 'seamount' sled; NIWA 3621. Southern Kermadec Ridge. 1 F ov. (PCL: 5.9 mm); Southern Kermadec Ridge, $35.380^{\circ}$ S, $178.980^{\circ}$ E, 1184.1 m; 7 February 2017; RV Sonne Stn. SO254/33ROV08, Remote Operated Vehicle; NIWA 127111; found inside Corbitella sp.; NIWA 127123. 


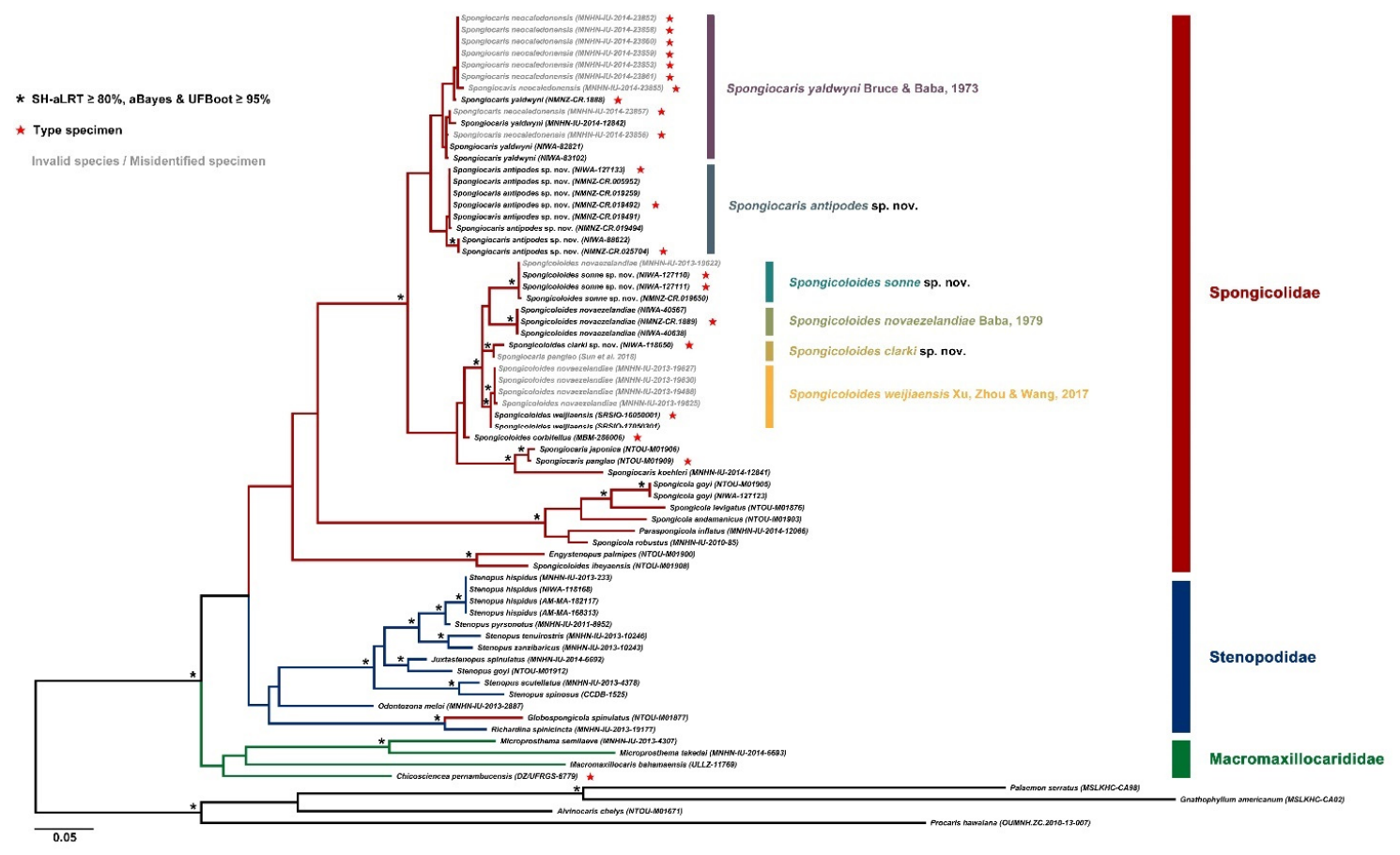

Figure 2. Maximum likelihood tree inferred from the 16S rRNA gene sequences. The colors of the branches indicate the familial affiliation proposed by Bochini et al. [10]. * indicate high nodal support and a star highlights a type specimen.

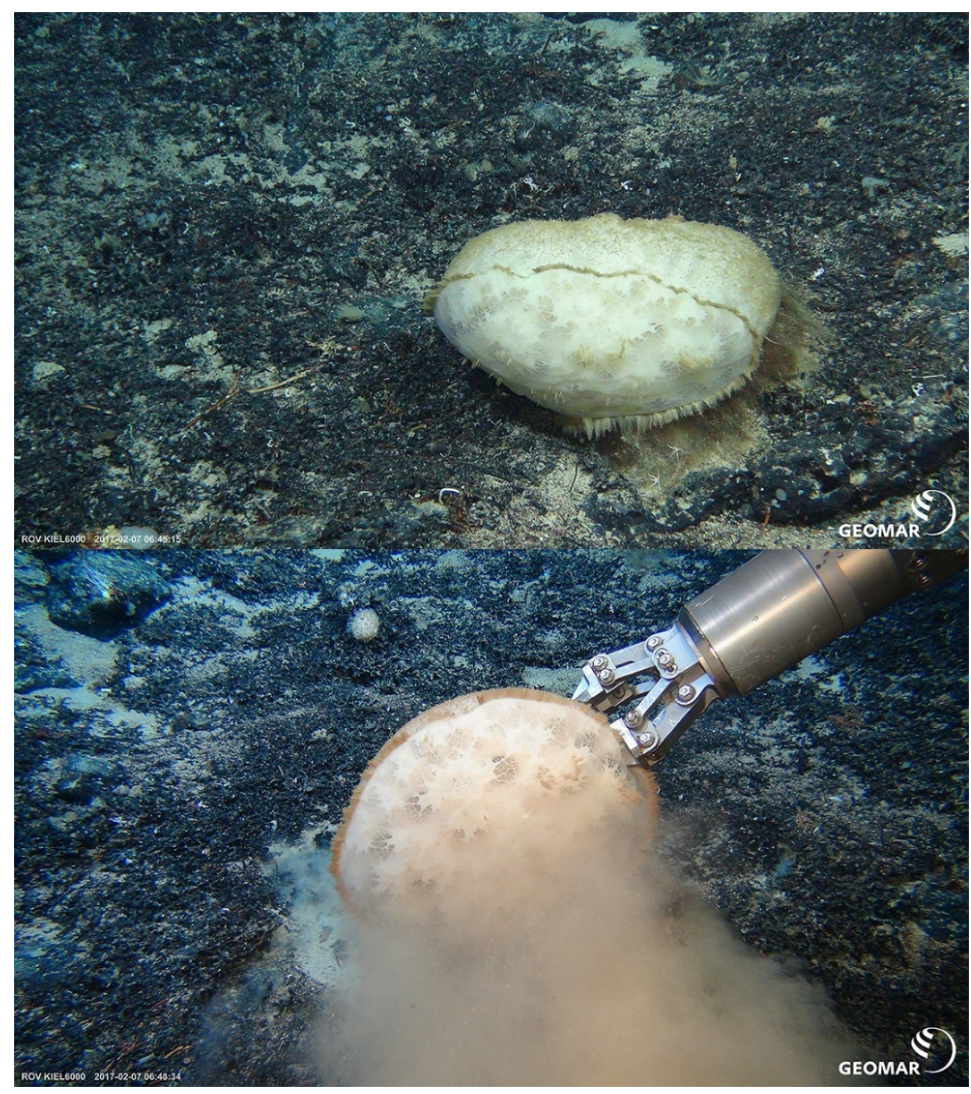

Figure 3. Spongicola goyi Saito \& Komai, 2008 [12] (NIWA127123) sponge host, most likely Pheronema conicum Lévi \& Lévi, 1982 [43] (det. Michelle Kelly, NIWA), (Hexactinellida, Amphidiscosida, Pheronematidae) immediately prior to (top) and during collection (bottom) on the southern Kermadec Ridge (1168 m). Image courtesy of ROV Kiel 6000 GEOMAR, SO254 voyage PoriBacNewZ, ICBM. 


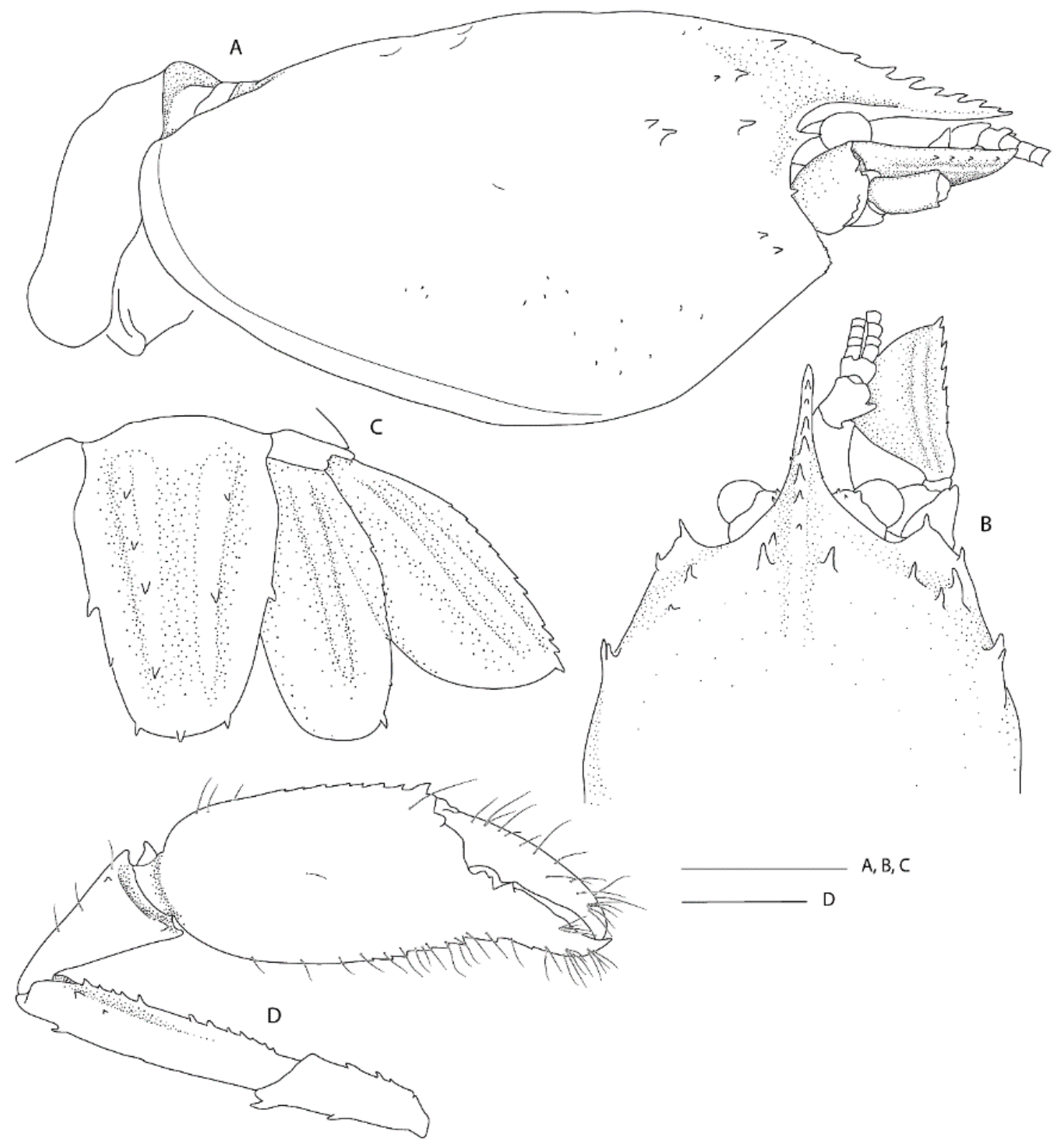

Figure 4. Spongicola goyi Saito \& Komai, 2008 [12], F ov. (NIWA 127123). (A) Carapace and anterior pleonal segments, lateral. (B) Anterior portion of carapace and cephalic appendages, dorsal. (C) Telson and uropods, dorsal. (D) Third pereiopod, lateral. Scale bars $=2 \mathrm{~mm}$.

Diagnosis. Carapace with postrostral submedian and anterolateral spines; branchial region with fine scattered spinules or granules. Merus of third pereiopod unarmed or armed with row of small teeth or denticles on lateral margin; palm distinctly carinate on dorsal margin. Lateral margin of uropodal endopod serrate.

Measurements. CL: $7.6 \mathrm{~mm}$ (female), $7.9 \mathrm{~mm}$ (male), PCL: $5.9 \mathrm{~mm}$ (female), $5.7 \mathrm{~mm}$ (male), TL: $26.0 \mathrm{~mm}$ (female), $19.4 \mathrm{~mm}$ (male).

Distribution. Japan, Indonesia, Vanuatu, New Caledonia, Australia, Madagascar, and now northern New Zealand; 315-1184 m.

Hosts. Previously reported on Demospongia sp., Hexactinellidae sp., Hyalonema sp., Euplectella sp. and Pheronema semiglobosum Lévi \& Lévi, 1982 [43] by Saito \& Komai [12] and Euhyalonema sp. by Goy [13]. The female (NIWA 127123) reported here was collected with a sponge host most likely Pheronema conicum Lévi \& Lévi, 1982 [43] (NIWA 126108, det. Michelle Kelly, Figure 3). The male (NIWA 3621) included a collection note "with 
hexactinellid", of which eight were collected at the same station, including three Pheronema conicum but also Chonelasma sp. and Euryplegma auriculare Schulze, 1886 [44].

Colour in life. Unknown. Collection note with NIWA 127123 refers to 'bright blue eggs'.

Remarks. This is the first record for this genus and species in the New Zealand region, although the type series included specimens from New Caledonia and the Norfolk Ridge just north of New Zealand. The two specimens presented here extend the known range slightly southward to seamounts off the Northland Plateau and the southern Kermadec Ridge (Figure 1). They were both collected from within hexactinellid sponges, possibly both from the amphidiscosid Pheronema conicum. Genetically, the female (NIWA 127123) aligns with conspecific reference sequences (see below). Morphologically, both specimens match the type description in nearly all aspects. Slight variation for the ovigerous female compared to the original description is an additional large postorbital carapace spine, the first pleonite being more distinctly ridged (Figure $4 \mathrm{~A}$ ), the posterior margin of the telson being distinctly convex (rather than slightly convex or nearly truncate) (Figure 4C), the dactylus of the third pereiopod is smooth on the dorsal margin (not with row of teeth or denticles) (Figure 4D) and the subdivision of the propodi of pereiopods 4 and 5 is indistinct. The specimen bears approximately 100 spherical eggs of a diameter $0.8 \mathrm{~mm}$ each. The male (NIWA 3621) matches the paratypes illustrated by Saito \& Komai [12], the third pereiopod is distinctly spinose along the ischium and merus and serrate along the margins of the palm and fingers. A slight difference is apparent in the shape of the eighth thoracic sternite that is anteriorly projected to a distinct, round tooth (instead of subrectangular).

The species resembles S. andamanicus Alcock, 1901 [45] (widely distributed throughout the Indo-West Pacific) but can be chiefly distinguished by the lack of a large tooth on the lateral margin of the third pereiopod merus. The merus is instead furnished with a row of small teeth or denticles only.

DNA sequence data. DNA sequences for the large female (NIWA 127123) aligned well with previously published sequences, with intraspecific levels of divergences for $16 \mathrm{~S}$ $(\leq 0.8 \%)$ compared to four specimens from South China Sea, Papua New Guinea and New Caledonia [17] (Figure 2).

Genus Spongicoloides Hansen, 1908 [18].

\subsubsection{Spongicoloides clarki sp. nov.}

In (Figures 1, 2 and 5-7). Spongiocaris panglao.-Sun, Sha \& Wang 2018 [37]: 124 (complete mitochondrial genome) (not Spongiocaris panglao Komai, De Grave \& Saito, 2016 [15]).

Material examined. Holotype: F ov. (PCL: $11.8 \mathrm{~mm}$ ); Macauley Island, Kermadec

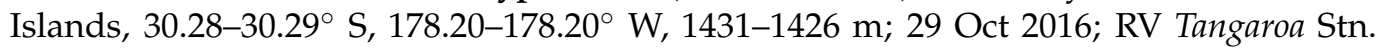
TAN1612/71, beam trawl; found inside Regadrella okinoseana; NIWA 118650.

Diagnosis. Carapace with faint hepatic groove; surface with only scattered small postrostral, hepatic and anterolateral spines, cervical groove not lined with distinct spines; anterior margins without antennal spine, few small anterolateral spines. Rostrum reaching distal margin of basal article of antennular peduncle; with nine small dorsal teeth, laterally unarmed. Epistome anteriorly straight, nearly smooth. Second and third pleonite with acute articular knob; fifth and sixth pleonites smooth on dorsal midline, unarmed posteroventral margin. Telson broadly rectangular, about twice as long as wide, small teeth along posterior margin. Antennular peduncle unarmed except for minute distomesial spine on second article, stout stylocerite. Antenna with small ventromedian spines on basicerite; scale with 7-8 small lateral teeth. First maxilliped with single arthrobranch. Second maxilliped with single arthrobranch, well-developed podobranch, lacking epipod. Third maxilliped with two arthrobranchs and rudimentary epipod, setiferous organ welldeveloped. First pereiopod with setiferous organ on propodus only. Third pereiopod nearly entirely glabrous and unarmed; fixed finger unarmed on distoventral margin; ischium with distodorsal spine and row of small ventral spines; coxa mesially unarmed. Fourth 
and fifth pereiopods dactyli with ventral unguis bearing a small ventral and dorsal tooth; coxa mesially unarmed; fourth pereiopod with paired arthrobranchs.

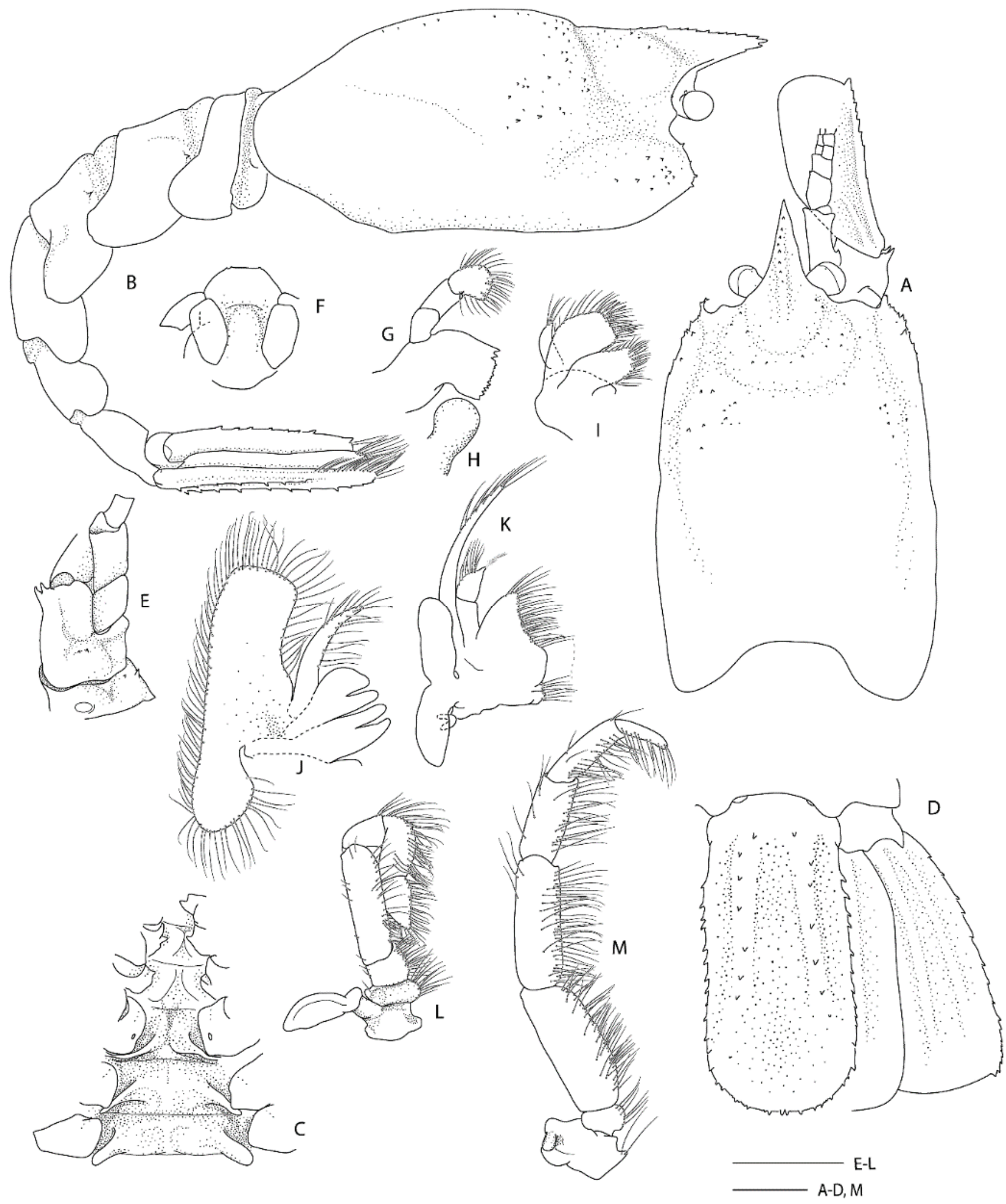

Figure 5. Spongicoloides clarki sp. nov., holotype F ov. (NIWA 118650). (A) Carapace and cephalic appendages, dorsal. (B) Carapace and pleon, lateral. (C) Thoracic sternites, ventral. (D) Telson and uropods, dorsal. (E) Right antennal peduncle, ventral. (F) Epistome and labrum showing the distal mandibular palp, ventral. (G) Right mandible, ventral. (H) Right paragnath, ventral. (I) Right maxillule. (J) Right maxilla. (K) Right Mxp1. (L) Right Mxp2. (M) Right Mxp3. Scale bars $=2 \mathrm{~mm}$. 


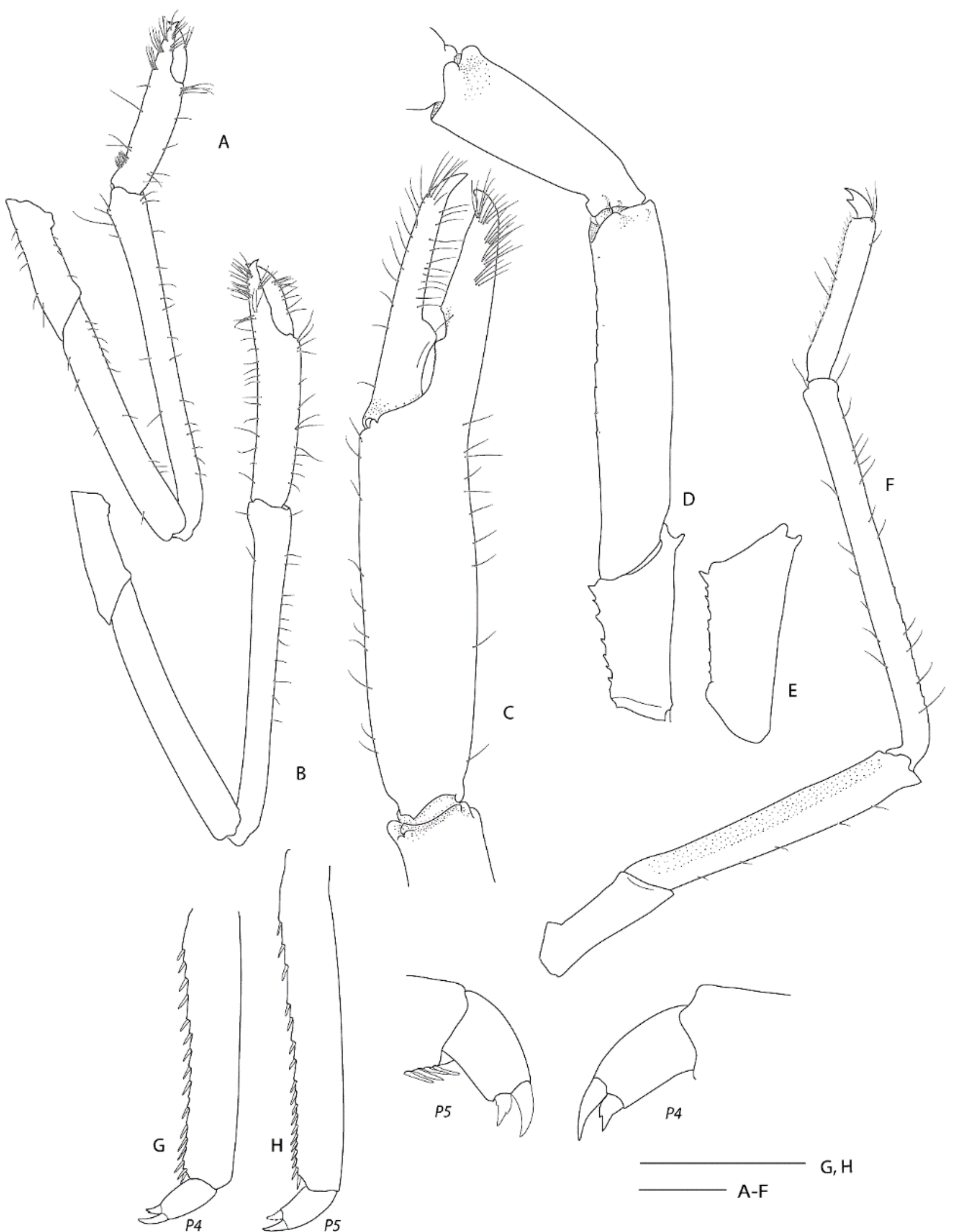

Figure 6. Spongicoloides clarki sp. nov., holotype F ov. (NIWA 118650). (A) P1, left, lateral. (B) P2, left, lateral. (C) P3, fingers, palm and distal carpus, right, outer surface. (D) P3, carpus, merus and ischium, right, mesial. (E) P3, ischium, left, lateral. (F) Left P4 lateral. (G) Right P4 propodus and dactylus, lateral. (H) Right P5 propodus and dactylus, lateral. Detail of P4 and P5 dactyli without scale. Scale bars $=2 \mathrm{~mm}$. 


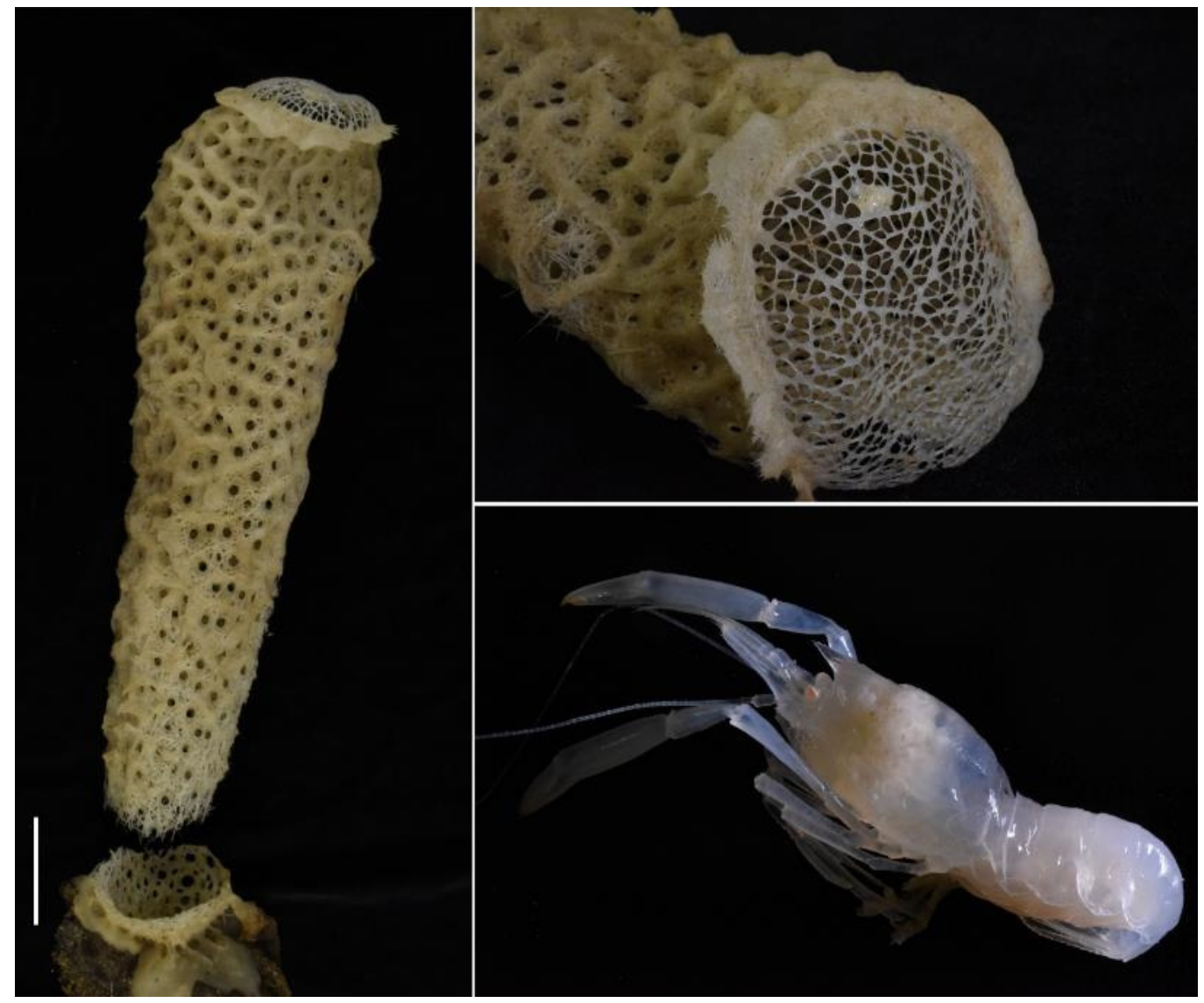

Figure 7. Spongicoloides clarki sp. nov., holotype F ov. (NIWA 118650) with euplectellid sponge host (NIWA 118649) collected off Macauley Island. Scale bar $=5 \mathrm{~cm}$. Image credits: Rob Stewart, NIWA.

Etymology. Named after Malcolm Clark, Principle Scientist at NIWA, for his contribution to deep-sea, specifically seamounts, research, and who led the voyage that collected the holotype (Kermadec-Rangitahua, TAN1612), with KS's gratitude for his mentoring and guidance.

Description of holotype female (Figures 5 and 6 ).

Body large, robust, surface generally glabrous. Rostrum narrowly triangular in dorsal view, one-third (0.3) as long as PCL, horizontal, slightly over-reaching distal margin of first article of antennular peduncle; dorsal margin with nine small teeth and posterior blunt eminence at level of posterior orbital margin; ventral margin with two small teeth close to rostral tip; ventrolateral ridges unarmed.

Carapace glabrous, slightly inflated. Cervical and branchiostegal grooves distinct. Small spines on anterolateral, anterior branchial surface, smaller spines and granules scattered loosely on postrostral, anterior cardiac and hepatic surfaces. Orbital margin concave, antennal margin unarmed, small branchiostegal spine present, pterygostomian angle round, with series of three small spines on margin.

Thoracic sternites 6-8 anteriorly rounded, minutely serrate but unarmed; sternite 6 posterior margins evenly concave.

Pleonal somites glabrous, surfaces smooth. First pleonite shortest; divided into two sections by distinct transverse carina; ventral margin continuous, straight. Second and third pleonite subequal in length, with feeble transverse carina and acute articular knob; ventral margin rounded. Fourth and fifth pleonites with round posteroventral margin, minute granule on fifth tergite; dorsally smooth and unarmed. Sixth pleonite dorsally 
smooth; posterolateral corner angular, with very small granule; posterior margin smooth. Pleonal sternites unarmed.

Telson about 2.2 times as long as broad, subquadrangular, posterior margin shallowly convex, with long plumose setae; dorsolateral ridges distinct, with 7-8 spines each, proximalmost largest and placed mesially; lateral margins nearly straight, slightly constricted proximally, each side armed with a subproximal spine and 10-11 small, lateral spines; posterior margin with 11 small spines (4-5 lateral and a pair of median spines).

Eye well developed; cornea semiglobular, about half length of ocular peduncle in dorsal view, distinctly inflated, unpigmented; minute mesial distal spine on both eye stalks, and 1-2 small spines on dorsal surface.

Antennular peduncle reaching to about middle of antennal scale, not reaching spinose lateral margin of antennal scale. Basal article stout, length-width ratio of 2.8 at midlength, without statocyst, about twice as long as second article; lateral margin concave, distally produced to small, rounded lobe, stylocerite short but distinct, acute, barely reaching proximal quarter of basal article; mesial margin almost straight, unarmed other than row of serration where plumose seta are inserted. Second article about 1.5 times longer than distal article, distomesially with small spine. Distal article as long as wide, unarmed. Flagella slender, about twice as long as peduncle.

Antenna with first article (coxa, bearing antennal gland) mesially glabrous, not carinate, two small mesial spines. Basicerite stout; mesially unarmed, paired spines distolaterally; dorsal and lateral surfaces smooth, one (left) or two (right) central small spines on ventral surface. Antennal scale broad, $2.6 \times$ as long as wide; lateral margin nearly straight, armed with 7-8 small teeth along the distal 0.4 portion, including the most prominent distal tooth; dorsal surface with two distinct longitudinal ridges. Carpocerite reaching to distal end of first article of antennular peduncle, minute dorsal and ventral spine distally. Flagellum at about 1.3 times the CL.

Epistome broadly convex, minutely granulate at anterior margin. Labrum smooth. Paragnaths bilobed, with deep median fissure, distodorsally spatulate.

Mandible robust, fused molar and incisor processes. Molar surface with three teeth; incisor bearing two distal teeth with regular row of small proximal teeth. Palp welldeveloped, 3-segmented; proximal article shortest, without setae; middle article with few setae on flexor and more, longer setae on extensor margins; distal article suboval, slightly longer than intermediate article (measured along extensor margin), densely setose.

Maxillule with simple palp, with four terminal setae; distal endite broad, round, with numerous simple setae and eight slender spines; proximal endite oval, with simple setae distally.

Maxilla with palp slender, tapering, with plumose setae, nearly reaching end of scaphognathite; distal and proximal endites both deeply bilobed, with numerous plumose setae; scaphognathite well developed, anterior portion longer than posterior portion, about three times longer than broad, with dense fringe of plumose setae along entire margin.

Branchial formula summarized in Table 2.

First maxilliped with 2-segmented palp, bearing long plumose setae; with distal blunt spine, bearing distal plumose seta; proximal article stout, slightly longer than distal article in length. Distal endite large, subtriangular, densely setose; proximal endite deeply bilobed, with distal setae. Exopod slender, with long plumose setae. Epipod well developed, subequally bilobed. Arthrobranch small.

Second maxilliped with 5-segmented endopod, unarmed; dactylus sub-oval, tapering distally, about twice as long as broad, with dense setae on flexor margin; propodus slightly longer than dactylus, densely setose along flexor margin; carpus triangular, about twothird length of propodus measured at mid-line, with long distodorsal setae; merus nearly straight, about $1.6 \times$ length of propodus, nearly four times longer than broad, with a row of setae along the mesial margin and sparse short setae on surfaces; ischium and basis not fused, each about $0.2 \times$ meral length and long setae along mesial margin. Coxa with blunt mesial process; epipod absent, podobranch and arthrobranch. Exopod absent. 
Table 2. Branchial formulae of New Zealand species of Spongicoloides and Spongiocaris ( $\mathrm{r}=$ rudimentary).

\begin{tabular}{|c|c|c|c|c|c|c|c|c|}
\hline \multicolumn{9}{|c|}{ Spongicoloides clarki sp. nov. } \\
\hline & \multicolumn{3}{|c|}{ Maxillipeds } & \multicolumn{5}{|c|}{ Pereiopods } \\
\hline & I & II & III & I & II & III & IV & V \\
\hline Pleurobranchs & - & - & 1 & 1 & 1 & 1 & 1 & 1 \\
\hline Arthrobranchs & 1 & 1 & 2 & 2 & 2 & 2 & 2 & - \\
\hline Podobranchs & - & 1 & - & - & - & - & - & - \\
\hline Epipods & 1 & - & $\mathbf{r}$ & - & - & - & - & - \\
\hline Exopods & 1 & - & - & - & - & - & - & - \\
\hline \multicolumn{9}{|c|}{ Spongicoloides novaezelandiae Baba, 1979 [20] } \\
\hline & \multicolumn{3}{|c|}{ Maxillipeds } & \multicolumn{5}{|c|}{ Pereiopods } \\
\hline & I & II & III & I & II & III & IV & $\mathbf{V}$ \\
\hline Pleurobranchs & - & - & 1 & 1 & 1 & 1 & 1 & 1 \\
\hline Arthrobranchs & 1 & 2,1 or $r$ & 2 & 2 & 2 & 2 & 2 & - \\
\hline Podobranchs & - & 1 & - & - & - & - & - & - \\
\hline Epipods & 1 & 1 & 1 & - & - & - & - & - \\
\hline Exopods & 1 & - & - & - & - & - & - & - \\
\hline \multicolumn{9}{|c|}{ Spongicoloides sonne sp. nov. } \\
\hline & \multicolumn{3}{|c|}{ Maxillipeds } & \multicolumn{5}{|c|}{ Pereiopods } \\
\hline & I & II & III & I & II & III & IV & V \\
\hline Pleurobranchs & - & - & 1 & 1 & 1 & 1 & 1 & 1 \\
\hline Arthrobranchs & 1 & 1 & 2 & 2 & 2 & 2 & 2 & - \\
\hline Podobranchs & - & 1 & - & - & - & - & - & - \\
\hline Epipods & 1 & 1 & - & - & - & - & - & - \\
\hline Exopods & 1 & - & - & - & - & - & - & - \\
\hline \multicolumn{9}{|c|}{ Spongiocaris antipodes sp. nov. } \\
\hline & \multicolumn{3}{|c|}{ Maxillipeds } & \multicolumn{5}{|c|}{ Pereiopods } \\
\hline & $\mathbf{I}$ & II & III & I & II & III & IV & $\mathbf{V}$ \\
\hline Pleurobranchs & - & - & 1 & 1 & 1 & 1 & 1 & 1 \\
\hline Arthrobranchs & 1 & 1 & 2 & 2 & 2 & 2 & 2 & - \\
\hline Podobranchs & - & 1 & - & - & - & - & - & - \\
\hline Epipods & 1 & 1 & - & - & - & - & - & - \\
\hline Exopods & 1 & 1 & - & - & - & - & - & - \\
\hline \multicolumn{9}{|c|}{ Spongiocaris yaldwyni Bruce \& Baba, 1973 [2] } \\
\hline & \multicolumn{3}{|c|}{ Maxillipeds } & \multicolumn{5}{|c|}{ Pereiopods } \\
\hline & $\mathbf{I}$ & II & III & I & II & III & IV & V \\
\hline Pleurobranchs & - & - & 1 & 1 & 1 & 1 & 1 & 1 \\
\hline Arthrobranchs & 1 & 1 & 2 & 2 & 2 & 2 & 2 & - \\
\hline Podobranchs & - & 1 & - & - & - & - & - & - \\
\hline Epipods & 1 & 1 & $1 /-$ & - & - & - & - & - \\
\hline Exopods & 1 & 1 & - & - & - & - & - & - \\
\hline
\end{tabular}

Third maxilliped endopod 5-segmented, slender, unarmed; dactylus narrow, gently tapering, about 4 times longer than broad (at mid-length), setose; propodus slightly less than twice as long as dactylus, with setiferous organ along entire length of flexor margin; carpus slightly longer than propodus; merus longest, about $1.5 \times$ carpal length; ischium broadest, subequal in length to merus; all segments with long setal fringe along flexor margin; basis short. Coxa with rudimentary epipod, arthrobranchs present. Exopod absent.

First pereiopod slender, glabrous and sparsely setose; dactylus about $0.5 \times$ palm length, distally setose; palm subcylindrical, tufts of long setae distally and along ventral margin of fixed finger; carpus $3 \times$ palm length, ventral carpo-propodal setiferous organ 
pronounced on propodus, absent on carpus; merus about $0.7 \times$ carpal length; ischium half meral length. Basis and coxa short, coxa with sharp mesial spine. Epipod absent.

Second pereiopod similar to first, $1.5 \times$ longer and stronger, sparsely setose; dactylus $0.4 \times$ palm length, distal tip formed into a strong corneous spine, tips of fingers cross when chela closed, cutting edges entire; propodus with a few tufts of setae distally and along fixed finger; carpus about twice palm length; merus $0.8 \times$ carpal length; ischium $0.4 \times$ length of merus. Basis and coxa short; coxa mesially produced to angular process. Epipod absent.

Third pereiopod largest, subequal and similar, about $2 \times \mathrm{CL}$, overreaching the tip of antennal scale by length of chela, very sparsely setose except for a few distal tufts of setae along fingers; dactylus slightly less than $0.5 \times$ palm length, ending in strong, hooked corneous tip, cutting edge with narrow trench along distal half, with broadly rounded tooth at mid-length, otherwise smooth; propodal cutting edge with sharp corneous spine distally, followed by narrow trench along distal half, with shallow trianguloid process at mid-length and distinct notch to accommodate dactylar tooth, proximal quarter straight, with numerous tiny teeth; outer margin of fixed finger unarmed, bearing tufts of long setae; palm sub-cylindrical, 3.1-3.3 times as long as broad, nearly entirely smooth, with few small spines on inner ventrodistal surfaces; carpus about $0.5 \times$ palm length, narrowing proximally, without spines, with two distinct distodorsal lobes; merus $0.9 \times$ length of palm, nearly 5 times longer than broad in lateral view, proximally compressed laterally, distoventral corners blunt, smooth other than ventral ridge with row of minute granules; ischium about three-fourth length of carpus, laterally compressed, with small, sharp distodorsal spine and small ventrodistal spine, preceded by ventral row of granules or small spines, distalmost strongest. Basis and coxa short; coxa mesially densely setose and finely granulate. Epipod absent.

Fourth and fifth pereiopods long and slender, similar, sparsely setose; dactylus about one-fifth the length of propodus, biungulate, both unguis clearly demarcated, both P5 with small accessory tooth on dorsal margin, right P5 with obsolescent accessory tooth on ventral margin proximally ( $\mathrm{P} 4$ dactyli missing or damaged); propodus not subdivided, about $0.5 \times$ carpal length, P5 propodus as wide as P4 propodus, with single row of 19-21 (P4) and 21 (P5) movable spine along entire flexor margin, both margins with few long, simple setae; carpus longest, not subdivided, with movable spine at distoventral angle; merus about 0.7 (P4) -0.7 (P5) $\times$ carpal length, unarmed; ischium about half length of merus, unarmed. Basis and coxa short, coxa mesially with dense setae, unarmed. Epipod absent.

First pleopod uniramous, second to fifth biramous, all lacking appendices, unarmed.

Uropod well developed, about as long as telson. Protopod stout, with sharp posterolateral spine. Exopod broader than endopod; lateral margin slightly convex, with 13 (left) and 16 (right) teeth along distal 0.8 portion of margin, closely spaced in distal quarter, distal margin nearly straight, dorsal surface with two distinct longitudinal ridges. Endopod simple, unarmed, surface with one longitudinal ridge. Exopod and endopod fringed with dense, plumose seta.

Eggs: The ovigerous female incubated around 100 eggs of diameters $1.4 \times 2.1 \mathrm{~mm}$.

Measurements. Holotype: CL: $15.2 \mathrm{~mm}$, PCL: $11.8 \mathrm{~mm}$, TL: $42.0 \mathrm{~mm}$.

Distribution. Only known from holotype with certainty, Macauley Island, 1426-1431 m. Specimens that are displaying intraspecific levels of genetic divergence were collected on Yap Seamount, central-western Pacific at $1452.5 \mathrm{~m}$ ('Spongiocaris panglao' [37]) and Caroline Seamount, Micronesia, at a depth of $1205 \mathrm{~m}$ (Q. Kou pers. comm.)

Coloration. Unpigmented, most of the integument appears transparent (Figure 7)

Hosts. Found inside euplectellid glass sponge Regadrella okinoseana Ijima, 1896 [46] (Hexactinellida, Lyssacinosida, Euplectellidae) (NIWA 118649, det. Michelle Kelly, Figure 7). This host species is one of the most common euplectellids in the New Zealand region [47].

Remarks. Spongiocoloides clarki sp. nov. most closely resembles the two other New Zealand congeners S. novaezelandiae and S. sonne sp. nov.; the third maxilliped and the first four pereiopods have two arthrobranchs each, the pleonites are dorsally smooth, the telson 
is sub-rectangular and the fixed finger of the third pereiopod is unarmed on the distoventral margin. The new species is distinct in its branchial formula with the second maxilliped lacking an epipod (usually present in both S. novaezelandiae and S. sonne) and a rudimentary epipod on the third maxilliped (present in S. novaezelandiae and absent in S. sonne) (Table 2). Furthermore, the second and third pleonite has a distinctly acute articular knob (round in both other species, although this can be allometric), the labrum is nearly smooth anteriorly (furnished with granules or small spines in both other species), and the coxa of pereiopods 3-5 are mesially smooth (S. sonne has distinct and S. novaezelandiae small mesial spines). Spongiocoloides clarki shares with $S$. novaezelandiae the smoother carapace surface with only scattered small spines but it lacks the distinct spines along the cervical groove which are small in S. novaezelandiae and pronounced in S. sonne, the shorter rostrum, barely overreaching the first antennular segment (reaching the end of the second antennular segment in S. sonne). Conversely, S. clarki shares with S. sonne the spinose ischium of the third pereiopod (ventrally smooth in $S$. novaezelandiae).

The characteristics of the pereiopods $4-5$ dactylar spination warrants further investigation, both available intact pereiopods of $S$. clarki have a minute dorsal accessory tooth on the ventral unguis and lacked a distinct ventral accessory tooth or teeth. The latter are pronounced in both S. novaezelandiae and S. sonne. The collection of further intact specimens might prove this character to be fixed and diagnostic.

DNA sequence data. Closest allies with intraspecific levels of divergences in all cases are a GenBank sequence presented as 'Spongiocaris panglao' by Sun et al. [37] (MG812382) and a specimen of Spongicoloides sp. (Qi Kou pers. comm.).

CO1: intra-specific divergences between 1.9\% ('Spongiocaris panglao' [37]) and 2.2\%, Spongicoloides sp. (Q.Kou, unpubl.); intra-generic divergences range from $4.4 \%$ (Spongicoloides novaezelandiae) to 7.1\% (S. corbitellus Kou, Gong \& Li, 2018 [35]).

16S rRNA: intra-specific divergences of 1.0\% ('Spongiocaris panglao' [37] and Spongicoloides sp. (Q. Kou, unpubl.); intra-generic divergences range from 2.3\% (Spongicoloides weijiaensis) to $15.1 \%$ (S. iheyaensis Saito, Tsuchida \& Yamamoto, 2006 [48]).

\subsubsection{Spongicoloides novaezelandiae Baba, 1979}

In (Figures 1 and 8-11). Spongicoloides novaezelandiae Baba, 1979 [20]: 311.-Goy 1980 [49]: 770.—Baba 1983 [50]: 477.—Saito et al. 2006 [48]: 224.—Burukovsky 2009 [51]: 498.-Goy 2010 [3]: 227.—De Grave \& Fransen 2011 [42]: 252.—Goy 2015 [13]: 310, Figures 9-11 (in part).-Kou et al. 2018 [35]: 105 (table).

Material examined. Holotype: M (PCL: $14.4 \mathrm{~mm}$ ); Chatham Rise, $44.73^{\circ} \mathrm{S}, 175.70^{\circ}$ E, 1782-1998 m; 16 Jul 1968; RV Kaiyo Maru Stn. KM36, trawl; NMNZ CR.001889. Other material. Macquarie Ridge: $1 \mathrm{~F}$ (PCL: $\sim 9.8 \mathrm{~mm}$, specimen damaged); Seamount 7, 53.731-53.733 ${ }^{\circ}$ S, $159.166-159.169^{\circ}$ E, 1150-1270 m; 12 Apr 2008; RV Tangaroa Stn. TAN0803/81, 'seamount' sled; NIWA 40567. $1 \mathrm{M}$ (PCL: $\sim 6.6 \mathrm{~mm}$, specimen damaged); Seamount 7, 53.705-53.705 S, 159.115-159.106 E; 998-1100 m; 13 Apr 2008, 'seamount' sled; RV Tangaroa Stn. TAN0803/84; NIWA 40638. 


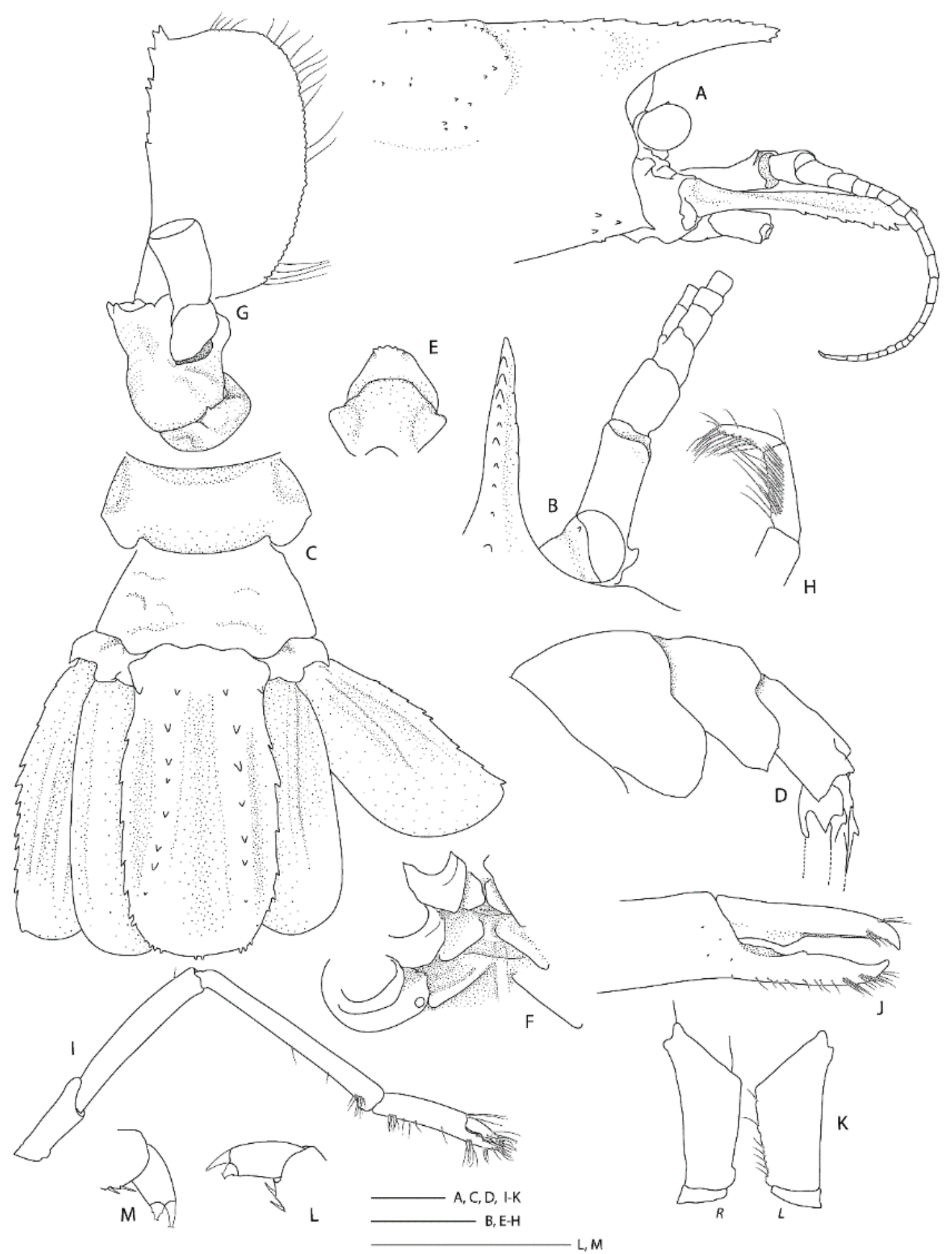

Figure 8. Spongicoloides novaezelandiae Baba, 1979 [20], holotype M (NMNZ CR.001889). (A) Anterior carapace and cephalic appendages, lateral. (B) Rostrum, right ocular peduncle and antennule, dorsal. (C) Pleonites 5 and 6, urosome and telson, dorsal. (D) Pleonites 4-6 and proximal urosome and telson, lateral. (E) Epistome and labrum, ventral. (F) Thoracic sternites 6-8 with coxae of pereiopods, ventral. (G) Right antenna, ventral. (H) Distal portion of Mxp3 showing the setiferous organ on propodus. (I) Right P1, lateral. (J) P3 fingers and distal palm, mesial. (K) Right $(R)$ and left $(L)$ ischia of P3, lateral. (L) Left P4 or P5 dactylus and distal propodus. (M) Right P5 dactylus and distal propodus. Scale bars $=2 \mathrm{~mm}$. 


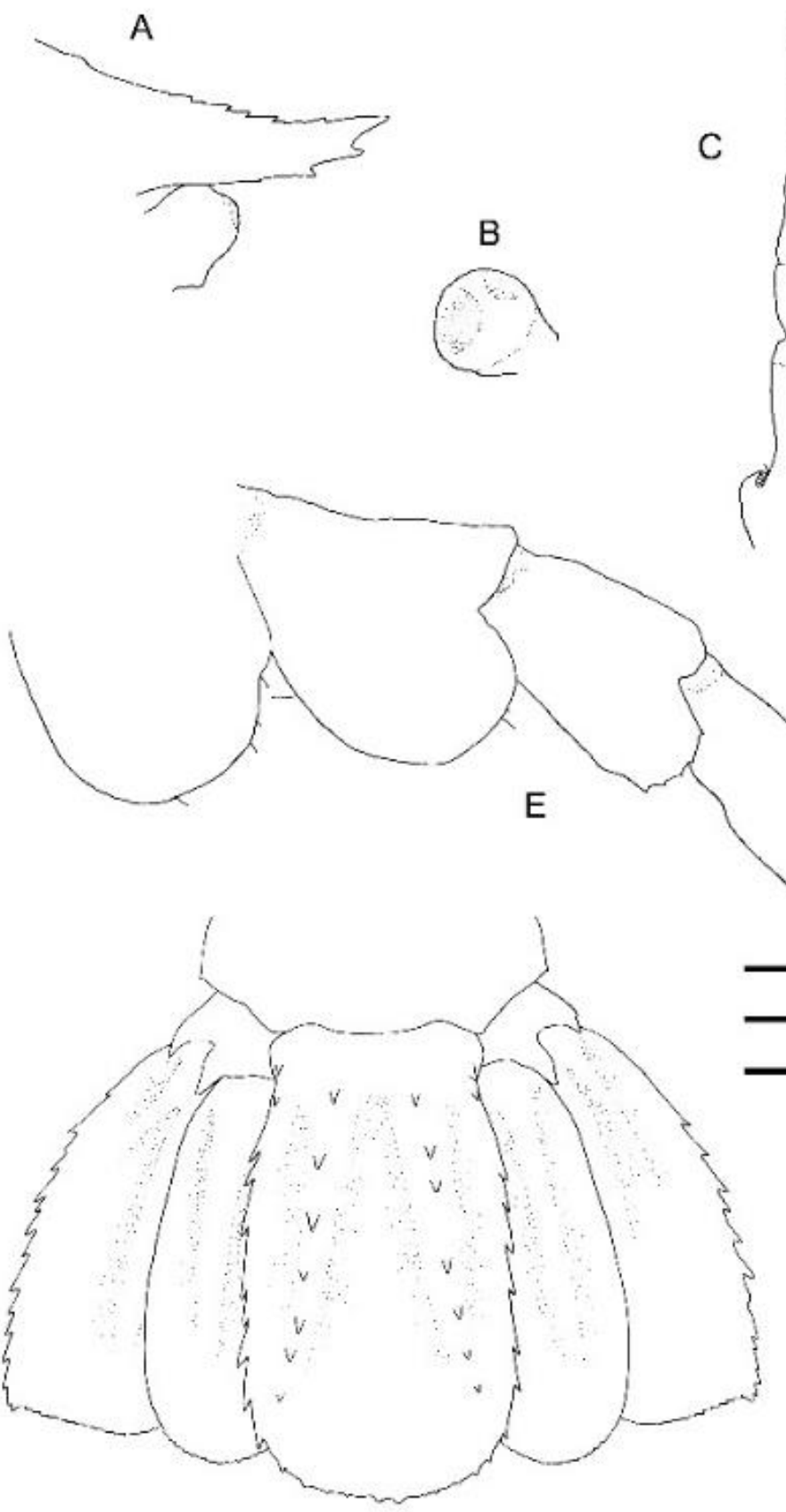

F
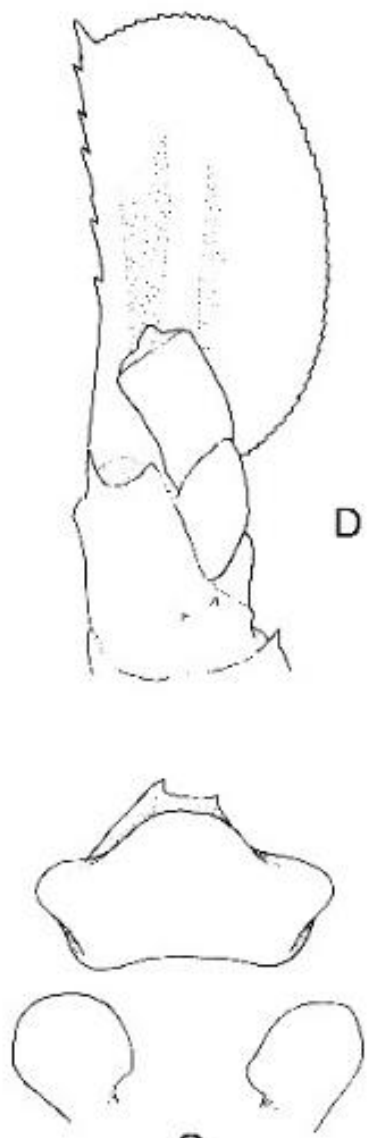

G

D

G

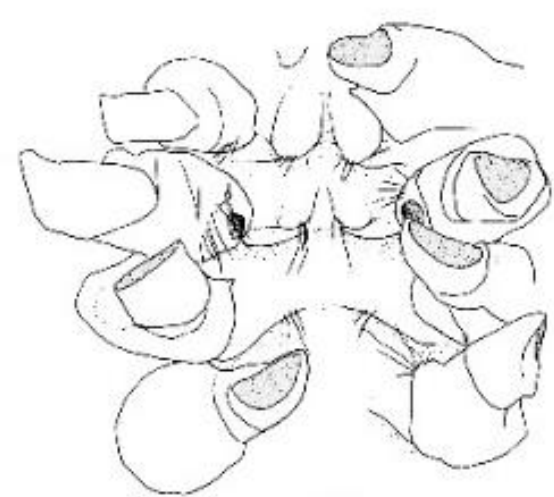

$\mathrm{H}$

Figure 9. Spongicoloides novaezelandiae Baba, 1979 [20], F (NIWA 40567). (A) Rostrum, lateral. (B) Left eye, outer view. (C) Left antennule, dorsal. (D) Left antennal scale, dorsal. (E) Third to sixth pleura, lateral. (F) Telson and uropods, dorsal.

(G) Epistome, labrum and paragnaths, ventral. $(\mathbf{H})$ Thoracic sternites, ventral. Scale bars $=1 \mathrm{~mm}$. 

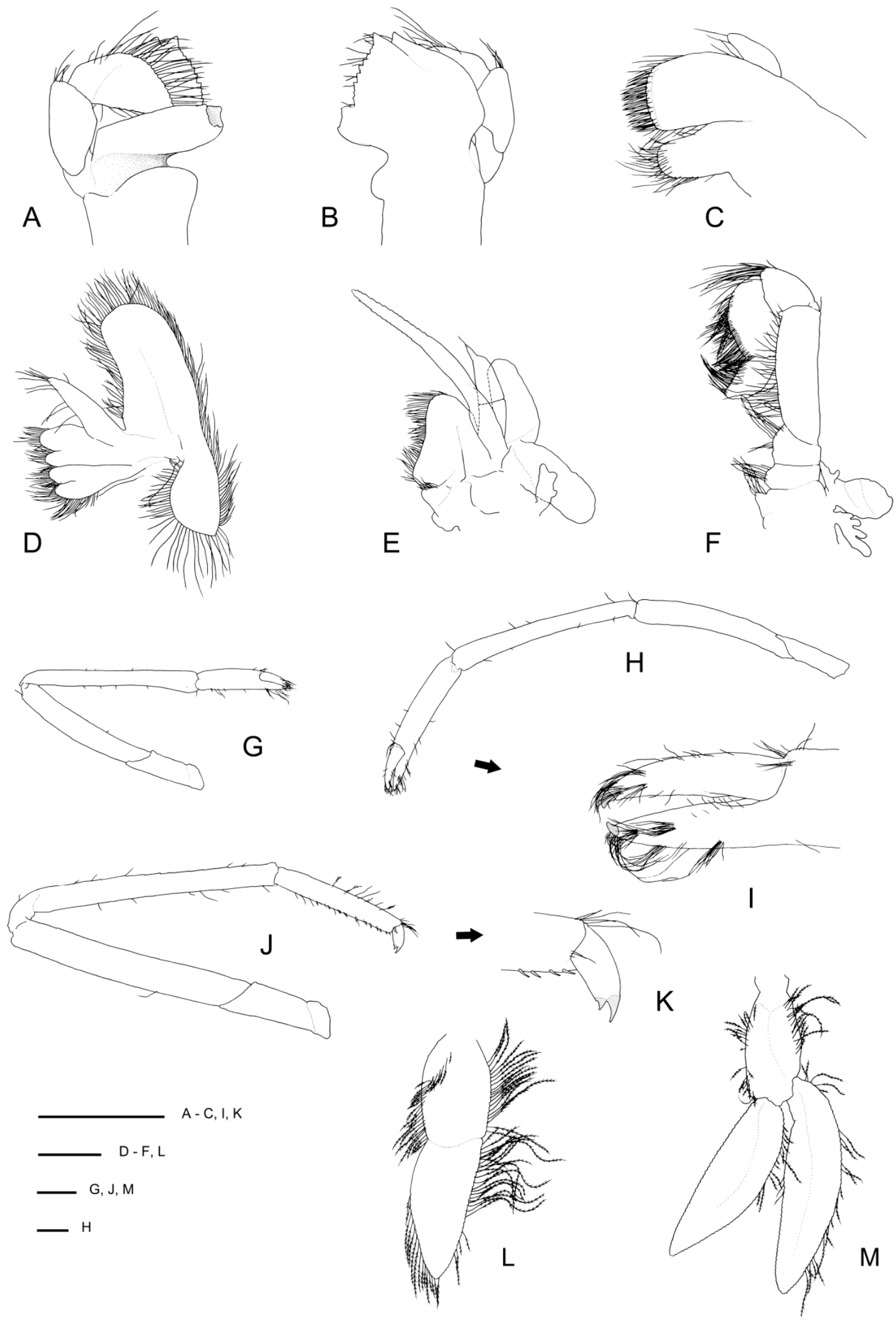

Figure 10. Spongicoloides novaezelandiae Baba, 1979 [20], F (NIWA 40567). (A) Left mandible, inner view. (B) Same, outer view. (C) Left maxillule, outer view. (D) Left maxilla, outer view. (E) Left Mxp1, outer view. (F) Left Mxp2, outer view. (G) Right P1, lateral. (H) Right P2, mesial. (I) Same, fingers, mesial. (J) Right P4 or P5, lateral. (K) Same, dactylus, lateral. (L) Right first pleopod, mesial. (M) Right second pleopod, mesial. Scale bars $=1 \mathrm{~mm}$. 


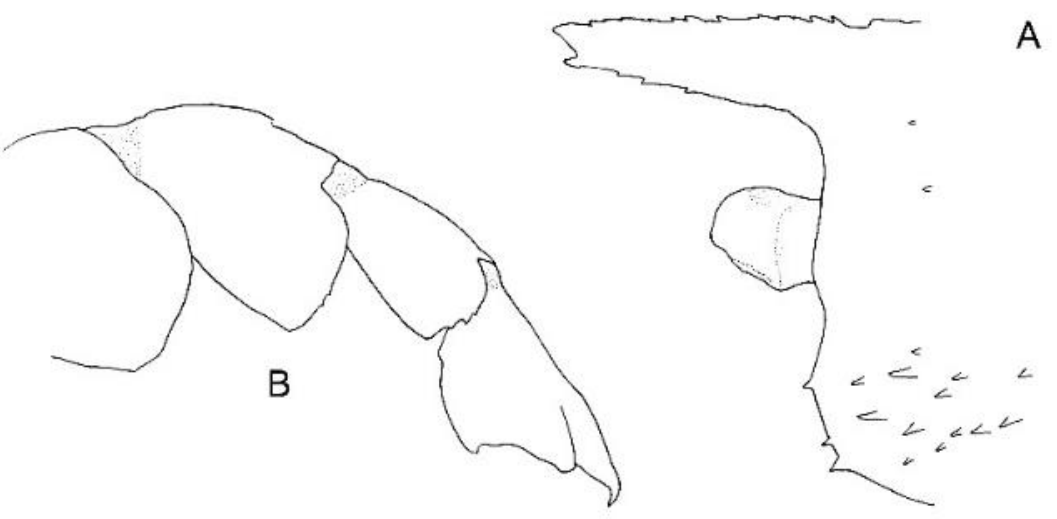

A

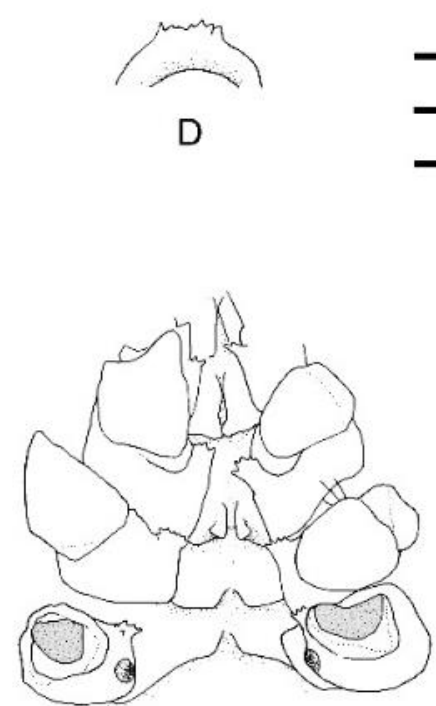

$\mathrm{E}$
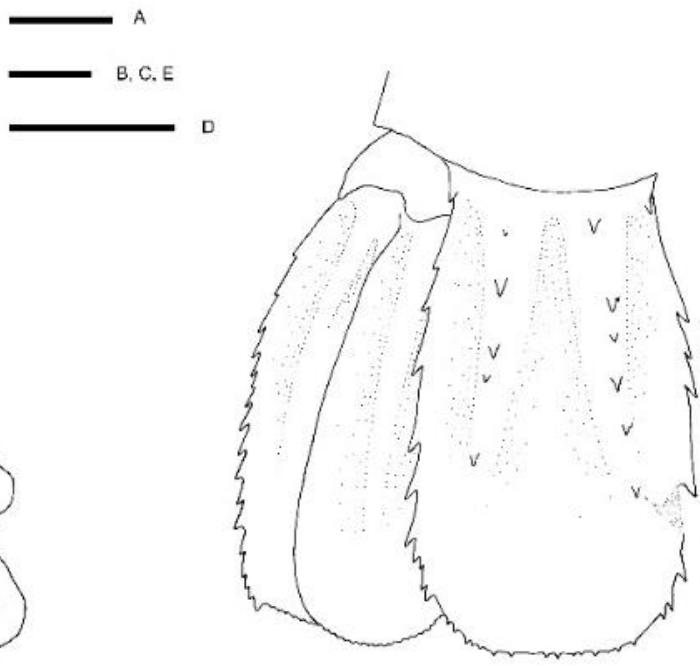

C

Figure 11. Spongicoloides novaezelandiae Baba, 1979 [20], M (NIWA 40638). (A) Rostrum, lateral. (B) third to sixth pleura, lateral. (C) Telson and uropods, dorsal. (D) Epistome, ventral. (E) Thoracic sternites 6-8, ventral. Scale bars $=1 \mathrm{~mm}$.

Diagnosis. Carapace with shallow hepatic groove; postorbital surface smooth; minute hepatic spines; cervical groove with few distinct spines; anterior margins without antennal spine, few small anterolateral spines. Rostrum reaching distal margin of basal segment of antennular peduncle; with 8-11 small dorsal teeth, laterally unarmed. Epistome anteriorly convex, with small teeth. Pleonites smooth on dorsal midline; pleonites 5-6 with 1-2 small spines along posteroventral margin. Telson broadly rectangular, about twice as long as wide; posterior margin with median pair of spines, regular row of spines absent. Antennule unarmed, stout stylocerite. Antennal basicerite with pair of distolateral teeth, ventromedially unarmed; scale with 7-8 lateral teeth. First maxilliped with single arthrobranch developed. Second maxilliped with two arthrobranchs and well-developed podobranch. First pereiopod with setiferous organ on propodus and carpus. Third pereiopod nearly entirely glabrous and unarmed; fixed finger unarmed on distoventral margin; ischium with distodorsal spine, ventrally unarmed; coxa with or without mesial granules. Fourth and fifth pereiopod dactyli with ventral unguis bearing a small ventral and with or without slight indication of dorsal tooth; coxa with small distomesial granules; P4 with paired arthrobranchs.

Description of the holotype male (Figure 8).

Body large, robust, surface generally glabrous.

Rostrum narrowly triangular in dorsal view, one-third (0.3) as long as PCL, nearly horizontal, slightly overreaching basal segment of antennular peduncle; dorsal margin 
armed with 11 small, low teeth, posteriormost placed on carapace posterior to level of orbital margin; distoventral margin with two small teeth; no distinct ventrolateral ridges, lateral margins smooth, unarmed.

Carapace glabrous, not inflated. Cervical and branchiostegal grooves distinct; cervical groove lined with five small spines. Group of small spinules placed on lateral portion of gastric region; postrostral, postorbital surfaces nearly smooth, minute dorsal granules. Orbital margin concave, antennal and branchiostegal margin unarmed, anterior pterygostomian angle round, with 1-3 small spines on margin; field of several spinules just behind them.

Thoracic sternites 6-8 anteriorly rounded, unarmed; sternite six posterior margins straight.

Pleonal somites glabrous. First pleonite shortest; divided into two sections by distinct transverse carina; ventral margin continuous, not produced. Second and third pleonite subequal in length, with feeble transverse groove and blunt articular knob; ventral margin of second to fourth segments broadly rounded. Fifth and sixth pleura with acute posteroventral margin; dorsally smooth and unarmed; posterior margins smooth. Pleonal sternites unarmed.

Telson, twice as long as broad, subquadrangular, posterior margin shallowly convex, with long plumose setae; dorsolateral ridges distinct, with 8 spines each, distalmost spine very small, near posterolateral margin, distinctly separated from ordinary row. Lateral margins nearly straight, slightly constricted proximally, each side armed with a subproximal spine and 6-7 small, lateral spines. Posterior margin with two denticles equidistant between lateral groups of 3-4 similar denticles.

Eye well developed; cornea semiglobular, about half length of ocular peduncle in dorsal view, slightly inflated, unpigmented; minute distomesial spine on both eye stalks.

Antennular peduncle overreaching middle of antennal scale, reaching spinose lateral margin of antennal scale. Basal article relatively stout, length-width ratio of about 3.0 at mid-length, without statocyst, about twice as long as second article, distally unarmed but with short distodorsal carina; lateral margin concave, stylocerite small and blunt but distinct; mesial margin almost straight, unarmed other than row of serration where plumose seta are inserted. Second article about 1.5 times longer than distal article, unarmed. Distal article as long as wide, unarmed. Flagella slender, about twice as long as peduncle.

Antenna with first article (coxa, bearing antennal gland) mesially glabrous, not inflated or carinate, one small mesial spine and a row of small setiferous denticles. Basicerite stout; mesially unarmed, one (left) or two (right) outer terminal spines; surfaces smooth, unarmed. Antennal scale broad, around twice as long as broad; lateral margin almost straight, not setiferous, with 6-7 spines in distal half, distally paired on both sides; dorsal surface with two distinct longitudinal ridges; inner margin convex, inner and distal margins with long setae. Carpocerite reaching to distal end of first article of antennular peduncle, unarmed. Flagellum at least as long as PCL.

Epistome narrowly convex, with short transverse row of granules at anterior margin. Labrum smooth. Paragnaths bilobed, with deep median fissure, distodorsally spatulate.

Mandible robust, fused molar and incisor processes. Molar surface with two teeth; incisor bearing distal tooth followed by regular row of small teeth along midlength. Palp well-developed, 3-segmented; proximal article shortest, without setae; middle article with few setae on flexor and more, longer setae on extensor margins; distal article suboval, longer than intermediate article (measured along extensor margin), densely setose.

Maxillule with simple palp, with four terminal setae; distal endite broad, round, with numerous simple setae and eight slender spines; proximal endite oval, with four simple setae distally.

Maxilla with palp slender, tapering, with plumose setae, falling well short of end of scaphognathite; distal and proximal endites both deeply bilobed, with numerous plumose setae; scaphognathite well developed, anterior portion longer than posterior portion, about 3.5 times longer than broad, with dense fringe of plumose setae along entire margin.

Branchial formula summarized in Table 2. 
First maxilliped with 2-segmented palp, bearing long plumose setae; distal article as long as wide, rounded, with plumose seta; proximal article stout, slightly longer than distal article in length. Distal endite large, subtriangular, densely setose; proximal endite deeply bilobed, with distal setae. Exopod slender, with long plumose setae. Epipod well developed, subequally bilobed. Arthrobranch small.

Second maxilliped with 5-segmented endopod, unarmed; dactylus sub-oval, tapering distally, about 1.5 times as long as broad, with dense setae on flexor margin; propodus slightly longer than dactylus, densely setose along flexor margin; carpus triangular, about two-third length of propodus measured at mid-line, with long distodorsal setae; merus nearly straight, about twice as long as propodus, three times longer than broad, with row of setae along mesial margin and sparse short setae on surfaces; ischium and basis not fused, each about $0.2 \times$ meral length and long setae along mesial margin. Coxa with blunt mesial process; small epipod, podobranch and pair of arthrobranchs present. Exopod absent.

Third maxilliped endopod 5-segmented, slender, unarmed; dactylus narrow, gently tapering, about 4 times longer than broad (at mid-length), setose; propodus slightly less than twice as long as dactylus, with setiferous organ along entire length of flexor margin; carpus subequal in length to propodus; merus longest, about twice carpal length; ischium broadest, subequal in length to merus; all articles with long setal fringe along flexor margin; basis short. Coxa with small epipod, mesial margin bluntly triangular; arthrobranchs present. Exopod absent.

First pereiopod slender, glabrous and sparsely setose; fingers unarmed, half as long as palm, distally setose; palm subcylindrical, tufts of long setae distally and along ventral margin of fixed finger; carpus 2.3 times as long as palm, ventral carpo-propodal setiferous organ pronounced on propodus and carpus; merus about $0.7 \times$ carpal length; ischium half meral length. Basis and coxa short, coxa with small mesial spine. Epipod absent.

Second pereiopod similar to first, $1.5 \times$ longer and stronger, sparsely setose; dactylus $0.4 \times$ palm length, distal tip formed into a strong corneous spine, tips of fingers cross when chela closed, cutting edges entire; propodus with a few tufts of setae distally and along fixed finger; carpus about $1.5 \times$ palm length; merus $0.8 \times$ carpal length; ischium $0.4 \times$ length of merus. Basis and coxa short. Epipod absent.

Third pereiopod largest, subequal and similar, about $1.7 \times \mathrm{CL}$, very sparsely setose except for a few distal tufts of setae along fingers; dactylus slightly less than $0.5 \times$ palm length, ending in strong, hooked corneous tip, cutting edge with narrow trench along distal half, with broadly rounded tooth at proximal third, otherwise smooth; propodal cutting edge with sharp corneous spine distally, followed by narrow trench along distal half, mid-length barely produce, distinct proximal notch to accommodate dactylar tooth; outer margin of fixed finger unarmed, bearing tufts of long setae; palm sub-cylindrical, moderately compressed, 3.4 times as long as broad, smooth, with few minute spines on inner ventrodistal surfaces; carpus about $0.4 \times$ palm length, narrowing proximally, without spines, with knoblike process at anterior end of inner surface; merus $0.8-0.9 \times$ length of palm, around four times longer than broad in lateral view, proximally compressed laterally, distoventral corners blunt, smooth; ischium about three-fourth length of carpus, laterally compressed, with small, sharp distodorsal spine only, ventral margin smooth. Basis and coxa short; coxa mesially densely setose, unarmed. Epipod absent.

Fourth and fifth pereiopods long and slender, similar, sparsely setose; dactylus about one-fifth the length of propodus, biungulate; both unguis clearly demarcated, with small accessory tooth on ventral margin, distinct shoulder dorsally; propodus not subdivided, slightly less than $0.5 \times$ carpal length, fifth pereiopod propodus as wide as fourth pereiopod propodus, with single row of 10-12 movable spine along entire flexor margin, both margins with few long, simple setae; carpus longest, not subdivided, with movable spine at distoventral angle; merus about $0.9 \times$ carpal length, unarmed; ischium about half length of merus, unarmed. Basis and coxa short, coxa mesially with dense setae, with small granules. Epipod absent.

First pleopod uniramous, second to fifth biramous, all lacking appendices, unarmed. 
Uropod well developed, about as long as telson. Protopod stout, with sharp posterolateral spine. Exopod broader than endopod; lateral margin slightly convex, with 8-10 teeth along distal 0.8 portion of margin, distal margin convex, dorsal surface with 2 distinct longitudinal ridges. Endopod simple, unarmed, surface with 1 longitudinal ridge. Exopod and endopod fringed with dense, plumose seta.

Measurements. Holotype: CL: $19.5 \mathrm{~mm}$, PCL: $14.4 \mathrm{~mm}$, TL: $55 \mathrm{~mm}$. NIWA 40567*: CL: $12.7 \mathrm{~mm}$, PCL: $9.8 \mathrm{~mm}$, TL: $34.2 \mathrm{~mm}$. NIWA 40638*: CL: $9.3 \mathrm{~mm}$, PCL: $6.6 \mathrm{~mm}$, TL: $29.3 \mathrm{~mm}$. *Measurements for both NIWA specimens are approximate as the specimens are damaged.

Distribution. New Zealand (type locality), southern Chatham Rise, 990-1110 m. New records presented here extend the range southwards to Macquarie Ridge, 998-1270 m. Based on the confirmed records at hand, this appears to be the only species in this genus with a southern temperate to sub-Antarctic distribution (Figure 1). Records recently presented by Goy [13] of S. novaezelandiae from New Caledonia are referable to S. sonne sp. nov. and $S$. weijiaensis based on DNA sequence similarities (Figure 2 and see comments below). Further specimens from Tasmania, Madagascar, Indian Ocean and Fiji mentioned by Goy [13] require more detailed examination.

Coloration. Body and appendages transparent, cornea yellow [20].

Hosts. Unknown.

Remarks. Following the examination of the male holotype of S. novaezelandiae, the following characters were not previously presented and can be added as follows: the epistome is anteriorly rounded, bearing a row of small granules along the anterior margin; the labrum is anteriorly rounded and smooth (Figure 8D); both ocular peduncles bear a small dorsomesial granule (Figure 8A); the basal antennal articles are smooth and not bearing any ventromesial processes (Figure $8 \mathrm{~F}$ ); the coxa of pereiopods $4-5$ bear small distomesial granules only (Figure $8 \mathrm{E}$ ). The proposed apomorphy for S. novaezelandiae is the first maxilliped distal segment broad and rounded (not tapering) [20], this is consistent on both sides of the holotype, however, the additional specimens presented below do not share this character (Figure 10E). Baba [20] illustrates the entire dorsal and the left anterior carapace but fails to include the small but distinct series of spines that line the cervical groove. They are less distinct on the left than the right, illustrated here (Figure 8A).

Two single specimens collected at two stations on Macquarie Ridge at $>53^{\circ} \mathrm{S}$ provide the most southerly records for the genus to date. Unfortunately, both specimens are badly damaged, both lack third maxilliped and pereiopod 3, and only one pereiopod 4 or 5 of NIWA 40567 is preserved (Figures 9-11). Genetically, these specimens clearly align with the holotype of $S$. novaezelandiae (see below). Morphologically, they share the following characters that may prove to be diagnostic: e.g., the nearly smooth postrostral carapace surface; the telson is sub-rectangular, length-width ratio is $\leq 2.0$, posterior margin with few or irregular row of spines; anterior margin of epistome bearing at least two granules; maxillipeds 2 and 3 bear a small epipod each. Notably, the distal segment of the first maxilliped palp bears a distinct spine (Figure 10E).

Spongicoloides novaezelandiae was described from a single male collected on the New Zealand Chatham Rise (Figure 1) and was recently reported again from a wide geographic range and with considerable morphological variation [13]. Following the examination of New Zealand material presented here in combination with DNA sequencing, we propose that only the additional New Zealand material reported, NIWA 40567 and 40638 from Macquarie Ridge, belong to $S$. novaezelandiae and that all remaining specimens are referable to the following species:

\section{(1). Spongicoloides weijiaensis Xu, Zhou \& Wang, 2017 [36]}

Three of four specimens reported from New Caledonia (BIOCAL specimens listed in Goy [13] as MNHN-Na-11996 [IU-2013-19630], Na-11997 [IU-2013-19488] and Na-11998 [IU2013-19627]) were successfully sequenced and are referred to $S$. weijiaensis (Figure 2), see comments under DNA sequence section below). According to figures provided (Goy [13]: Figure 10), these all share dorsal carapace spines on parts of the postrostral, hepatic and 
cardiac regions, but specimens will need to be examined in more detail. In the meantime, we propose the following characteristics to separate S. novaezelandiae and S. weijiaensis to include:

(a). The postorbital carapace region is nearly entirely smooth in S. novaezelandiae (with at least some scattered spines in S. weijiaensis).

(b). The epistome bears anterior teeth or row of small granules (smooth in S. weijiaensis).

(c). The antennal basicerite with nearly entirely smooth ventral surface in $S$. novaezelandiae (small ventral ridge armed with 1-3 spines present in S. weijiaensis).

(d). P3 ischium is smooth on ventral margin in S. novaezelandiae (irregular, with at least some proximal granules in S. weijiaensis).

The presence and number of arthrobranchs on the maxilliped 1 and 2 are usually considered diagnostic and the holotype of $S$. novaezelandiae has two arthrobranchs on maxilliped 2 which would differ from the single arthrobranch in S. weijaensis. However, this character is unusually variable in $S$. novaezelandiae with only one arthrobranch on maxilliped 2 of NIWA 40567 and one rudimentary arthrobranch on NIWA 40638.

The distribution of $S$. weijiaensis now extends from the northwestern Pacific to New Caledonia, north of the New Zealand region.

(2). Spongicoloides sonne sp. nov.

The figured CALSUB specimen (MNHN-NA 11999 [IU-2013-19487]) (Goy [13]: Figures $9 \mathrm{~A}$ and $10 \mathrm{~A}$ ) shows a distinct antennal spine on the anterolateral margin of the carapace (rounded in S. novaezelandiae) and a distinctly spinose ischium of the third pereiopod (smooth in S. novaezelandiae). Additionally, the rostrum reaches at least to the distal end of the second antennular article (reaching the end of the first article in S. novaezelandiae). These characteristics match those of $S$. sonne sp. nov. described and discussed below.

The material from Tasmania, Madagascar, Indian Ocean and Fiji referred to by Goy [13] will need to be examined in more detail in light of the review presented here.

Spongicoloides novaezelandiae most closely resembles $S$. clarki sp. nov. and S. sonne sp. nov., both reported from the northern New Zealand region (Figure 1). Morphological differences are discussed under those species below.

DNA sequence data. The holotype of S. novaezelandiae (NMNZ CR.001889) could be sequenced for both genes and aligned with the two specimens from Macquarie Ridge (NIWA 40567, 40638). The specimen reported as S. novaezelandiae by Chen et al. ([17] MNHN-IU-2014-6347) from the Solomon Islands belongs to a different species and aligns more closely with an undescribed species of Spongicoloides from the northwest Pacific (Zhao et al., in press.). Three of the four specimens presented as $S$. novaezelandiae by Goy [13] were successfully sequenced and align with the holotype sequence of $S$. weijiaensis (SRSIO-16050001, Figure 2).

CO1: intra-specific divergences between $0.6-1.7 \%$; intra-generic divergences range from $4.4 \%$ (Spongicoloides clarki sp. nov.) to $8.5 \%$ (S. corbitellus).

16S rRNA: intra-specific divergences were $0.0 \%$; intra-generic divergences range from $2.6 \%$ (Spongicoloides clarki sp. nov.) to $16.0 \%$ (S. iheyaensis).

\subsubsection{Spongicoloides sonne sp. nov.}

In (Figures 1, 2 and 12-17). Spongicoloides novaezelandiae.- Goy 2015 [13]: 310, Figures 9-11 (in part, New Caledonia, specimen MNHN-NA 11999 [IU-2013-19487]). 


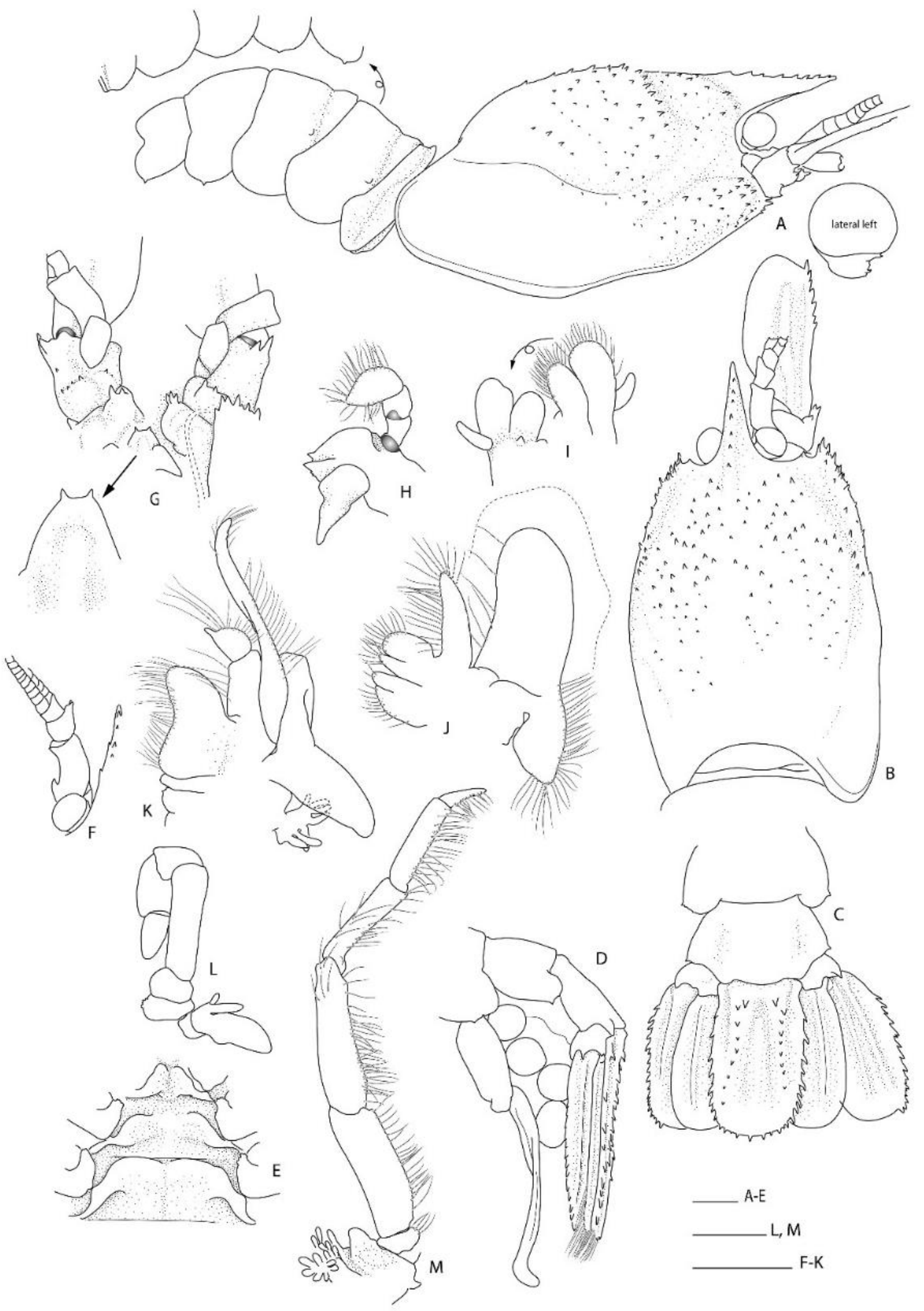

Figure 12. Spongicoloides sonne sp. nov., holotype F ov. (NIWA 127111). (A) Carapace and pleon, lateral, with inset of left pleural margins and enlarged lateral left ocular peduncle. (B) Carapace and cephalic appendages, dorsal. (C) Pleonites 5 and 6, urosome and telson, dorsal.(D) Pleura 4-6 with pleopod, urosome and telson, lateral. (E) Thoracic sternites 6-8 with coxae of pereiopods, ventral. (F) Rostrum, left antennule and ocular peduncle, dorsal. (G) Left and right antennae, left pterygostomian margin, epistome and labrum, ventral. (H) Left mandible with paragnath, inner and outer view. (I) Left maxillule, inner and outer view. (J) Left maxilla. (K) Left Mxp1. (L) Left Mxp2. (M) Right Mxp3. Scale bars = 2 mm. 


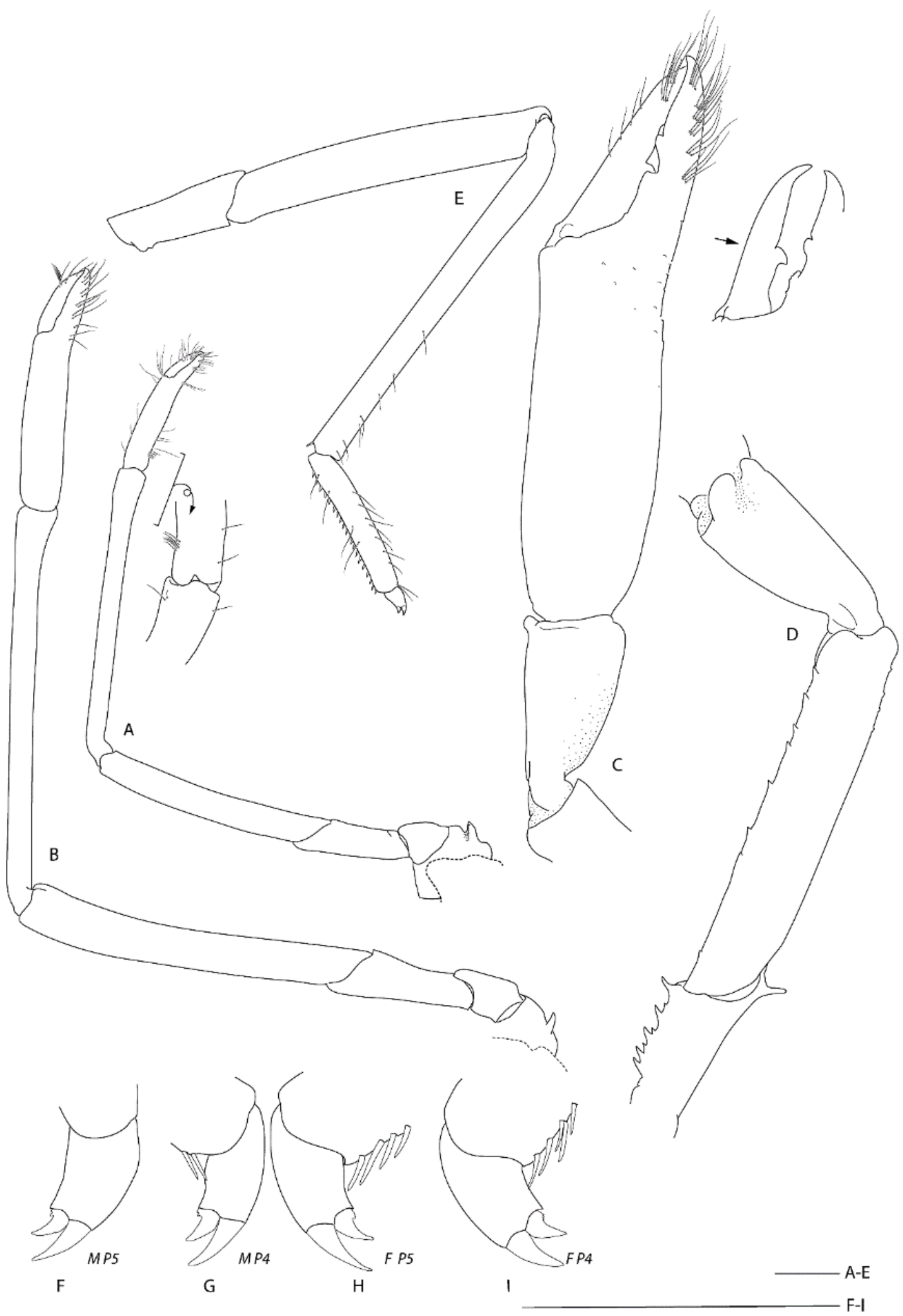

Figure 13. Spongicoloides sonne sp. nov., (A-D,H,I): holotype F ov. (NIWA 127110). F, G: allotype M (NIWA127111). (A) Right P1, lateral, with rotated inset of merocarpal setiferous organ. (B) Right P2, lateral. (C) Distal P3, right, lateral, with inset detail of incisor margin of fingers. (D) Proximal P3, right, mesial. (E) Right P4, lateral. (F-I) Dactyli and distal propodi of $\mathrm{P} 4-5$ for male $(M)$ allotype and female $(F)$ holotype. Scale $=2 \mathrm{~mm}$. 


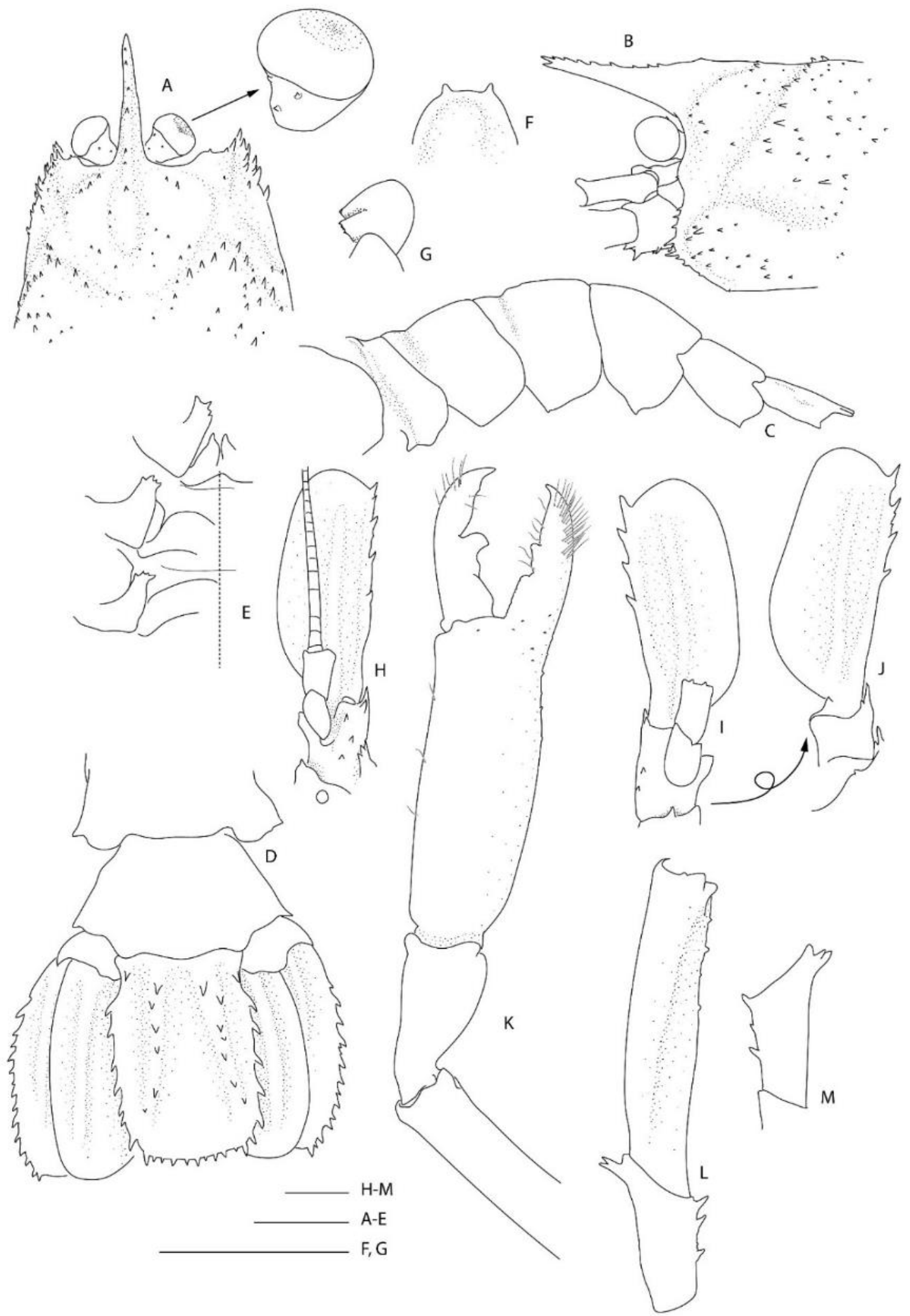

Figure 14. Spongicoloides sonne sp. nov., allotype M (NIWA 127110). (A) Anterior carapace, dorsal, with inset of enlarged right ocular peduncle. (B) anterior carapace and cephalic appendages, lateral. (C) Pleon, lateral. (D) Pleonites 5-6, urosome and telson, dorsal. (E) Thoracic sternites 6-8 with coxae of pereiopods, ventral. (F) Anterior margin of epistome, ventral. (G) Left mandible with paragnath, outer view. (H) Left antennae, ventral. (I) Right antenna, ventral. (J) Right antenna, dorsal. (K) Distal P3, lateral, right. (L) Proximal P3, lateral, right. (M) P3 ischium, left, lateral. Scale bars = 2 mm. 


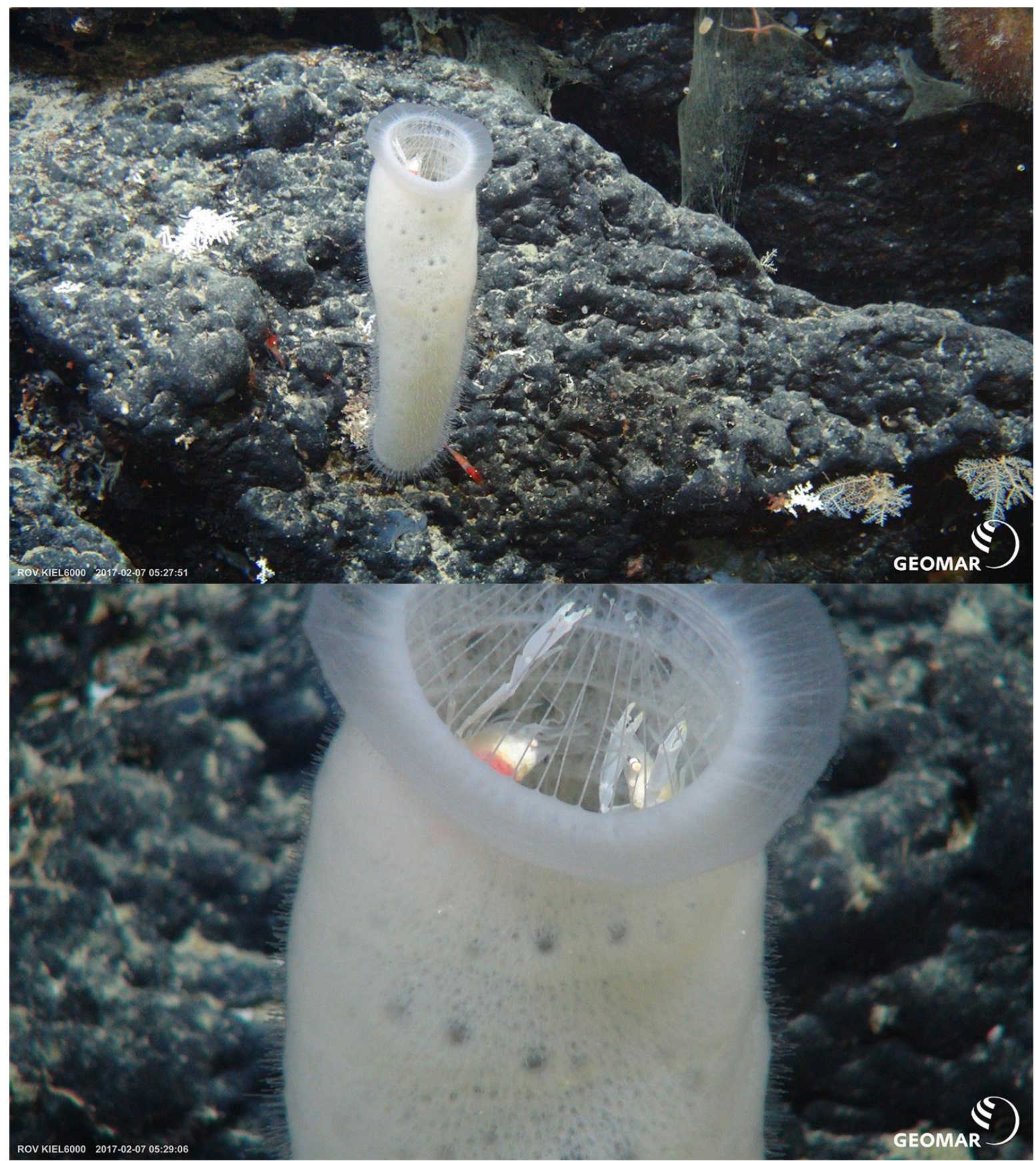

Figure 15. Spongicoloides sonne sp. nov. (pair NIWA 127110 and NIWA 127111) sponge host Corbitella sp. (det. Henry Reiswig, University of Victoria, Victoria, BC, Canada), Lyssacinosida, immediately prior to collection on the southern Kermadec Ridge (1168 m). Image courtesy of ROV Kiel 6000 GEOMAR, SO254 voyage PoriBacNewZ, ICBM. 


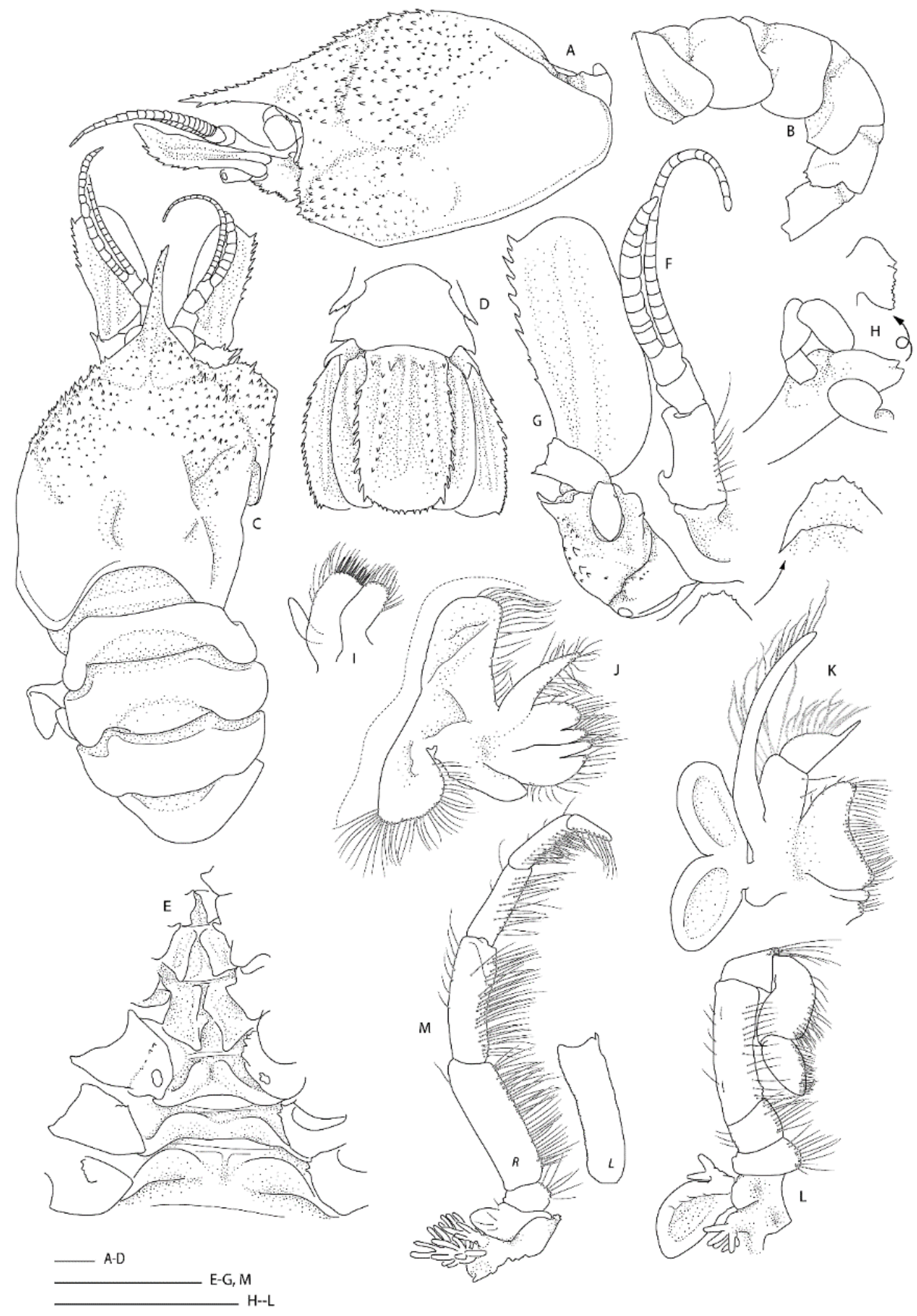

Figure 16. Spongicoloides sonne sp. nov. (NMNZ CR.019650). (A) Carapace and cephalic appendages, lateral. (B) Pleon, lateral. (C) Habitus, dorsal. (D) Pleonites 5-6, urosome and telson, dorsal. (E) Thoracic sternites with coxae of pereiopods, ventral. (F) Right antennule, ventral. (G) Right antenna, epistome and labrum, ventral. (H) Right mandible with paragnath, outer view, inset with rotated mandibular incisor margin. (I) Right maxillule. (J) Right maxilla. (K) Right Mxp1. (L) Right Mxp2. (M) Right (R) Mxp3 with inset left $(L)$ ischium. Scale bars $=2 \mathrm{~mm}$. 


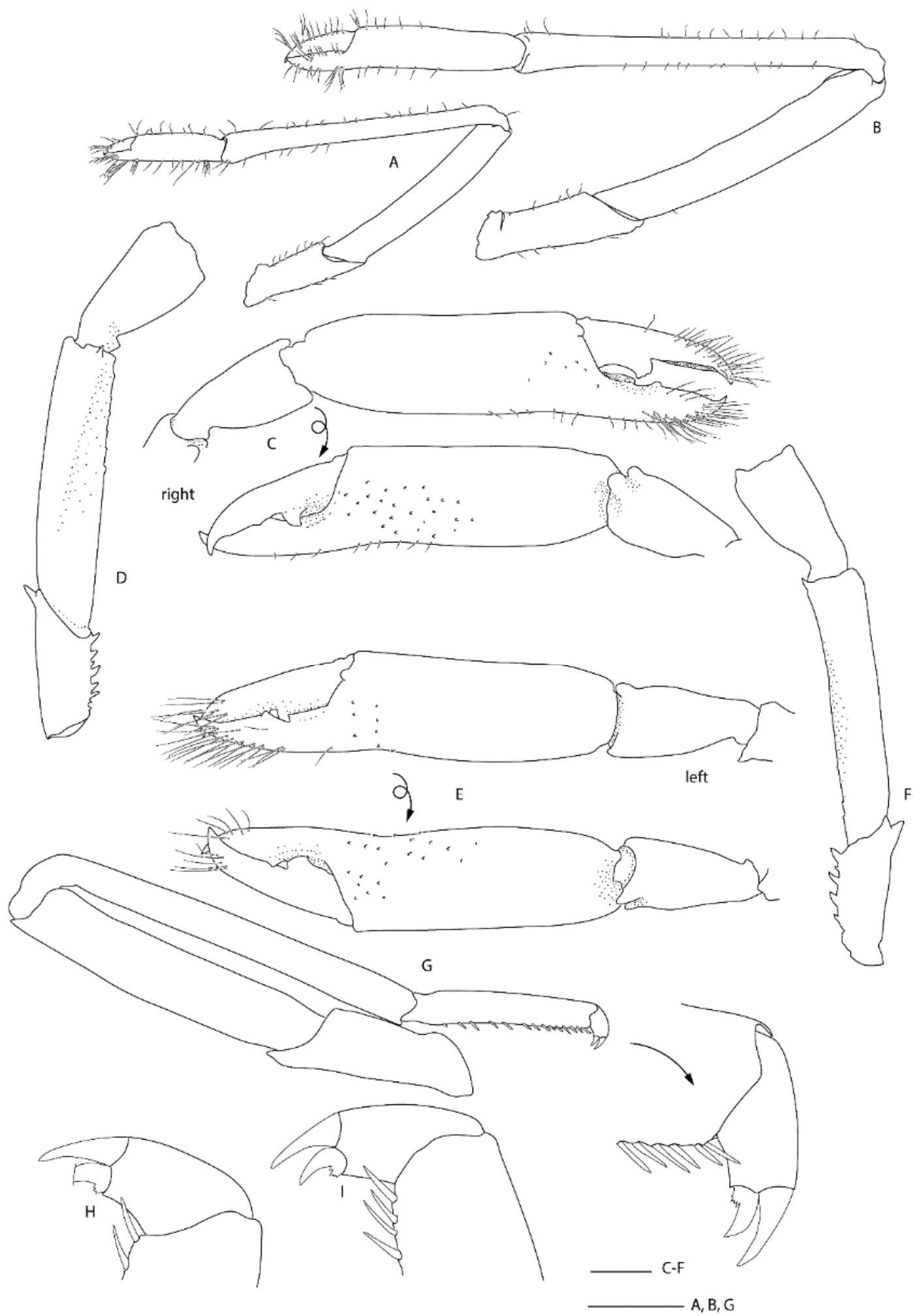

Figure 17. Spongicoloides sonne sp. nov. (NMNZ CR.019650). (A) Left P1, lateral. (B) Left P2, lateral. C. Right P3, distal portion, lateral (top) and mesial (bottom). (D) Right P3, proximal portion, lateral. (E) Left P3, distal portion, lateral (top) and mesial (bottom). (F) Left P3, proximal portion, lateral. (G) Right P4, lateral, inset detail of dactylar spination. (H,I) Dactyli and distal propodi of loose left P4 or P5. Scale bars $=2 \mathrm{~mm}$.

Material examined. Holotype: F ov. (PCL: $15.0 \mathrm{~mm}$ ); Southern Kermadec Ridge, $35.380^{\circ}$ S, $178.980^{\circ}$ E, 1184.1 m; 7 February 2017; RV Sonne Stn. SO254/33ROV08, Remote 
Operated Vehicle; NIWA 127111; found inside Corbitella sp. Allotype: M (PCL: $11.4 \mathrm{~mm}$ ); Southern Kermadec Ridge, 35.380 S, $178.980^{\circ}$ E, 1184.1 m; 7 February 2017; RV Sonne Stn. SO254/33ROV08, Remote Operated Vehicle; NIWA 127110; found inside Corbitella sp. Other material. $1 \mathrm{~F}$ (PCL: $11.0 \mathrm{~mm}$ ); West Norfolk Ridge, 34.28 ${ }^{\circ} \mathrm{S}, 168.41^{\circ} \mathrm{E}, 1246-1249 \mathrm{~m}$; 2 June 2003; TAN0308/142, Orange Roughy trawl; NMNZ CR.019650. 1 M (PCL: 12.0 mm); Lillie Seamount, Kermadec Ridge, 35.857-35.857 ${ }^{\circ} \mathrm{S}, 178.448-178.443^{\circ}$ E, 1237-1460 m; 19 March 2011; RV Tangaroa Stn. TAN1104/124, 'seamount' sled; NIWA 72929.

Diagnosis. Carapace with distinct hepatic groove; scattered small spines on postrostral, cardiac, hepatic and branchial surfaces; cervical groove lined with distinct spines; antennal spine and anterolateral spines small but distinct. Rostrum at least reaching distal margin of basal article of antennular peduncle; with 8-10 dorsal teeth. Epistome anteriorly produced, with small anterior teeth. Second and third pleonite with blunt articular knob. Fourth to sixth pleonites smooth on dorsal midline; one or more small spine along each posteroventral margin. Telson broadly rectangular, about twice as long as wide; regular row of teeth along posterior margin. Ocular peduncle with 2-3 granules on dorsal surface. Antennule basal article unarmed on mesial margin; stout stylocerite. Antenna basal article with distinct ventral spines; basicerite with scattered spines on ventral surface; scale with 4-9 lateral teeth along distal half of margin. First maxilliped distal article with sharp distal spine; single arthrobranch developed. Second maxilliped with single arthrobranch and well-developed podobranch; epipod present. Third maxilliped with well-developed setiferous organ; lacking epipod; with paired arthrobranchs. First pereiopod with setiferous organ on propodus only. Second pereiopod similar to first, $1.5 \times$ longer and stronger. Third pereiopod nearly entirely glabrous and smooth; fixed finger unarmed on distoventral margin; palm with few to many minute granules scattered along distoventral portion; ischium with distinct distodorsal spine, with row of ventral spines; coxa mesially granulate. Fourth and fifth pereiopods dactyli with ventral unguis bearing a number of small ventral teeth. First four pereiopods with paired arthrobranchs.

Etymology. Named after the German Research Vessel Sonne that collected the first specimens assigned to this new species during the 2015 PoribacNewZ voyage SO254. Used as a substantive in apposition.

Description of holotype female (Figures 12 and 13).

Body large, robust, surface generally glabrous.

Rostrum narrowly triangular in dorsal view, one-third (0.33) as long as PCL, horizontal, barely reaching to distal margin of second article of antennular peduncle; dorsal margin with seven small teeth and posterior blunt eminence at level of posterior orbital margin; ventral margin with one small tooth close to rostral tip; ventrolateral ridges with 1-2 (right-left) small teeth on distal half.

Carapace glabrous, slightly inflated. Cervical and branchiostegal grooves distinct. Gastric, hepatic, and anterior portions of cardiac and branchial regions armed with numerous scattered small spines. Orbital margin concave, inferior orbital angle slightly produced and furnished with 1-2 small antennal spines. Small branchiostegal spine present. Pterygostomian angle round, with series of five small spines on margin.

Thoracic sternites 6-8 anteriorly rounded, minutely serrate but unarmed; sternite six posterior margins evenly concave.

Pleonal somites glabrous, surfaces smooth. First pleonite shortest; divided into two sections by distinct transverse carina; ventral margin continuous, straight. Second and third pleonite subequal in length, with feeble transverse carina and small articular knob; ventral margin rounded, left side with slight indication of a granule. Fourth and fifth pleonites each with small sharp or blunt posteroventral tooth on broad, round margin; dorsally smooth and unarmed. Sixth pleonite dorsally smooth; posterolateral process straight, angular, with small, sharp spine at corner; posterior margin smooth. Pleonal sternites unarmed.

Telson about 1.9 times as long as broad, subquadrangular, posterior margin shallowly convex, with long plumose setae; dorsolateral ridges distinct, with nine spines each, proximalmost largest and placed mesially; lateral margins relatively straight, slightly 
constricted proximally, each side armed with a subproximal spine and nine lateral spines; posterior margin with 10 small pines (4-5 lateral and one median spine).

Eye well developed; cornea semiglobular, about half length of ocular peduncle in dorsal view, distinctly inflated, unpigmented; minute mesial proximal spine on both eye stalks, and small distal spine on left eye stalk only.

Antennular peduncle reaching to about middle of antennal scale, does not reach spinose lateral margin of antennal scale. Basal article stout, length-width ratio of 2.7 at midlength, without statocyst, about three times as long as second article; lateral margin concave, distally produced to small, rounded lobe, stylocerite distinct, acute, reaching $1 / 3$ length of basal article; mesial margin almost straight, unarmed other than row of serration where plumose seta are inserted. Second article about 1.5 times longer than distal article, distomesially with two small spines. Distal article as long as wide, unarmed. Flagella slender, about twice as long as peduncle.

Antenna with first article (coxa, bearing antennal gland) mesially carinate, bearing three distinct spines. Basicerite stout; mesially bearing minute (left) or distinct (right) spine, paired spines distolaterally; dorsal and lateral surfaces smooth, minute spine at midlength mesially, scattered spines on ventral surface. Antennal scale broad, $2.6 \times$ as long as wide; lateral margin nearly straight, armed with seven (left) or eight (right) teeth along the distal 0.4 portion, including the distal tooth; dorsal surface with two distinct longitudinal ridges. Carpocerite reaching to distal end of second article of antennular peduncle, unarmed. Flagellum at least 1.7 times the CL.

Epistome narrow, subquadrate, with two small spines at anterolateral angles. Labrum smooth. Paragnaths bilobed, with deep median fissure, distodorsally spatulate.

Mandible robust, fused molar and incisor processes. Molar surface with three teeth; incisor bearing two distal teeth with five small proximal teeth. Palp well-developed, 3segmented; proximal article shortest, without setae; middle article with few setae on flexor and more, longer setae on extensor margins; distal article suboval, slightly longer than intermediate article (measured along extensor margin), densely setose.

Maxillule with simple palp, with few terminal setae; distal endite broad, round, with numerous simple setae and seven slender spines; proximal endite oval, with simple setae distally.

Maxilla with palp stout, tapering, with plumose setae, falling short of end of scaphognathite; distal and proximal endites both deeply bilobed, with numerous plumose setae; scaphognathite well developed, anterior portion longer than posterior portion, about three times longer than broad, with dense fringe of plumose setae along entire margin.

Branchial formula summarized in Table 2.

First maxilliped with 2-segmented palp, bearing long plumose setae; distal segment broad, with distal blunt spine; proximal article stout, about $1.6 \times$ distal article in length. Distal endite large, subtriangular, densely setose; proximal endite deeply bilobed, with distal setae. Exopod slender, with long plumose setae. Epipod well developed, subequally bilobed. Arthrobranch present.

Second maxilliped with 5-segmented endopod; dactylus sub-oval, tapering distally, about twice as long as broad, with dense setae on flexor margin; propodus subequal in length to dactylus, densely setose along flexor margin; carpus triangular, about threeforth length of propodus measured at mid-line, with long distodorsal setae; merus nearly straight, about $1.8 \times$ length of propodus, nearly 4 times longer than broad, with row of setae along mesial margin and sparse short setae on surfaces; ischium and basis not fused, each about $0.2 \times$ meral length and long setae along mesial margin. Coxa with mesial spine; oval epipod, podobranch and arthrobranch. Exopod absent.

Third maxilliped endopod 5-segmented, slender; dactylus narrow, about 4.5 times longer than broad (at mid-length), setose; propodus about twice as long as dactylus, with setiferous organ along distal two-thirds of flexor margin; carpus subequal in length to propodus; merus longest, about $1.5 \times$ carpal length, minute distolateral spine on left, absent on right; ischium broadest, $0.8 \times$ meral length, small distolateral spine on both sides; 
all segments with long setal fringe along flexor margin; basis short. Coxa without epipod, arthrobranchs present. Exopod absent.

First pereiopod slender, just overreaching antennal scale when extended, glabrous and sparsely setose; dactylus about $0.5 \times$ palm length; palm subcylindrical, tufts of long setae dorsodistally and along ventral margin of fixed finger; carpus $3 \times$ palm length, ventral carpo-propodal setiferous organ more pronounced on propodus, very weak on carpus; merus about $0.8 \times$ carpal length; ischium one-third meral length. Basis and coxa short, coxa with sharp mesial spine. Epipod absent.

Second pereiopod similar to first, $1.5 \times$ longer and stronger, sparsely setose; dactylus $0.4 \times$ palm length, distal tip formed into a strong corneous spine, tips of fingers cross when chela closed, cutting edges entire; propodus with a few tufts of setae distally and along fixed finger; carpus about $2.2 \times$ palm length; merus $0.8 \times$ carpal length; ischium one-third length of merus. Basis and coxa short; coxa with mesial spine. Epipod absent.

Third pereiopod largest, subequal and similar, about $2 \times \mathrm{CL}$, overreaching the tip of antennal scale by length of chela, very sparsely setose except for a few distal tufts of setae along fingers; dactylus about $0.5 \times$ palm length, ending in strong, hooked tip, cutting edge with narrow trench along distal half, with strong, hook-shaped tooth at mid-length, otherwise smooth; propodal cutting edge with sharp corneous spine distally, followed by narrow trench along distal half, rounded tooth at mid-length and molariform process with numerous tiny teeth at proximal third; outer margin of fixed finger unarmed, bearing tufts of long setae; palm sub-cylindrical, 3.3 times as long as broad, dorsal margin smooth, with few scattered small granules on surface, along ventral margin and more dense across inside palm surface; carpus about $0.5 \times$ palm length, narrowing proximally, without spines; merus subequal in length to palm, five times longer than broad in lateral view, proximally compressed laterally, with small distoventral tooth, dorsally with few distal granules and ventral ridge with row of small teeth and granules, otherwise smooth; ischium about three-fourth length of carpus, laterally compressed, with sharp distodorsal spine and ventral row of spines, distalmost strongest. Basis and coxa short; coxa mesially granulate. Epipod absent.

Fourth and fifth pereiopods long and slender, similar, sparsely setose; dactylus about one-fourth the length of propodus, biungulate, both unguis clearly demarcated, with small, irregularly shaped accessory tooth on ventral margin proximally; propodus not subdivided, about $0.4 \times$ carpal length, pereiopod 5 propodus $1.1 \times$ wider than pereiopod 4 propodus, with single row of 21-22 (P4) and 24-25 (P5) movable spines along entire flexor margin, both margins with few long, simple and very few plumose setae; carpus longest, not subdivided, with movable spine at distoventral angle; merus about $0.8 \times$ carpal length, unarmed; ischium less than half length of merus, unarmed. Basis and coxa short, coxa with blunt, serrated distomesial tooth. Epipod absent.

First pleopod uniramous, second to fifth biramous, all lacking appendices, unarmed.

Uropod well developed, about as long as telson. Protopod stout, with sharp posterolateral spine. Exopod broader than endopod; lateral margin slightly convex, with 17 (left) and 19 (right) teeth along distal three-fourth of margin, distal margin shallowly convex, dorsal surface with two distinct longitudinal ridges. Endopod simple, unarmed, surface with 1 longitudinal ridge. Exopod and endopod fringed with dense, plumose seta.

Eggs: The ovigerous female incubates around 200 eggs of diameters $1.8 \times 2.2 \mathrm{~mm}$.

Comparison of female holotype to male allotype (Figures 13 and 14).

Body smaller than female holotype.

Rostrum proportionally longer, $0.4 \times$ PCL, dorsal margin with eight small teeth in addition to proximal shallow rounded eminence at level of posterior orbital margin; ventral margin with two teeth; laterally unarmed.

The carapace less inflated, distribution of spines similar, but spines generally longer with exception of antennal spine smaller, otherwise similar to holotype.

Sixth thoracic sternites with narrowly triangular process, anteriorly furnished with sharp spine each. Seventh and eight sternites broadly rounded, unarmed. 
Pleonal somites similar to holotype; first pleonite with pronounced anteroventral spine; ventral margins of tergites 3-6 more angular and with sharper distal spine each; dorsally smooth. Fifth pleomere with small median spine distally, directed posteriorly.

Telson similar, dorsal ridges with 6-7 spines, laterally with 7-8 spines; distal margin with 9 small spines (median spine with four lateral pairs).

Eye similar, eye stalk with 2-3 dorsal spines.

Antennule similar, second article with single, small distomesial granule only.

Antenna with first article (coxa) bearing strong mesial tooth (not carinate). Basicerite similar. Antennal scale with $4-5$ lateral spines.

Epistome with two pairs of small spines and smooth median margin.

Mouthparts as for female holotype. Left third maxilliped merus with sharp distolateral spine, merus unarmed (right third maxilliped missing).

Pereiopod 1, 2, 4 and 5 as for female holotype. Pereiopod 3 slightly longer, $2.5 \times \mathrm{CL}$; the palm is slightly more massive at 2.7-2.8 times longer than wide (left-right); ischium with double distodorsal spine, otherwise as holotype.

Uropodal exopod with 14-15 teeth along lateral margins.

Measurements. CL: 16.3-18.5 mm (M), 16.6-[20.0] mm (F), PCL: 12.0-11.4 mm (M), 11-[15] mm (F), TL: 38.5-46.0 mm (M), 40.2-[53.2] mm (F). Holotype measurements are given in square brackets.

Distribution. Confirmed in New Zealand, 1184-1460 m. Sequence only, pending morphological examination: Vanuatu, 1210-1250 m (MNHN-IU 2013-19622).

Coloration. Collection notes are retained as "white" (NIWA 127110) and "pink" (NIWA 127111).

Hosts. The pair of type specimens collected by ROV from the Southern Kermadec Ridge was taken with a sponge host of Corbitella sp. nov. (det. Henry Reiswig, Figure 15). This genus of glass sponges was recently reported as a host for the first time by Kou et al. [35] and this is the second record of a Spongicoloides species with Corbitella. An unidentified species of Farrea glass sponge is the only sponge collected at the same station with NIWA 72929 and is the most likely host at present.

Variation and remarks. Two further specimens are reported in addition to the pair of type specimens, displaying a limited amount of variation: NMNZ CR.019650 appears more spinose both considering the surface of the carapace and rostrum, the antennal peduncle and scale and the uropodal endopod (Figures 16 and 17). The epistome of the holotype is distinctly bispinose anteriorly, but all other specimens have more, indistinct spines distally. The palp of the first maxilliped bears a long and slender distal spine in this female specimen, which is shorter and blunter in all others, including the female holotype. Saito and colleagues [48] indicated this might be sexually dimorphic when describing S. iheyaensis. The armature of the third maxilliped ischium and merus varies slightly across specimens but all have a small or distinct distal spine on at least one side or article (NIWA 72929 had a small spine on both merus and ischium of the one remaining third maxilliped). Some (sexually dimorphic and/or allometric) variation is apparent in the proportions of the third pereiopod: it is slightly shorter for the two females (1.7-2.0 $\times \mathrm{CL})$ and longer $(2.5 \times \mathrm{CL})$ for the male allotype (pereiopod 3 are missing in the male NIWA 72929). Typical sexual dimorphism is evident with the palm more slender in the large holotype female (length-width ratio of 3.3) and proportionally broader (2.7-2.9) for the male allotype and female NMNZ CR.019650 that are both approximately the same size.

Spongicoloides sonne sp. nov. closely resembles the group of species with two arthrobranchs on third maxilliped and pereiopods 1-4, dorsally unarmed uropodal endopod, dorsally smooth pleonites and smooth distoventral margin of pereiopod 3 fixed finger. This includes S. clarki sp. nov., S. novaezelandiae, S. hawaiiensis Baba, 1983 [49], S. weijiaensis and S. corbitellus. Spongicoloides sonne sp. nov. can be distinguished from these species by the following fixed characters: 
- The postrostral, cardiac and at least the anterior branchial carapace surface is covered with small spines; S. hawaiiensis has a nearly smooth carapace and the remaining species only have a few scattered small spinules.

- $\quad$ Third maxilliped is lacking an epipod; which all others have present (rudimentary in S. clarki).

- $\quad$ Third maxilliped endopod ischium and/or merus with small distolateral spine (typically varies from left to right but present on at least one of the articles); the endopod is unarmed in all other species.

- Coxa of third maxilliped and pereiopods 1-2 with distinct mesial spine or process; rounded in all other species.

- $\quad$ Rostrum overreaches the basal antennular article in S. sonne, S. novaezelandiae, S. weijiaensis and S. clarki but it falls short of the distal end of the article in S. corbitellus (the rostrum in S. hawaiiensis remains unknown).

- Pereiopod 3 ischium with distinct distodorsal spine and row of sharp spines along ventral margin, the distodorsal spine is small in S. novaezelandiae, S. weijiaensis, S. clarki and S. corbitellus and absent in S. hawaiiensis; the ventral margin smooth or irregular but not furnished with sharp spines in all other species.

A notable characteristic that has in the past been rarely considered is the ventromesial ornamentation of the first antennal segment (coxa, bearing the antennal gland) which is distinctly ridged and carinate (as in the holotype), always furnished with at least one distinct spine. In S. novaezelandiae the first antennal article is simple, with only a small spine. This character might hold additional phylogenetic value and could be considered further across the remaining species.

At least one of the specimens presented by Goy [13] as S. novaezelandiae from New Caledonia most likely belong to this new species based on the clearly spinose carapace surface and the row of distinct spines illustrated on the third pereiopod ischium of MNHN Na-11999 (Goy [13]: Figure 9; MNHN-IU-2013-19487). Most of the remaining material presented by Goy [13] are referable to $S$. weijiaensis (see comments under S. novaezelandiae above).

DNA sequence data. A clade formed by 3-4 sequences were monophyletic for all genes considered (Figure 2). This included a sequence from a specimen from Vanuatu (1210-1250 m) held at the MNHN (IU-2013-19622) which is considered conspecific and pending more detailed examination.

CO1: intra-specific divergences between $0-1.2 \%$; intra-generic divergences range from $4.2 \%$ (Spongicoloides clarki sp. nov.) to $7.3 \%$ (S. weijiaensis).

16S rRNA: intra-specific divergences between $0-0.3 \%$; intra-generic divergences range from 3.3\% (Spongicoloides weijiaensis) to 16.7\% (S. iheyaensis).

Genus Spongiocaris Bruce \& Baba, 1973 [21].

\subsubsection{Spongiocaris antipodes sp. nov.}

In (Figures 1, 2 and 18-22). Material examined. Holotype: F ov. (PCL: $7.7 \mathrm{~mm}$ ); West Norfolk Ridge, $34.342^{\circ} \mathrm{S}, 168.387^{\circ} \mathrm{E}, 382-390 \mathrm{~m}$; 2 June 2003; NORFANZ Stn. TAN0308/139; NMNZ CR.025704. Allotype: M (PCL: $5.2 \mathrm{~mm}$ ); West Norfolk Ridge, $34.285^{\circ} \mathrm{S}, 168.358^{\circ} \mathrm{E}$, 785-800 m; 2 June 2003; NORFANZ Stn. TAN0308/141; NMNZ CR.019492. Paratype: $1 \mathrm{M}$ (poor condition, PCL: $\sim 6.2 \mathrm{~mm}$ ); station details as for holotype; NMNZ CR.019493. $1 \mathrm{~F}$ (PCL: 8.0 mm); Seamount No. 986, off Hawkes Bay shelf, 39.991 S, 178.215 E, 792 m; 9 February 2017; method: manipulator arm; R/V Sonne, ROV KIEL 6000, cruise: SO254, dive: 36 ROV 10; NIWA 127133. 


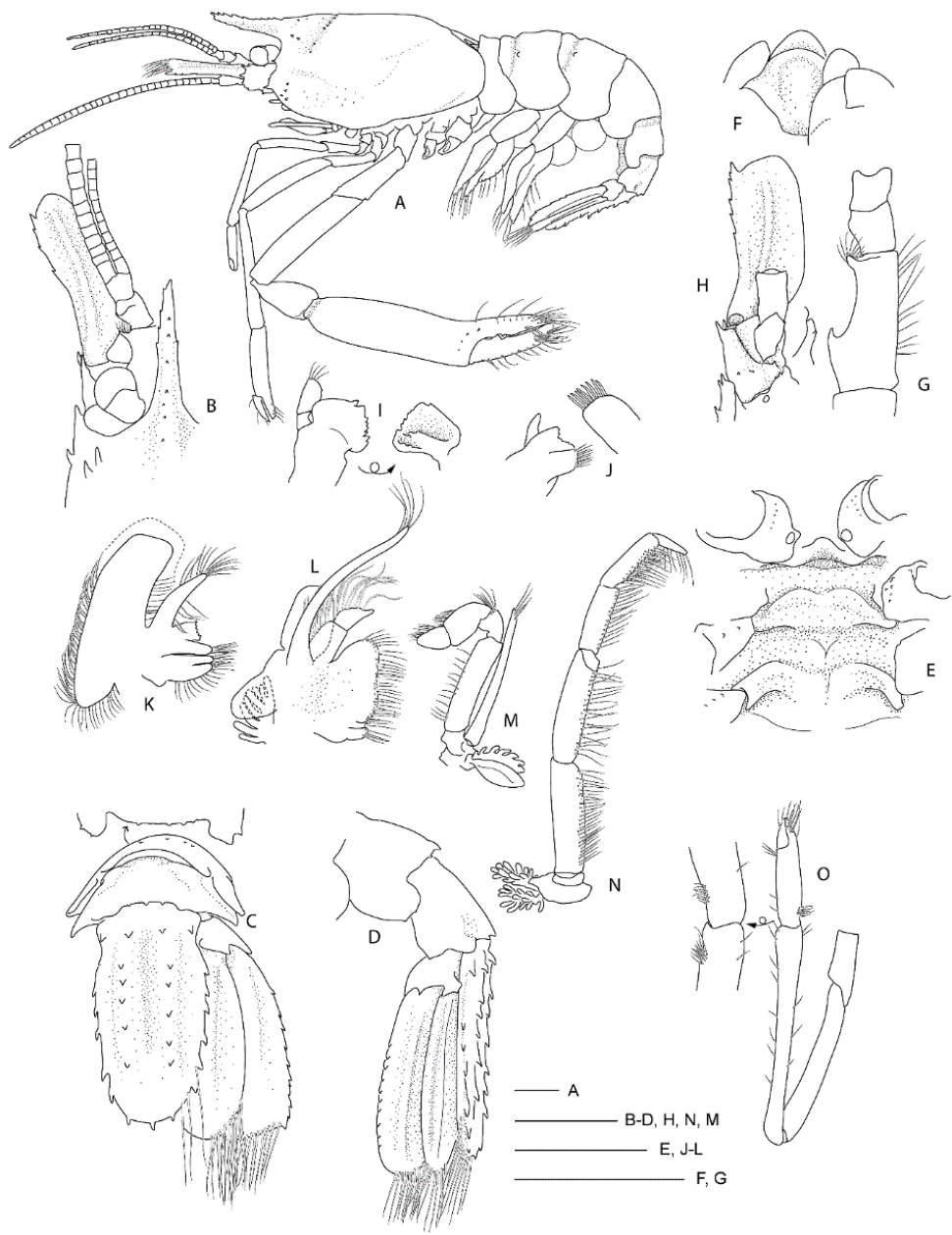

Figure 18. Spongicaris antipodes sp. nov., holotype F ov. (NMNZ CR.025704). (A) Habitus, lateral. (B). Anterior portion of carapace and cephalic appendages, dorsal. (C) Pleonites 6, urosome and telson, dorsal, with inset of dorsal view of pleonite 5. (D) Pleura 5-6, urosome and telson, lateral. (E) Thoracic sternites 6-8 with coxae of pereiopods, ventral. (F) Epistome, labrum partially covered by following mouthparts, ventral. (G) Right antennular peduncle, ventral. (H) Right antennae with inset view of mesial margin of basicerite. (I) Right mandible, inner and outer view. (J) Right maxillule with broken upper lacinia and left maxillule upper lacinia. (K) Right maxilla. (L) Right Mxp1. (M) Left Mxp2. (N) Right Mxp3. (O) Right P1, lateral, with inset detail of carpo-propodal setiferous organ. Scale bars $=2 \mathrm{~mm}$.

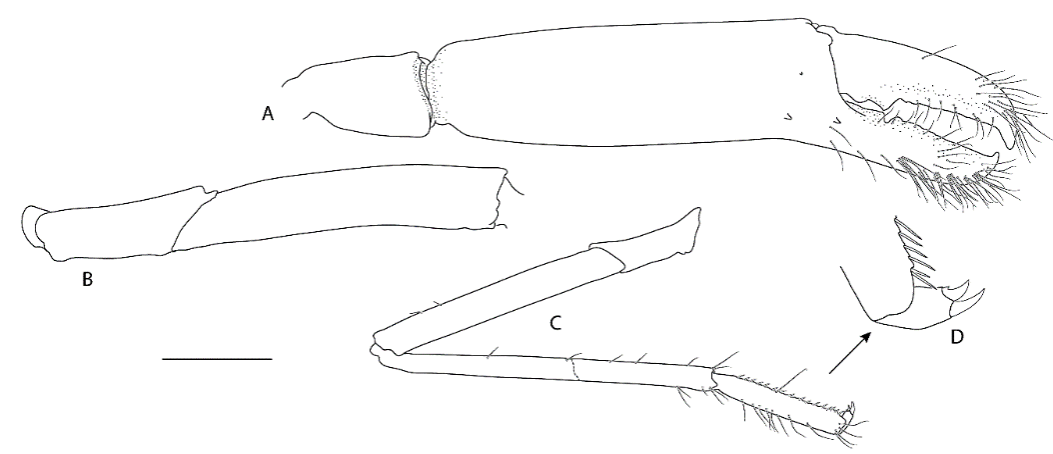

Figure 19. Spongicaris antipodes sp. nov., holotype F ov. (NMNZ CR.025704). (A) Right P3, distal portion, lateral. (B) Right P3, proximal portion, lateral. (C) Left P5, lateral, with enlarged detail of dactylar spination enlarged. Scale bar $=2 \mathrm{~mm}$. 


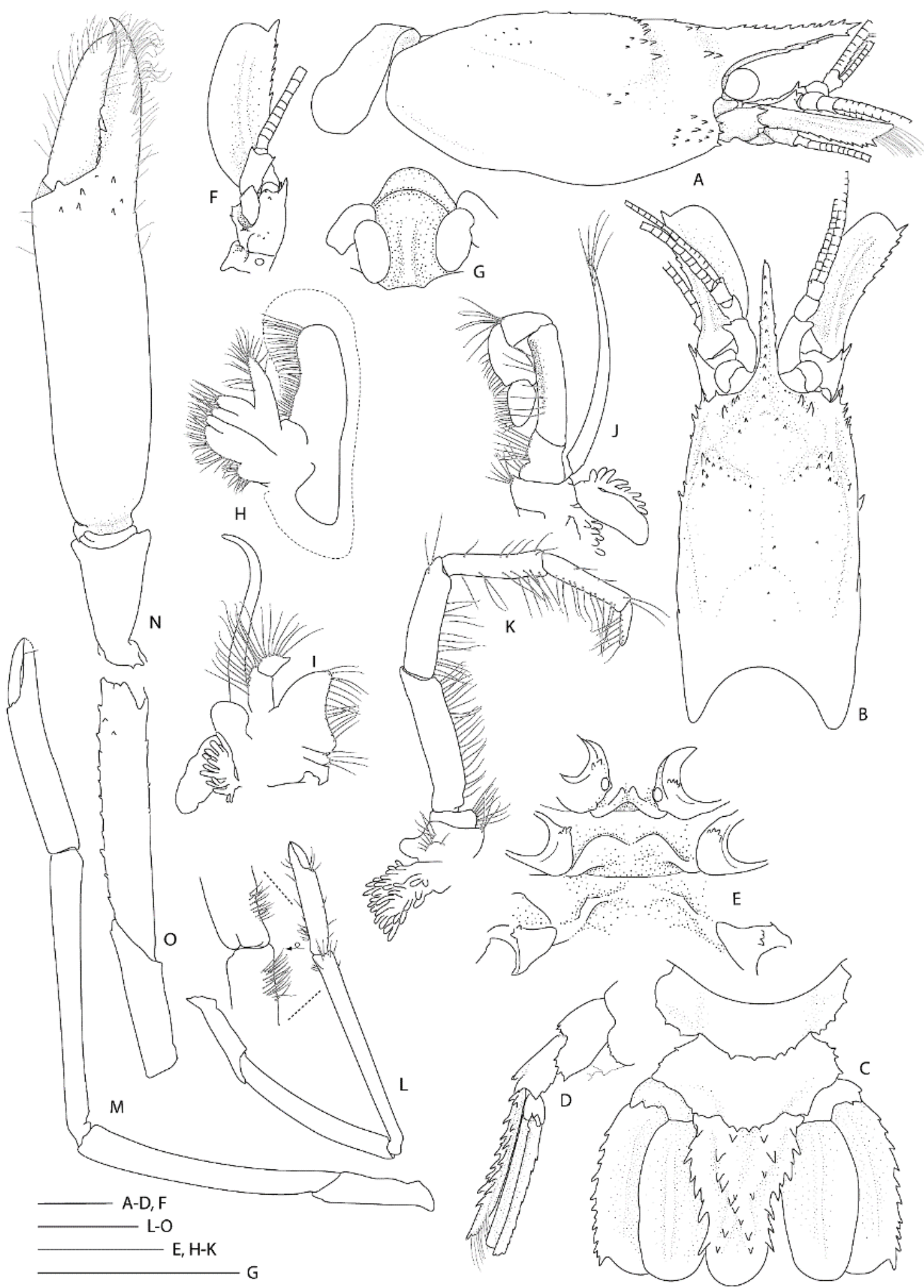

Figure 20. Spongiocaris antipodes sp. nov., paratype F (NIWA 127133). (A) Carapace and first pleonite, lateral. (B) Carapace and cephalic appendages, dorsal. (C) Pleonites 5-6, urosome and telson, dorsal. (D) Pleonites 5-6, urosome and telson, lateral. (E) Thoracic sternites 6-8 with coxae of pereiopods, ventral. (F) Left antenna, ventral. (G) Epistome, labrum partially covered by mandibular palps, ventral. (H) Left maxilla. (I) Left Mxp1. (J) Left Mxp2. (K) Right Mxp3. (L) Left P1 with detail of merocarpal setiferous organ. (M) Right P2. (N) Right P3 distal portion, lateral. (O) Right P3 proximal portion, lateral. Scale bars $=2 \mathrm{~mm}$. 


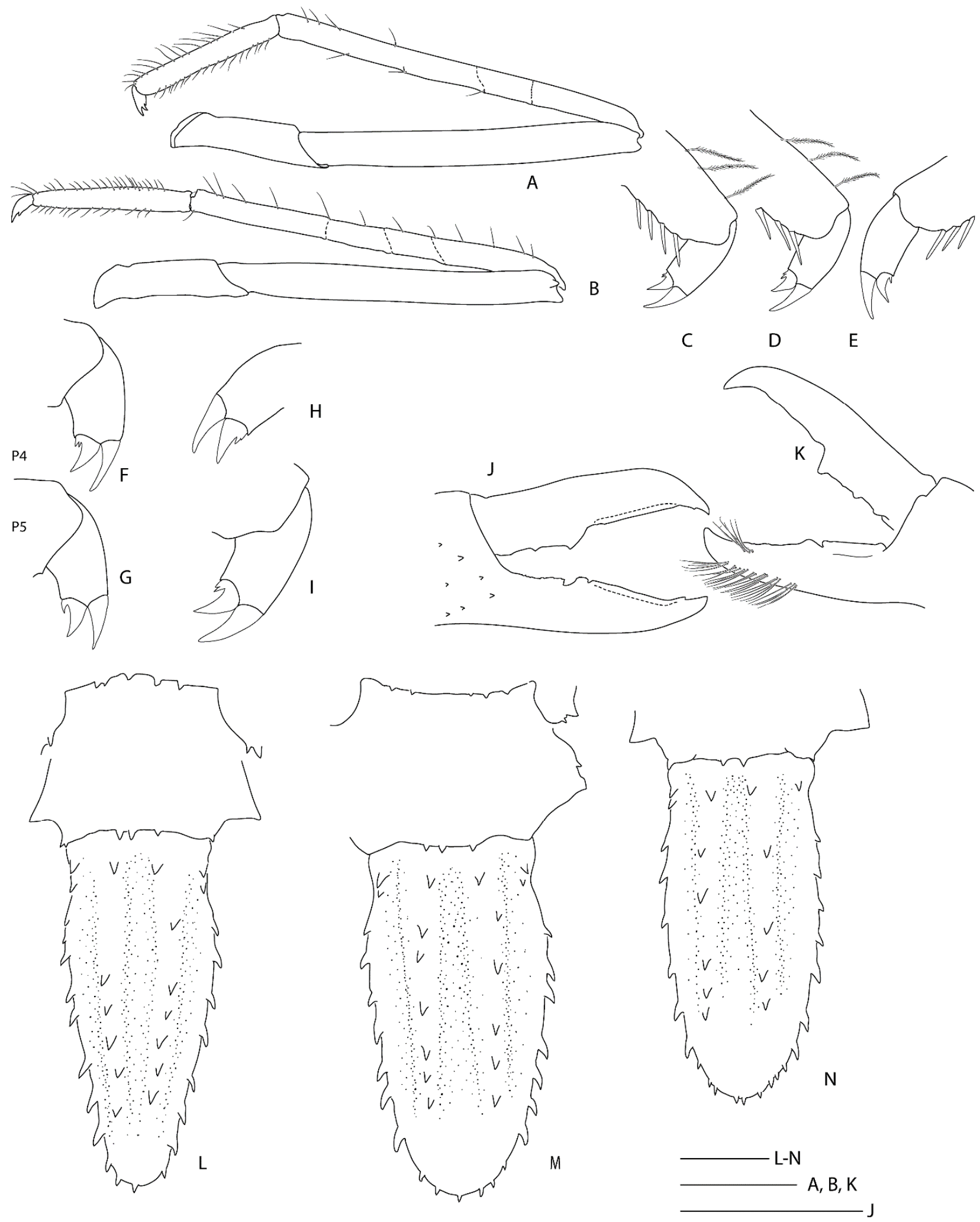

Figure 21. Spongiocaris antipodes sp. nov., (A-E): paratype F, PCL 8.0 mm (NIWA 127133); (F,G): F ov., PCL 7.9 mm (NMNZ CR.019259); H,I: lose appendages, unknown origin (NMNZ CR.019491); (J): M, PCL 4.6 mm (NIWA 135621); (K,N): M, PCL 7.3 mm (NMNZ CR.019494); (L): M, PCL 7.5 mm (NMNZ CR.019491); (M): F ov., PCL 8.0 mm (NMNZ CR.019491). (A,B) lose right P4 and P5. (C,D) Dactylus and distal propodus, lose right P4 and P5. (E) dactylus and propodus, presumed left P4. (F-I) Dactylus and distal propodus, P4 and P5. (J,K) fingers and distal palm, P3, outside view. (L-N) telson and pleonite 6, dorsal. Scale bars $=2 \mathrm{~mm}$. 

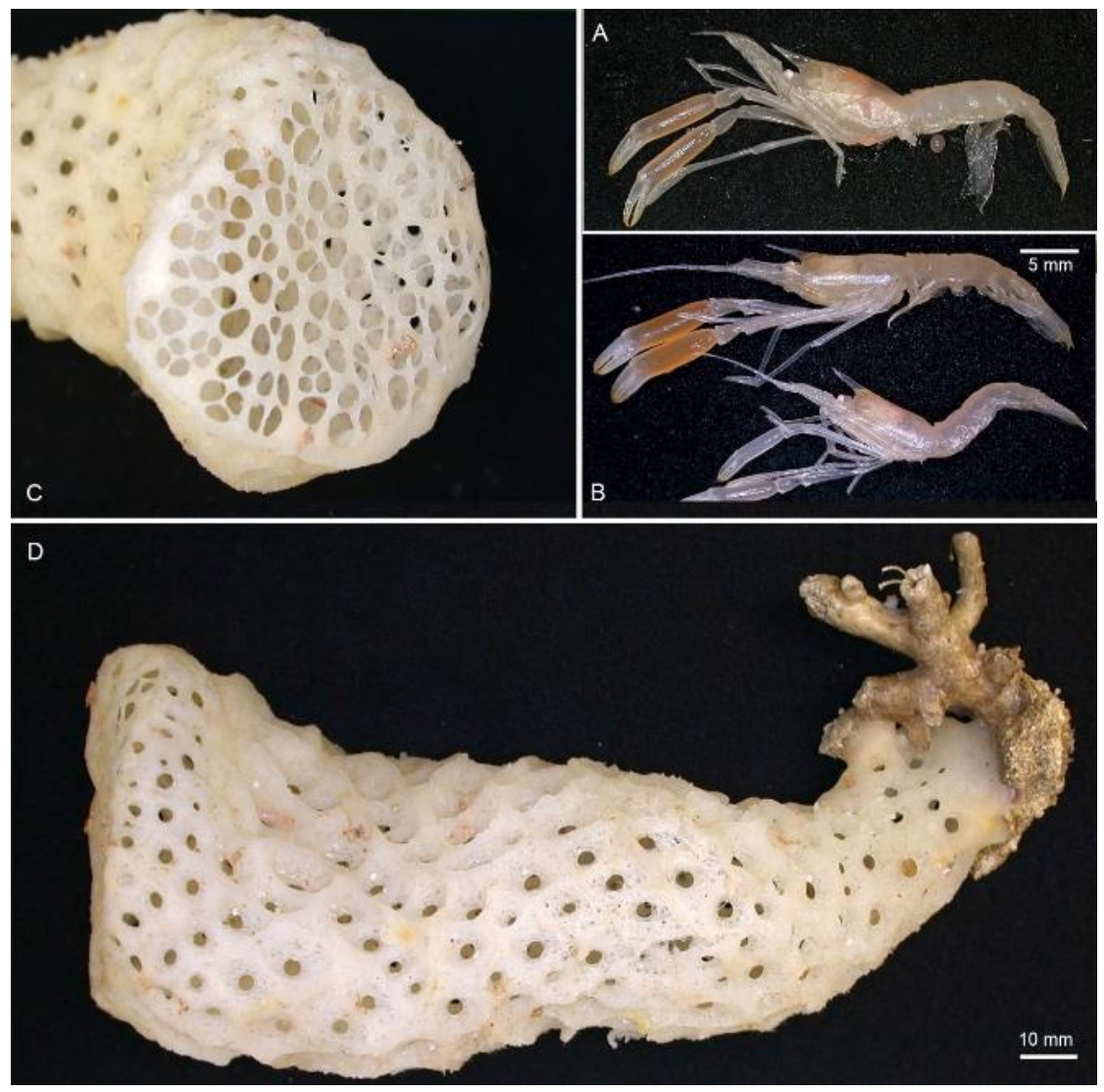

Figure 22. Live coloration of Spongiocaris antipodes sp. nov and euplectellid sponge host Regadrella okinoseana Ijima, 1896 [46] (Hexactinellida, Lyssacinosida, Euplectellidae) specimen collected on southern Norfolk Ridge during 2003 NORFANZ expedition: (A) NMNZ CR.019259, (B-D) NMNZ CR.019494, scale applies to both A and B.

Other material: Norfolk Ridge. $1 \mathrm{~F}$ ov. (PCL: $12.9 \mathrm{~mm}$ ), $1 \mathrm{M}$ (PCL: $8.7 \mathrm{~mm})$, Wan-

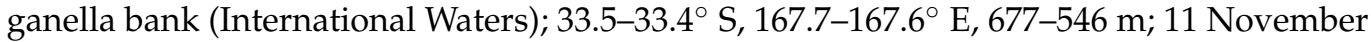
2013; SOP Stn. TRIP3933/23; bottom longline; NIWA 88622. 2 M (PCL: 6.4, $7.3 \mathrm{~mm}$ ); southern Norfolk Ridge, NW of Three Kings Islands, 33.390-33.391 ${ }^{\circ}$ S, 170.210-170.196 E, 469-490 m; 1 June 2003; beam trawl; NORFANZ Stn. TAN0308/136; NMNZ CR.019494 (with Regadrella sp.). $1 \mathrm{~F}$ ov. (PCL: 8.0), $2 \mathrm{M}$ (PCL: 7.5, $5.2 \mathrm{~mm}$ ); southern Norfolk Ridge, NW of Three Kings Islands, 33.390-33.391 ${ }^{\circ}$ S, 170.210-170.196 E, 469-490 m; 1 June 2003; beam trawl; NORFANZ Stn. TAN0308/136; NMNZ CR.019491. 3 F (PCL: 7.8, 7.9, 8.7 mm), 1 M (PCL: $6.3 \mathrm{~mm}$ ); southern Norfolk Ridge, Reinga Ridge, 33.390-33.396 ${ }^{\circ}$ S, 170.190-170.203 E; 469-526 m; 31 May 2003; NORFANZ Stn. TAN0308/126; NMNZ CR.019259. Three Kings Ridge. $1 \mathrm{~F}$ (PCL: $6.0 \mathrm{~mm}$ ), $2 \mathrm{M}$ (PCL: 7.2, $4.6 \mathrm{~mm}$ ); Seamount 148, 31.980 $\mathrm{S}, 174.265^{\circ} \mathrm{E}$, $700 \mathrm{~m}$; date unknown; Stn. Z9026; NIWA 135621. Kermadec Ridge. 1 M (PCL: 7.5 mm); Raoul Island, $6.4 \mathrm{~km}$ NNE of Herald Islet, $29.20^{\circ} \mathrm{S}, 177.82^{\circ} \mathrm{W}, 1189-1225 \mathrm{~m}$; 5 April 1973; NMNZ Stn. 73312: NMNZ CR.016806; "inside glass sponge". Hikurangi Margin. $1 \mathrm{~F}$ ov. (damaged, TL $\sim 33 \mathrm{~mm}$ ), East Coast, E of Cape Kidnappers, $40.03^{\circ} \mathrm{S}, 178.06^{\circ} \mathrm{E}, 935 \mathrm{~m}$; 28 Aug 1986; bottom trawl; RV James Cook; Stn. J10/40/86; NMNZ CR.005952 (collection note: "from Euplectella"). $1 \mathrm{~F}$ ov. (poorly preserved), $1 \mathrm{M}$ (PCL: $7.0 \mathrm{~mm}$ ); SE of Cape Kidnappers, $40.02^{\circ} \mathrm{S}, 178.08^{\circ}$ E, 840 m; 28 August 1986; bottom trawl; RV James Cook; Stn. J10/39/86; NMNZ CR.004792.

Diagnosis. Small commensal spongicolid shrimp so far known to be associated with euplectellid glass sponges; body slightly depressed. Carapace with distinct cervical groove, each side furnished with 6-10 small spines; small branchiostegal spine and antennal spine present or absent; 2-3 pairs of postrostral spines; typically two pairs of supraorbital spines; 
pterygostomian angle furnished with a few small spines; a few anterolateral spines always present; hepatic spines typically present. Rostrum length reaching to distinctly overreaching last antennular peduncle article, entire dorsal margin with spines with 5-11 dorsal, 1-3 ventral, 0-3 lateral spines; cornea unpigmented. Antennal scale subrectangular, with 4-9 spines along the lateral margin. Epistome nearly always unarmed, may have single anterior spine; endopod of maxillule unarmed. Third maxilliped setiferous organ covering nearly entire length of propodal ventral margin; epipod always absent. First pereiopod with well-developed setiferous organ. Third pereiopod robust; carpi unarmed except for low blunt distal spines; meri smooth or with dorsal row of low spines; palm with a few scattered spines along distal portion of outer surface, at least three times longer than wide; fixed finger with dense fringe of setal brushes along two-thirds of ventral margin, unarmed. Fourth and fifth pereiopods with carpi distinctly segmented by 1-3 sutures; coxa may be armed with short distomesial spinose ridge (males) or granular (females); all pereiopods lack epipods. Posterior margin of fifth pleonal tergite ending in a few spines, posterior margins of pleura irregular; sixth tergite with 3-4 posterior dorsal spines, surface smooth, posterior margin of pleura with 1-3 spines. Telson with 6-8 spines along each lateral margin. Uropodal endopodite with two terminal dorsal hairs.

Etymology. Named antipodes, an archaic vernacular for Australia and New Zealand, as this species is so far restricted to the southwestern Pacific region. The term is used as a noun in apposition.

Description of holotype female (Figures 18 and 19).

Body robust, surface generally glabrous.

Rostrum narrowly triangular in dorsal view, one-third (0.3) as long as PCL, horizontal, nearly reaching to distal end of antennular peduncle; dorsal margin with 7 small teeth or granules and small posterior blunt eminence at level of posterior orbital margin; ventral margin with three small teeth in distal one-third; ventrolateral ridges with 1-2 (right-left) small teeth on distal half.

Carapace glabrous, not inflated. Cervical and branchiostegal grooves distinct, seven (right)-eight (left) distinct spines line cervical groove. Postrostral region with two small submedian spines on either side; two pairs of postorbital spines; hepatic region smooth; four pairs of anterolateral spines; two small spines on anterior branchial region; otherwise carapace surface is smooth. Orbital margin concave, inferior orbital angle slightly produced and furnished with one small antennal spine (left) or granule (right); branchiostegal spine small to minute; pterygostomian angle round, with 1-2 spines on margin.

Thoracic sternites 6-8 anteriorly rounded, minutely serrate but unarmed; sternite 6 posterior margins evenly concave.

Pleonal somites glabrous, surfaces smooth. First pleonite shortest; divided into two sections by distinct transverse carina; ventral margin continuous, straight. Second to fourth pleonites subequal in length, with feeble transverse carina and blunt articular knob; ventral margin rounded. Fifth pleonite with two small posteroventral granules on broad, round margin; dorsal surface smooth, unarmed; posterior margin with four small spines. Sixth pleonite dorsally smooth; posterolateral process straight, angular, with small spine at corner; posterior margin with three small spines. Pleonal sternites unarmed.

Telson about twice as long as broad, subquadrangular, posterior margin distinctly convex, with long plumose setae; dorsolateral ridges distinct, with six spines each, proximalmost largest and placed mesially; lateral margins relatively straight, slightly constricted proximally, each side armed with a subproximal spine and six lateral spines; posterior margin with three small spines (one median spine and one lateral pair).

Eye well developed; cornea semiglobular, about half length of ocular peduncle in dorsal view, moderately inflated, unpigmented; unarmed.

Antennular peduncle nearly reaching to middle of antennal scale, does not reach spinose lateral margin of antennal scale. Basal article stout, length-width ratio of 2.0 at midlength, without statocyst, about three times as long as second article; lateral margin concave, distally produced to small, rounded lobe, stylocerite distinct, acute, reaching 
one-third length of basal article; mesial margin almost straight, unarmed other than row of serration where plumose seta are inserted. Second article slightly longer than distal article, unarmed. Distal article as long as wide, unarmed. Flagella slender, about twice as long as peduncle.

Antenna with first article (coxa, bearing antennal gland) with 1-2 mesial spines. Basicerite stout; 1 mesial spine proximal to base of carpocerite; $2-3$ small spines on ventral surface; dorsal and lateral surfaces smooth. Margins with paired spines distolaterally; small spine below ventral angle; small spine below mesial angle (Figure 18H inset). Antennal scale broad, $2.5 \times$ as long as wide; lateral margin slightly concave, armed with 4 (left) or 6 (right) small teeth along the distal 0.4-0.5 portion, including the distal tooth; dorsal surface with two distinct longitudinal ridges. Carpocerite not reaching to distal end of second article of antennular peduncle; first article with small mesial spine; second article with minute distoventral spine. Flagellum at least as long as CL.

Epistome narrow, inflated, subtriangular, unarmed. Labrum smooth, with median ridge. Paragnaths bilobed, with deep median fissure, distodorsally spatulate.

Mandible robust, fused molar and incisor processes. Molar surface with three blunt teeth; incisor with irregular teeth. Palp well-developed, 3-segmented; proximal article shortest, without setae; middle article with few distal setae; distal article suboval, slightly longer than intermediate article (measured along extensor margin), densely setose.

Maxillule with simple palp, with few terminal setae; distal endite broad, round, with numerous simple setae and eight slender spines; proximal endite oval, with simple setae distally.

Maxilla with palp stout, tapering, with plumose setae, falling short of end of scaphognathite; distal and proximal endites both deeply bilobed, with numerous plumose setae; scaphognathite well developed, anterior portion longer than posterior portion, about 3 times longer than broad, with dense fringe of plumose setae along entire margin.

Branchial formula summarized in Table 2.

First maxilliped with 2-segmented palp, bearing long plumose setae; distal article longer than broad, with distal spine; proximal article stout, about $1.5 \times$ distal article in length. Distal endite large, subtriangular, densely setose; proximal endite deeply bilobed, with distal setae. Exopod slender, with long plumose setae. Epipod well developed, subequally bilobed. Arthrobranch well developed.

Second maxilliped with 5-segmented endopod; dactylus sub-oval, tapering distally, with dense setae on flexor margin; propodus twice as long as dactylus, densely setose along flexor margin; carpus triangular, about two-third length of propodus measured at midline, with long distodorsal setae; merus nearly straight, about $1.8 \times$ length of propodus, 4 times longer than broad, with row of setae along mesial margin and sparse short setae on surfaces; ischium and basis not fused, ischium slightly longer, about one-fourth meral length, long setae along mesial margin. Coxa mesially produced to blunt process; exopod well developed; oval epipod present, podobranch and arthrobranch well developed.

Third maxilliped endopod 5-segmented, slender, unarmed; dactylus narrow, distally tapering, setose; propodus about twice as long as dactylus, with setiferous organ along entire flexor margin; carpus subequal in length to propodus; merus 1.5 times longer than carpus, about as long as ischium; all segments with long setal fringe along flexor margin; basis short. Coxa mesially angular, not produced to spine, without epipod, arthrobranchs well developed. Exopod absent.

First pereiopod slender, glabrous and sparsely setose, slightly overreaching antennal scale when extended. Dactylus about $0.4 \times$ palm length; palm subcylindrical, tufts of long setae dorsodistally and along ventral margin of fixed finger; carpus about 3 times palm length, ventral carpo-propodal setiferous organ well developed on both articles; merus about $0.7 \times$ carpal length, about 3 times longer than ischium. Basis and coxa short, unarmed. Epipod absent.

Second pereiopod similar to first, $1.5 \times$ longer and stronger, sparsely setose; dactylus $0.4 \times$ palm length, distal tip formed into a strong corneous spine, tips of fingers cross 
when chela closed, cutting edges entire; propodus with a few tufts of setae distally and along fixed finger; carpus about $1.8 \times$ palm length; merus $0.8 \times$ carpal length; ischium $0.4 \times$ merus. Basis and coxa short; coxa unarmed. Epipod absent.

Third pereiopod largest, subequal and similar, about $2 \times \mathrm{CL}$, sparsely setose except for a few distal tufts of setae along fingers; dactylus about $0.5 \times$ palm length, ending in strong, hooked tip, cutting edge with narrow trench along distal half, with blunt, trianguloid tooth at distal quarter, preceding fossa not pronounced; propodal cutting edge with sharp corneous spine distally, followed by narrow trench along distal half, distinct fossa to accommodate dactylar tooth at distal third, followed proximally by flat molariform process with numerous tiny teeth; outer margin of fixed finger unarmed, distally bearing tufts of long setae; surface with small proximal spine; palm sub-cylindrical, 3.4 times as long as broad, dorsal margin smooth, with 2-3 small granules on distal surface, very few small granules on inside palm surface; carpus about $0.3 \times$ palm length, narrowing proximally, without spines; merus three-fourth length of palm, 5 times longer than broad in lateral view, proximally compressed laterally, margins entirely smooth; ischium about as long as carpus, laterally compressed, unarmed. Basis and coxa short; coxa mesially granulate. Epipod absent.

Fourth and fifth pereiopods long and slender, similar, sparsely setose; dactylus (including spines) about one-fourth the length of propodus, biungulate, both unguis clearly demarcated, with small, simple or distally faintly bifurcate accessory tooth on proximal ventral margin; propodus not subdivided, about $0.4 \times$ carpal length, pereiopods 4 and 5 propodi similar in width, 5.7 times longer than wide, with single row of 16-20 movable spine along entire flexor margin, both margins with few long, simple and very few plumose setae; carpus longest, $2.2-2.5 \times$ propodus, with movable spine at distoventral angle, one median suture present; merus about $0.8 \times$ carpal length, unarmed; ischium less than half length of merus, unarmed. Basis and coxa short, coxa mesially granular but unarmed. Epipod absent.

First pleopod uniramous, second to fifth biramous, all lacking appendices, unarmed.

Uropod well developed, about as long as telson. Protopod stout, with sharp posterolateral spine. Exopod broader than endopod; lateral margin slightly convex, with 12-13 small teeth along distal three-fourth of margin, distal margin shallowly convex, dorsal surface with two distinct longitudinal ridges. Endopod simple, unarmed, surface with one longitudinal ridge. Exopod and endopod fringed with dense, plumose seta.

Eggs: The ovigerous female retained 10 sub-oval eggs of diameters $1.5 \times 2.0 \mathrm{~mm}$.

Comparison of female holotype to male allotype (Figures 20 and 21).

Body smaller than female holotype.

Rostrum proportionally longer, $0.5 \times \mathrm{PCL}$, distinctly overreaching the antennular peduncle, dorsal margin with 8 small teeth in addition to proximal shallow rounded eminence at level of posterior orbital margin; ventral margin with two teeth; with 3 small ventrolateral teeth.

The carapace is slightly less inflated, the distribution of spines is similar, the numbers vary slightly: 6-7 spines along the branchiostegal groove, three small postrostral spines, 3-5 anterolateral marginal spines. The two prominent postorbital spines match the holotype and are considered diagnostic.

Thoracic sternites 6-8 anteriorly produced, with spines, the coxa of the pereiopods and furnished with denticulate processes.

Pleonal somites similar to holotype; posteroventral margins of tergite 4 with 1-2 spines, tergite 5 with 3-4 small spines, posterior margin with rows of small spines; dorsal surfaces smooth. Fifth pleomere with small median spine ventrodistally, directed posteriorly.

Telson similarly shaped, dorsal ridges with 5-6 spines, laterally also with 6 spines; distal margin with 6 small spines (median spine with 2 and 3 lateral spines).

Antennule and antenna of similar shape and proportions; antennal basicerite with additional distoventral and distolateral spine, mesial angle unarmed. Antennal scale slightly more slender at 2.8 (length-width ratio), with 6 lateral spines. 
Epistome similarly inflated, smooth.

Mouthparts as for female holotype.

Pereiopod 1 and 2 as for female holotype. Pereiopod 3 slightly more robust, similar length with $2.0 \times \mathrm{CL}$; dactylus $0.6 \times$ palm; palm slightly more massive at 2.8-2.9 times longer than wide; merus with distoventral spine and regular dorsal row of granules and small spines; ischium smooth as for holotype. Single loose pereiopod 4 or 5 retained for allotype has a simple, sharp accessory tooth on dactylus; propodus with 14 spines along flexor margin; carpus with two sutures.

Uropods as for holotype, except for protopod distally with pair of distolateral spines exopod with 12 and 14 teeth along lateral margins.

Measurements. CL: 9.3-12.3 [10.3] mm (females, this does not include the largest female that has a broken rostrum), 7.4-11.2 mm (males), PCL: 6.0-12.9 [7.7] mm (females) 5.2-8.7 mm (males), TL: 25-37 [25.5] mm (females), 19.5-30.7 (males). Measurements for the holotype are given in square brackets.

Distribution. Southern Norfolk Ridge, West Norfolk Ridge, eastern North Island, New Zealand; 382-1225 m (Figure 1).

Coloration. Collection note with NMNZ CR.016806 "white shrimp from inside glass sponge". Live coloration was captured for NORFANZ specimens NMNZ CR.019259 and CR.019494: the body is pale apricot, carapace and most appendages transparent, palm of third pereiopod orange (Figure 22).

Hosts. Two specimens were collected from inside the euplectellid glass sponge $R e-$ gadrella okinoseana (Hexactinellida, Lyssacinosida, Euplectellidae) (NMNZ Cr. 09494, det. M Kelly, Figure 22). Other collection records retained are: "from Euplectella" (NMNZ CR.05952) and "from inside glass sponge" (NMNZ CR.016806).

Parasites. One male (NMNZ CR.016806) bears a sacculinid rhizocephalan under the pleon.

Remarks. Multi-gene sequencing revealed a clade that resolved most of the New Zealand specimens of Spongiocaris as an undescribed species, while it united the type specimens of both S. yaldwyni and S. neocaledonensis in a well-supported clade, requiring that the latter be synonymized with the former (see below, Figure 2). Morphologically, the variability of characters across the material examined rendered it difficult to establish fixed diagnostic characters.

Spongiocaris species are currently separated using differences in the length of the rostrum, distribution of spines on the carapace surface and anterior margin, pleomere and telson, as well as the pereiopods 3-5 [11]. Examination of a total of 21 specimens assigned to $S$. antipodes sp. nov. indicate the following variability: the rostrum is slightly shorter to longer than the antennular peduncle (not reaching to overreaching article 3), $0.3-0.5 \times$ PCL, with 5-11 dorsal, 1-3 ventral and 0-3 lateral teeth; the carapace has 2-3 pairs of small postrostral spines always present, at least one but typically two distinct postorbital spines, 4-10 pairs of postcervical spines are always distinct, occasionally followed by a few scattered dorsal cardiac spinules (Figure 20A,B), a field of 4-10 distinct anterolateral spines, a few small hepatic and/or branchial spines are usually present (Figure 20B); an antennal spine on the anterior carapace margin may be absent, minute or well-developed and can vary from side to side (e.g., Figure 20B), a small branchiostegal spine may be present or absent and the pterygostomian angle with 1-3 distinct spines; the dorsal surfaces of the pleonites are always unarmed and smooth, the ventrodistal margins of pleura 4-6 usually bear some spines (pleuron 4 may be smooth, pleuron 5 always bears multiple spines and pleuron 6 has at least an acute angle); the telson shape is variable (Figures 18C, 20C and 21L-N), 6-8 lateral spines in addition to subproximal spine, 5-8 dorsal spines and 3-8 small spines along the distal margin, usually arranged with a median spine separated from pairs of laterally-placed spines (with the exception of the larger male, NMNZ CR.019491, that has a continuous row of 6 spines); the third cheliped is about twice as long as CL with limited sexual dimorphism apparent, the fingers are $0.5-0.6 \times$ palm length, margins unarmed, with dense setal brushes distally, along about the 
distal two-thirds of the margin of the fixed finger, the palm length-width ratio ranges from 2.8 in small to 3.4 in larger specimens, the proximal portion always has 2-7 small granules, the merus is smooth (Figure 19B) or serrated (Figure 20O), the ischium is always unarmed with smooth margins; pereiopods $4-5$ carpi with $1-3$ sutures, propodi with $14-23$ movable spines along the entire flexor margin and dactyli biungulate with ventral unguis bearing a variable accessory tooth, from simple hook-shaped (Figure 21G) to bifurcate (Figure 21F,I).

Further notable variation is the presence of an anterior spine on the epistome of a male of NMNZ CR.019491, the shape is otherwise the same as in all others, anteriorly inflated and round. The $\mathrm{P} 4-5$ propodi usually have between $17-22$ spines along the flexor margin, but these can be as few as 12 (e.g., NMNZ CR.019491 and CR.019492)

Based on the combination of these characteristics, S. antipodes closely aligns with S. yaldwyni (to include $S$. neocaledonensis, see below). These two species appear to be difficult to separate morphologically. Diagnostic characters proposed are:

- the presence of postrostal and, typically, at least two pairs of postorbital carapace spines (the postrostral area is usually smooth in S. yaldwyni but see Goy ([13]: Figure 12) and the carapace only has a single postorbital spine). This character can vary from side to side and some small specimens (e.g., NMNZ CR.019494, CR.019491, NIWA 135621) have only a single spine.

- $\quad$ the dorsal surface of pleonal tergite 6 is always smooth (S. yaldwyni often has 2-3 median spines, see Figures 24C and 25A, but is smooth in holotype, Figure 23B).

- the dense setal brushes along the distal fixed finger of the third pereiopod is distinct along about two-thirds in S. antipodes but reach to $0.7-0.8$ portion in S. yaldwyni.

- the fourth and fifth pereiopod dactyli are never triungulate in S. antipodes but can be both biungulate and triungulate in S. yaldwyni.

There may be a degree of overlap in these characters and DNA sequencing for confirmation of identification is advised.

DNA sequence data. Between six and nine specimens were sequenced across the genes examined (Figure 2). In all cases they formed a monophyletic clade with some indication of further intraspecific structure that might warrant further investigation in the future.

CO1: intra-specific divergences between $0.2-2.3 \%$; intra-generic divergences between $4.9-6.7 \%$ (Spongiocaris yaldwyni).

16S rRNA: intra-specific divergences between $0.0-1.6 \%$; intra-generic divergences range from $1.9 \%$ (Spongiocaris yaldwyni) to $11.4 \%$ (S. koehleri).

\subsubsection{Spongiocaris yaldwyni Bruce \& Baba, 1973}

In (Figures 1, 2 and 23-25). Spongiocaris yaldwyni Bruce \& Baba, 1973 [21]: 163, Figures 7-10.—Goy 2010 [3]: 257 (list).—Komai, de Grave \& Saito 2016 [11]: 445 (key).

Spongiocaris neocaledonensis Goy, 2015 [13]: 313, Figures 12-14.

Material examined. Holotype: F (PCL $7.6 \mathrm{~mm}$ ); Motunau Island (Plate Island), Bay of Plenty, 37.50 ${ }^{\circ}$ S, $176.55^{\circ}$ E, 585-622 m; 29 Sep 1962; N.Z. Marine Department Haul 12; NMNZ CR.001888 (collection note: "venus flower basket sponge").

Other material: Kermadec Ridge. 1 F ov. (PCL: $7.6 \mathrm{~mm}$ ), 1 M (PCL: $6.6 \mathrm{~mm}$ ); $41 \mathrm{~km}$ NNE of Macauley Island, 29.8617 S, 178.1817 W, 965 m, 27 Jul 1974; NZOI Stn K831; Agassiz trawl; NIWA 10483. 1 F (PCL: $5.0 \mathrm{~mm}$ ); NE of summit, Clark Seamount, Southern Kermadec Ridge, 36.445-36.442 ${ }^{\circ}$ S, 177.839-177.840 E, 850-927 m; 24 Apr 2012; NIWA Stn. TAN1206/99; Sled, epibenthic; NIWA 83102. Bay of Plenty. 1 M (PCL: $12.7 \mathrm{~mm}$ ), Whakatane Seamount, 36.790-36.790 S, 177.454-177.456 E, 1160-1155 m; 23 Apr 2012; epibenthic sled; NIWA Stn. TAN1206/90; NIWA 82821. 1 F (crushed carapace, TL 25 mm); ca. $22 \mathrm{~km}$ E of Aldermen Islands, $36.96^{\circ} \mathrm{S}, 176.36^{\circ} \mathrm{E}, 803-846 \mathrm{~m}$; 24-Jan-79; RV Tangaroa; NMNZ Stn. 79760; NMNZ CR.009840. 


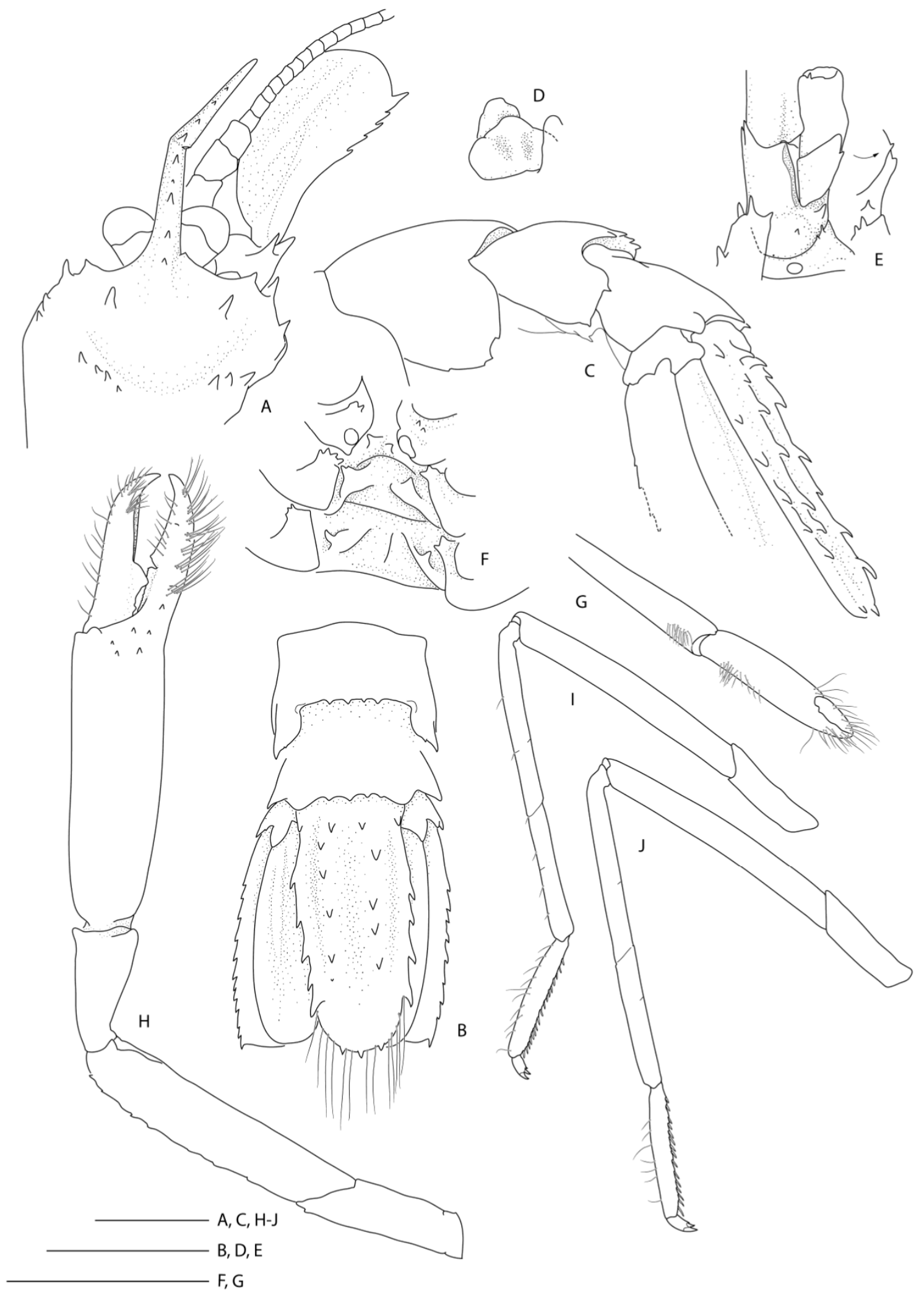

Figure 23. Spongicaris yaldwyni Bruce \& Baba, 1973 [21], holotype F (NMNZ CR.001888). (A) Anterior carapace and cephalic appendages, dorsal. (B) Pleonites 5 and 6, urosome and telson, dorsal. (C) Pleonites 4-6, urosome and telson, lateral. (D) Epistome and labrum, oblique ventral view. (E) Right antenna, ventral with detail of rotated mesial margin of basicerite. (F) Thoracic sternites 6-8 with coxae of pereiopods, ventral. (G) Left distal portion of P1, mesial. (H) Right P1, lateral. $(\mathbf{I}, \mathbf{J})$ Lose $\mathrm{P} 4$ or P5, lateral. Scale bars $=2 \mathrm{~mm}$. 


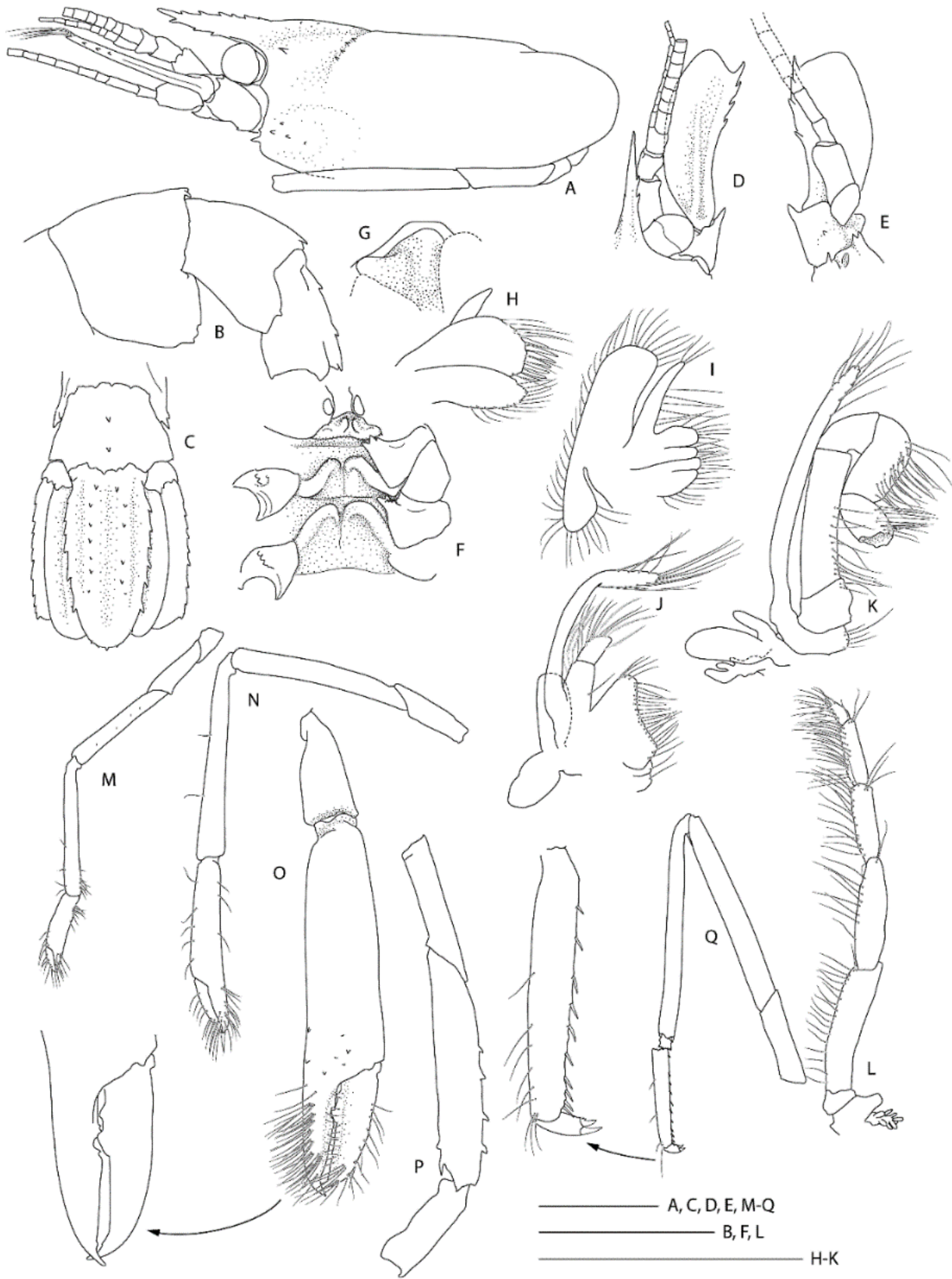

Figure 24. Spongicaris yaldwyni Bruce \& Baba, 1973 [21], F (NIWA 83102). (A) Carapace and cephalic appendages, lateral. (B) Plenites 4-6, lateral. (C) Pleonites 5-6, urosome and telson, dorsal. (D) Rostrum with right antennule, antenna and ocular peduncle, dorsal. (E) Right antenna, ventral. (F) Thoracic sternites 6-8 with coxae of pereiopods, ventral. (G) Epistome, labrum partially covered by mandibular palps, ventral. (H) Right maxillule. (I) Right maxilla. (J) Right Mxp1. (K) Right Mxp2. (L) Mxp3. (M) Left P1, lateral. (N) Left P2, lateral. (O) Left P3 distal portion, lateral, with inset detail of cutting edge. (P) Left P3 proximal portion, lateral. (Q) Left P5 with enlarged propodus and dactylus. Scale bars $=2 \mathrm{~mm}$. 


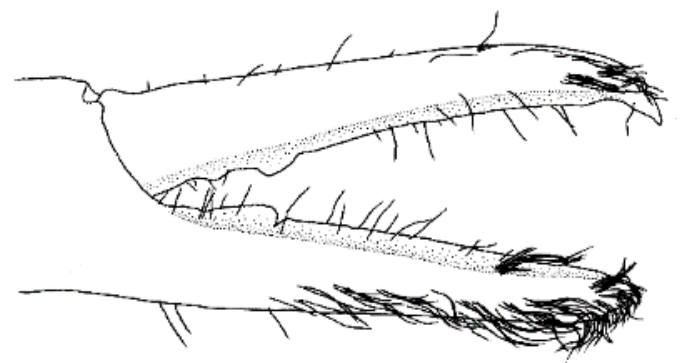

A

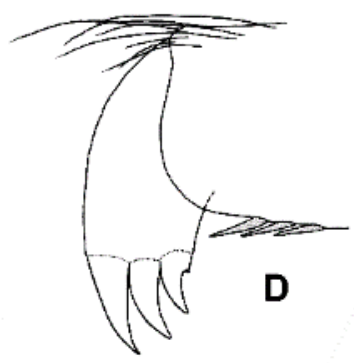

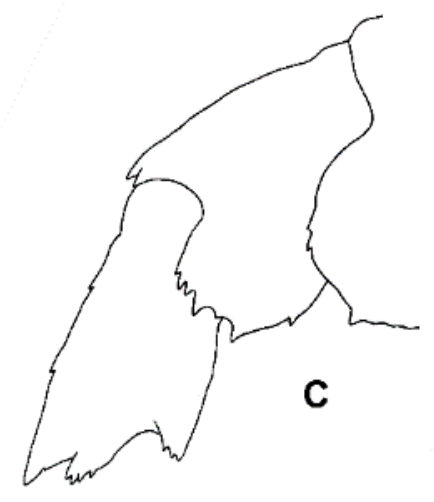

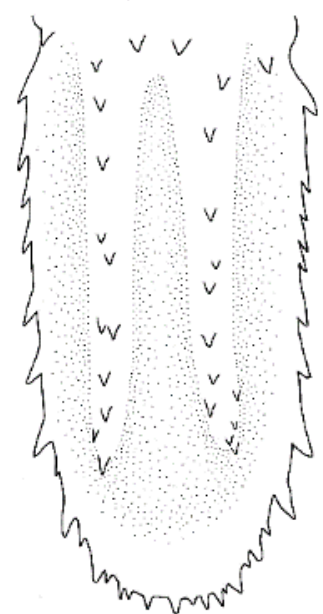

B

Figure 25. Spongiocaris yaldwyni Bruce \& Baba, 1973 [21], F (NIWA 82821). (A) Fingers of left P3, mesial view. (B) Telson, dorsal view. (C) Fourth to sixth pleura, lateral view. (D) Dactylus of left P5, lateral view. Scale bars $=1 \mathrm{~mm}$.

Diagnosis. Small commensal spongicolid shrimp so far known to be associated with euplectellid glass sponges and gorgonian corals; body slightly depressed. Carapace with distinct cervical groove furnished with 4-10 small spines; small branchiostegal spine and antennal spine present or absent; one pair of supraorbital spines; pterygostomian angle furnished with a few small spines; a few anterolateral spines always present; hepatic spines typically present. Rostrum length reaching to distinctly overreaching last antennular peduncle segment, entire dorsal margin with spines with 4-8 dorsal, $0-4$ ventral, $0-3$ lateral spines; only proximal part of cornea pigmented. Antennal scale subrectangular, with 4-7 spines along the lateral margin. Epistome unarmed; endopod of maxillule unarmed. Third maxilliped setiferous organ covering nearly entire length of propodal ventral margin; epipod present or absent. First pereiopod with well-developed setiferous organ. Third pereiopod robust; carpi unarmed; meri with row of small spines along dorsal margin; palm with a few scattered spines along distal portion of outer surface, at least 3 times longer than wide; fixed finger with dense fringe of setal brushes along more than two-thirds of ventral margin, unarmed. Fourth and fifth pereiopods with carpi distinctly or partly segmented, full suture typically present at approximately mid-point; coxa armed with short distomesial spinose ridge; all pereiopods lack epipods. Posterior margin of fifth pleonal tergite ending in four or five spines, posterior margins of pleura irregular to spinose; sixth tergite with 3-4 posterior dorsal spines, surface smooth or with two or more small spines along mid-line, posterior margin of pleura with 1-2 spines. Telson with 4-10 spines along each lateral margin. Uropodal endopodite with two terminal dorsal hairs.

Measurements. CL: 6.7-15.6 [11.8] mm, PCL: 4.6-12.7 [7.6] mm, TL: 18.0-43.0 mm. Holotype measurements are given in square brackets.

Distribution. Spongiocaris yaldwyni was purportedly endemic to New Zealand with a single record from the Bay of Plenty; 585-622 $\mathrm{m}$. Chen et al. [17] presented gene sequences for a specimen from Tonga (627-656 m, MNHN-IU-2014-12842). New records extend the regional distribution northwards along the Kermadec Ridge, 850-1160 m (Figure 1). 
Considering the synonymy of $S$. neocaledonensis, the distribution is extended to include New Caledonia, Norfolk Ridge, Loyalty Islands; 460-970 m.

Coloration. Unknown.

Hosts. The holotype was collected from within the hexactinellid sponge Regadrella okinoseana [21]. Goy [13] reported S. neocaledonensis from the hexactinellid sponge R. okinoseana and on a gorgonian octocoral.

Remarks. The original description of Spongiocaris yaldwyni is comprehensive and is not repeated here, the material presented is the first since the species was described from the single specimen [21]. The holotype (NMNZ CR.001888) is in poor condition and the body is deformed but allowed the verification of some characteristics: the epistome is unarmed, anteriorly truncate, and the labrum rounded (Figure 23D); all pleonal tergites have smooth surfaces, the posterior margins of pleonites 5-6 bear 3-4 median spines (Figure 23B), the posterior margins of the pleura bear spines (pleurae 4 and 5) or are angular (pleuron 6) (Figure 23C); sternites 6-8 are medially acute and the coxa of pereiopods $3-5$ bear mesial spines along their anterior corners (Figure 23F); third maxilliped has a setiferous organ on nearly entire flexor margin of the propodus; and the first pereiopod has a well-developed setiferous organ on the proximal palm and distal carpus (Figure 23G); the third pereiopod merus is distinctly serrate along the dorsal (extensor) margin and the setal brushes extend along more than 0.6 portion of the fixed finger (Figure $23 \mathrm{H}$ ). The fourth and fifth pereiopods carpi clearly have a suture at approximately mid-length, which was not illustrated by Bruce \& Baba [21].

The type description did not mention the sex of the specimen, it bears gonopores on the coxae of the third pereiopods but also possesses the single forward curving ventral medial spine on the fifth pleomere that is typical of males (Figure 23C,F). The female (NIWA 83102), however, lacks a spine.

Three further samples are presented here for the region that all share the long rostrum (overreaching the second antennular article). The rostral ornamentation can be expanded to 6-[8] dorsal, 2-[6] ventral and [0]-3 lateral spines (holotype details are presented in square brackets); all specimens have a single pair of postorbital spines, NIWA 10483 and 83102 have 2-3 minute postrostral spines (smooth in the holotype), the carapace has a hepatic spine in the holotype and the larger female of NIWA 10483 but is smooth in NIWA 83102 (Figure 24A); the surface of pleonite 6 bears dorsal spines in all other specimens (Figures 24B and 25A), but is smooth in the holotype. The antennal scale is relatively slender in the holotype $(3 \times$ longer than wide), similar to NIWA 83102 , but is relatively broader in NIWA 10483 with ratios of 2.6 and 2.8, the lateral margin has 3-7 spines; the basicerite has only a single lateral spine in NIWA 83102 (Figure 24D,E). The sternites of the females are typically rounded and the coxa are produced to distinctly projected and granulate mesial processes in all cases (e.g., Figure 24F). The third maxilliped is lacking an epipod in all specimens, the propodus is furnished with a dense fringe of seta (setiferous organ). The third pereiopod is similarly glabrous in both males and females except for the presence of small spines on the outer palm, at the base of the fixed finger, the setal brushes are distinct and extend up to $0.8 \times$ the length of the fixed finger in NIWA 10483 and 83102 (Figure 24O). The lose walking leg of NIWA 83102 is lacking a suture on its carpus (Figure 24Q) but 1-3 sutures are present in all pereiopods 4-5 of NIWA 10483, all specimens have dactyli with small accessory teeth on the ventral unguis, either sharp, simple, or divided (Figure 24Q inset), NIWA 82821 has all pereiopod 4-5 dactyli triungulate (Figure 25D). The holotype and two most recently collected specimens (NIWA 82821 and 83102 ) are closely related genetically ( $\mathrm{p}$-distances of $\leq 1.6 \%$ for $16 \mathrm{~S}$ rRNA fragment, see below) and are genetically distinct from $S$. antipodes.

DNA sequence analyses indicate that the holotype sequence for $S$. yaldwyni was in all cases near identical to the type series of S. neocaledonensis Goy, 2015 [13] (see Figure 2 and comments below). Goy [13] noted the close overall appearance between these two species but separated them based on the presence (S. neocaledonensis) and absence (S. yaldwyni) of an epipod on the third maxilliped and proposed S. neocaledonensis as distinct from S. yaldwyni 
(and all other congeners) based on the segmentation of the carpus of the last two pairs of pereiopods 4-5 (present in S. neocaledonensis and absent in S. yaldwyni), the presence of the third maxilliped's setiferous organ (absent in S. yaldwyni), and the dense fringe of setal brushes on the third pereiopod propodus (fixed finger) (absent in S. yaldwyni). As noted above, upon re-examination of the holotype and additional material of S. yaldwyni, characters overlap considering the presence of sutures on the pereiopod 4-5 carpi of nearly all specimens (absent on single remaining leg of NIWA 83102, Figure 24Q), presence of dense setal brushes on third maxilliped and pereiopod 3. However, none of the material examined had even rudimentary epipods on the Mxp3 and this character remains enigmatic. Nevertheless, Spongiocaris yaldwyni and S. neocaledonensis are here considered synonymous.

Most of the New Zealand specimens (the exception being the holotype) bear a median row of two small spines on pleonal tergite 6 , none are as spinose as figured for $S$. neocaledonensis male holotype (Goy [13]: Figure 12). In nearly all New Zealand specimens, the pereiopod 4-5 dactyli are biungulate, with a small accessory tooth on the ventral unguis (the exception being NIWA 82821 which has a triungulate dactylus as illustrated for S. neocaledonensis, Figure 25D). This character has been found to be variable in other species, e.g., the stenopodid Stenopus goyi Saito, Okuno \& Chan 2009 [52], which has the ambulatory dactyli from simple to triungulate, differing even among the pereiopods of the same specimen [52]. Variation in spination across this species is now considered as follows: the rostrum has $4-8$ dorsal, $0-4$ ventral and $0-3$ ventrolateral spines; the carapace spination is somewhat variable with some hepatic, postrostral, minute cardiac or branchial spine, 4-10 postcervical spines are always distinct, as is one pair of postorbital spines; the telson has 4-10 spines along the lateral margin, 4-9 spines along dorsal carinae and 3-12 posterior teeth; the antennal scale has 4-7 spines along the lateral margin and the pereiopods 4-5 propodi have 8-21 movable spines along the flexor margin.

The combined distribution range now encompasses New Caledonia, the Norfolk and Kermadec Ridges, which aligns with those of other southwestern Pacific subtropical to temperate decapods (e.g., [53,54]), with an overall depth range of 460-1160 m. Both species were first described from the same hexactinellid sponge host species (Regadrella okinoseana).

DNA sequence data. The holotype of $S$. yaldwyni and nine type specimens of $S$. neocaledonensis were successfully sequenced, including the holotype, allotype and seven paratype samples. The sequences presented by Chen et al. [17] from Tonga are confirmed as belonging S. yaldwyni (Figure 2, Table 1). Both genes resolved these specimens as belonging to a single clade, distinct from Spongiocaris antipodes sp. nov., however, substantial internal differences remain within this group that warrant future investigation.

CO1: intra-specific divergences between $0.2-4.2 \%$; intra-generic divergences between $4.9-6.7 \%$ (Spongiocaris antipodes sp. nov.).

16S rRNA: intra-specific divergences between $0.0-2.6 \%$; intra-generic divergences range from $1.9 \%$ (Spongiocaris antipodes sp. nov) to $11.4 \%$ (S. koehleri).

Family STENOPODIDAE Claus, 1872 [55]

Genus Stenopus Latreille, 1819 [56]

\subsubsection{Stenopus hispidus (Olivier, 1811)}

In (Figure 26). Palaemon hispidus Olivier, 1811 [23]: 666.

Stenopus hispidus.—Latreille 1819 [56]: 71.-Holthuis 1946 [57]: 12 (with references and complete synonomy).-Yaldwyn 1968 [22]: 278.—Doak 1971 [58]: pl. 39D.-Yaldwyn 1974 [59]: 1044.—de Saint-Laurent \& Cleva 1981 [60]: 157.—Goy 1992: 100 [61].-Poore 2004 [62]: 149.—Saito et al. 2009 [52]: 1009.—Yaldwyn \& Webber 2011 [63]: 183 (list).Webber et al. 2010 [64]: 225 (list).—Goy 2010 [3]: 215.—De Grave \& Fransen 2011 [42]: 253.-Goy 2015 [13]: 336. 


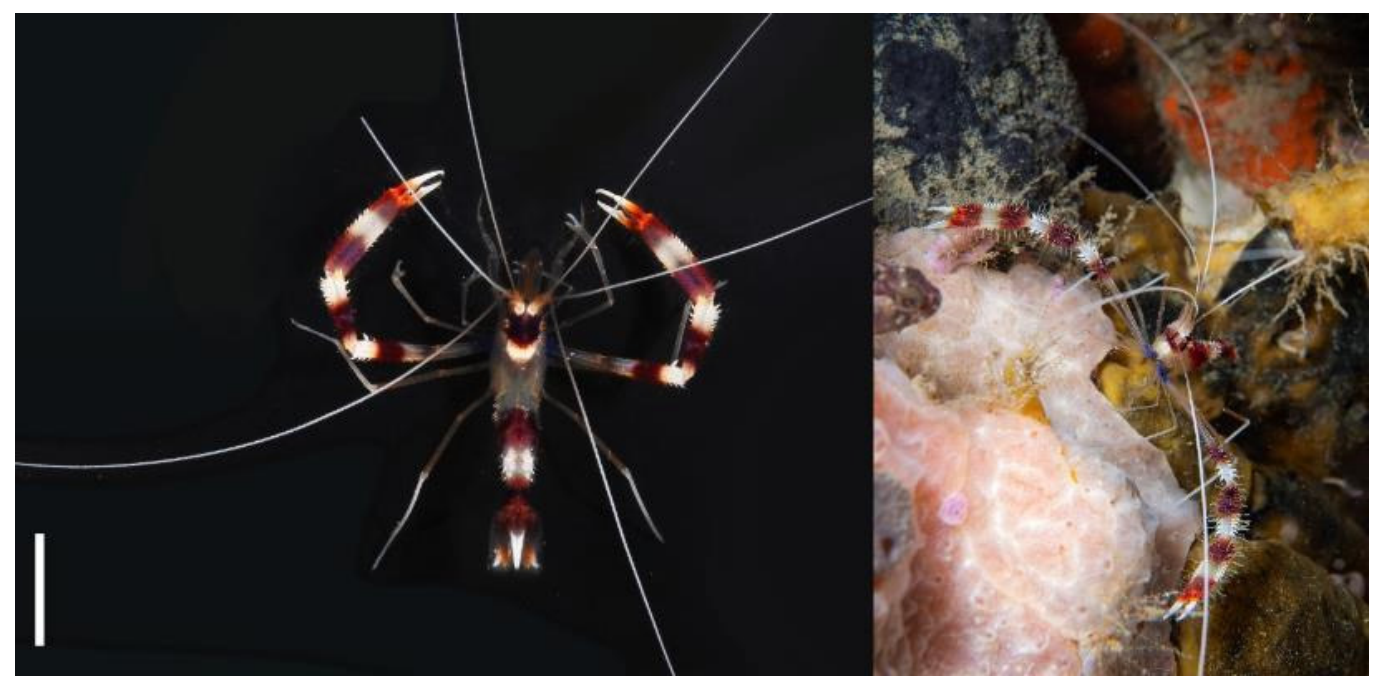

Figure 26. Stenopus hispidus (Olivier, 1811) [23]. (Left): M (AWMM MA182117). Scale bar $=2 \mathrm{~cm}$ (Image credit: Sadie Mills, NIWA). (Right): live specimen in Houhora Harbour, Northland (Image credit: Crispin Middleton, Seacology NZ).

Material examined. Kingdom of Tonga. $1 \mathrm{M}$ (PCL: $11.5 \mathrm{~mm}$ ); Tongatapu Island, Stn. I173, 21.130 S, $175.183^{\circ} \mathrm{W}, 0 \mathrm{~m}$; 8 June 1976; underwater hand sampler; NIWA 10308. Lord Howe Island (Australia EEZ). $1 \mathrm{M}$ (PCL: $14.5 \mathrm{~mm}$ ); Stn. P31, 29.007 $\mathrm{S}, 167.915^{\circ} \mathrm{E}$, 4-14 m; 28 January 1977; scuba; NIWA 10604. Kermadec Islands. 1 M (PCL: 9.8 mm), $1 \mathrm{~F}$ ov. (PCL: $12.6 \mathrm{~mm}$ ); Raoul Island, Stn. TAN1612/37, 29.226 $\mathrm{S}, 177.880^{\circ} \mathrm{W}, 0-30 \mathrm{~m}$; 25 October 2016; scuba; AWMM MA182117. 1 M (PCL: 15.8 mm); North of Napier Island, Stn. TAN1612/20, 29.230-29.231 ${ }^{\circ}$ S, 177.876-177.874 ${ }^{\circ}$ W, 0-30 m; 24 October 2016; scuba; NIWA 118168. 1 M (PCL: $10.0 \mathrm{~mm}$ ); Raoul Island, Denham Bay, southern end, 29.288 $\mathrm{S}$, 177.958 W, 3-18 m; 31 August 2017; scuba, col: Severine Hannam, Anna Murray, David Aguirre, Crispin Middleton, Carl Struthers, Matt Hill; AWMM MA168313. Northland. 1 M (PCL: $12.2 \mathrm{~mm}$ ), $1 \mathrm{~F}$ (PCL: $14.0 \mathrm{~mm}$ ); Bay of Islands, Tapuaetahi, $35.118^{\circ} \mathrm{S}, 173.978^{\circ} \mathrm{E}$, $11 \mathrm{~m}$; 4 September 1986; scuba, col: Brett Stephenson; AWMM MA6648. $1 \mathrm{~F}$ (poorly preserved); off northern tip of Poor Knights Islands, $35.417^{\circ} \mathrm{S}, 174.058^{\circ} \mathrm{E}, 40 \mathrm{~m}$; scuba; col: Kelly Tarlton; AWMM MA8585. 1 M (PCL: 12.0); Poor Knights, Southern Island Harbour, 15-18 m; 25 May 1969; col: A.N. Baker; NMNZ CR.006006. 1 F (PCL: 14.7 mm); Poor Knights Islands, 24 m; May 1968; NMNZ CR.016812. 1 M (PCL 11.0 mm); North Island, Poor Knights Islands; 10 January 1970; col: Wade Doak; NMNZ CR.016808. 1 M (PCL: $15.3 \mathrm{~mm}$ ); South Harbour, Poor Knights Islands, 18 m; 5 May 1969; col: B. Palmer; NMNZ CR.016811. 1 F (PCL: 13.6 mm); off Poor Knights, 18 m; 23 April 1967; col: B.B. Anderson; NMNZ CR.001779. Bay of Plenty. 1 M (PCL: 11.9 mm); Alderman Islands, underwater cave, several present on roof; Jan 2001; scuba; col: C.D. Roberts, J. Hope; NMNZ CR.016809.

Diagnosis. Large shrimp (total length 30-67 mm) with a slender, compressed body, densely covered with spines. Carapace and first three pleonites with curved forwarddirected spines. Last three pleonites with straight posteriorly directed spines. Rostrum strong, ultimate point reaching to about middle of second article of antennular peduncle with dorsal and lateral spines but no ventral spines. Stylocerite short and pressed against basal antennular segment. Scaphocerite with outer margin entire for considerable distance before final tooth. Third maxilliped with ischium, merus and carpus provided with external row of spinules. Body white with red transverse bands on carapace, third and sixth pleonite, and third pereiopods; base of the third pereiopod deep blue, the remaining appendages are pale.

Measurements of examined specimens. CL: 13.5-21.3 mm (males), 17.5-20.0 mm (females), PCL: 9.8-15.3 mm (males), 12.6-14.7 mm (females), TL: 34.7-57.0 mm (males), 44.5-51.7 mm (females). Previously reported TL: 30-67 mm.

Distribution. Stenopus hispidus is the only pantropical species in the infraorder Stenopodidea. Previously recorded from the Western Atlantic from Cape Lookout, North 
Carolina, throughout the Caribbean and Gulf of Mexico to the southern border of Brazil [65]; central Atlantic from Ascension Island [66]; Eastern Pacific from Taboga Island, Panama [61,67]; and throughout the tropical and warm temperate Pacific; from the intertidal to $210 \mathrm{~m}$ [57]. Specimens presented here are from the northern mainland New Zealand and the islands directly to the North (Lord Howe Island, Kermadec Islands); 3-40 m. Further specimens examined from the NMNZ collection were collected around the Solomon Islands, Niue and Tahiti, but are not presented in detail here.

Colour in life. Good descriptions of the color pattern for this species are previously given [22,57]. Considering the key to the species of Stenopus provided by Saito et al. [52], the diagnostic combination of coloration for this species are the broad red and white banding of the body and third pereiopod, not uniformly orange (as in S. spinosus Risso, 1827 [68]) and carapace not purple (as in S. tenuirostris de Man, 1888 [69]). The base of the third pereiopod deep blue, the remaining appendages are pale (the third maxilliped, fourth and fifth pereiopods are not blue as in S. cyanoscelis Goy, 1984 [70]) (see Figure 26).

Remarks. All specimens examined here match the keys provided by Saito et al. [52] well. Stenopus hispidus remains the sole pantropical species in this genus, however, recent population genetic studies indicated regional genetic divergences among locations in the Indonesian Archipelago [71] and between oceans [72]. Further studies might reveal that this supposedly widespread species indeed represents a species complex but is for now considered as $S$. hispidus sensu lato.

DNA sequence data. Three New Zealand specimens (NIWA 118168, AWMM MA182117 and MA168313, recently collected from the Kermadec Islands) unambiguously aligned with conspecific sequences deposited on GenBank with sequence divergences are $0.0 \%$ for both CO1 and 16S rRNA genes (Figure 2, Table 1). Reference sequences include specimens from across the Indo-Pacific $[17,72,73]$.

\section{Discussion}

Prior to this study, three species of shrimp belonging to the infraorder Stenopodidea were known in the New Zealand region; the widely-distributed, Indo-Pacific stenopodid cleaner shrimp Stenopus hispidus, and the sponge-associated spongicolids Spongicoloides novaezelandiae and Spongiocaris yaldwyni, the former purportedly widely distributed from Madagascar to New Zealand [13] and the latter only known from the holotype and recently published gene sequences only $[17,21]$. These crustaceans are naturally rare, with only a total of 54 specimens collected in the region since 1962, representing the entire available material in natural history collections. However, this material examined for our study comprised seven species, three new to science (Spongicoloides clarki, S. sonne and Spongiocaris antipodes) and one new record for the region (Spongicola goyi), more than doubling the previously known New Zealand diversity. Additional records are provided for the previously known species, including the southernmost record for Stenopodidea on the subantarctic Macquarie Ridge for S. novaezelandiae. This species now most likely remains an endemic New Zealand species, with most previous records referred to $S$. weijiaensis or considered dubious and in need of verification. In contrast, the previously endemic S. yaldwyni is synonymized with S. neocaledonensis and its combined distribution range now includes New Zealand and New Caledonia.

These revisions are supported by DNA sequencing and the increased taxon sampling provided for these select spongicolids provides valuable data for ongoing wider phylogenetic studies. The classification within the Stenopodidea remains unsettled with our findings e.g., corroborating recent studies resolving the genera Spongiocaris and Spongicoloides as paraphyletic $[10,17,35]$. Morphologically, these two genera are currently well defined, based on distinct characters such as the plesiomorphic presence (Spongiocaris) or derived absence (Spongicoloides) of an exopod on the second maxilliped [3]. However, Spongicoloides iheyaensis is placed far removed from its congeners in the molecular tree (Figure 2), more similar to Engystenopus palmipes Alcock \& Anderson, 1894 [74] that has a well-developed exopod on the second maxilliped [9]. These two deep-water spongicolids 
might share ontogenetic characteristics that could see them united in the future (J. W. Goy, pers. comm.), which would render the autapomorphies of the genus Spongicoloides homoplastic. These and other questions, such as the placement of the spongicolid Globospongicola spinulatus Komai \& Saito, 2006 [8] within the Stenopodidae and the monotypic Juxtastenopus Goy, 2010 [9] rendering the genus Stenopus paraphyletic, are currently addressed by a number of researchers.

The overall pattern remains of a predominantly cryptic and tropical to temperate group of shrimp, including the shallow-water stenopodid and deep-water spongicolids [3]. Also, nearly all spongicolids retain collection notes or records of host associations with hexactinellid sponges (Spongicoloides novaezelandiae so far lacks this information), conforming with our current understanding of symbiotic relationships with primarily glass sponges (unusually, Spongiocaris yaldwyni was recorded with gorgonian octocorals by Goy [13]).

Little is known about the host selection among symbiotic deep-sea invertebrates, yet limited studies have indicated that deep-sea sponge-associated decapods might have lower host specificity compared with shallow-water symbiotic species. For instance, the palaemonid genus Philarius Holthuis, 1952 [75] is an obligatory associate of shallow-water coral of the genus Acropora Oken, 1815 [76] (Scleractinia, Acroporidae) [77-80]. Among the snapping shrimps of the Alpheus armatus (Rathbun, 1901) [81] species complex, each species is associated with specific species of anemones [82]. In contrast, deep-water species appear less specific in their host association, e.g., species of Paralebbeus Bruce \& Chace, 1986 [83] (Caridea, Thoridae) are associated with sponges of two families, Euplectellidae Gray, 1867 [84] (Hexactinellida, Lyssacinosida) and Farreidae Gray, 1872 [85] (Hexactinellida, Sceptrulophora) (e.g., $[83,86,87])$. As the most well-known deep-sea sponge-associated crustaceans, spongicolid shrimps are reported to be in association with a relatively wide range of hexactinellid sponges [3,12,35]. In this study, we found Spongicoloides sonne sp. nov. could be associated with sponges belonging to Corbitella (Lyssacinosida, Euplectellidae) and Farrea (Sceptrulophora, Farreidae). Furthermore, Spongicola goyi in New Zealand was collected from a Pheronema conicum (Hexactinellida, Amphidiscosida), but was previously reported from a range of hexactinellids as well as a demosponge [12]. The low host specificity of spongicolid shrimps and other crustaceans could be attributed to the decrease of the diversity and number of suitable host sponges in deeper waters [35]. Conversely, Spongicoloides clarki sp. nov. and the two Spongiocaris species reported from New Zealand share the same host Regadrella okinoseana, which is one of the most common deep-sea hexactinellid sponges in this region [47]. Notably, a single host sponge has so far only been found to be physically occupied by a single species of spongicolid at the same time (authors, pers. obs.). Overall, these patterns corroborate the hypothesis that host shift may not play a key role in speciation of deep-sea sponge-associated decapods, as was recently found in certain axiidean shrimps [88].

Supplementary Materials: The following are available online at https:/ /www.mdpi.com/article/10 .3390/d13080343/s1, Table S1: CO1 K2P genetic distances, Table S2: 16S K2P genetic distances.

Author Contributions: Conceptualization, K.E.S. and Q.K.; methodology, all authors; molecular experiments and analyses, Q.K. and K.E.S.; resources, all authors; data curation, all authors; writingoriginal draft preparation, K.E.S. and Q.K.; writing, review and editing, all authors. All authors have read and agreed to the published version of the manuscript.

Funding: K.E.S. was funded by NIWA under Coasts and Oceans Research Programme 2 Marine Biological Resources: discovery and definition of the marine biota of New Zealand (2019-2021 SCI). Q.K. was funded by the Natural Science Foundation of China (No. 41876178), the Senior User Project of RV KEXUE (KEXUE2020GZ01), the National Key R\&D Program of China (2018YFC0309804), Science \& Technology Basic Resources Investigation Program of China (2017FY201404) and the China Ocean Mineral Resources Research and Development Association Program (Nos. DY135-E2-1-02 and DY135-E2-3-04).

Institutional Review Board Statement: Not applicable.

Informed Consent Statement: Not applicable. 
Data Availability Statement: The data presented in this study are openly available in NCBI Gen Bank at https: / / www.ncbi.nlm.nih.gov / genbank/ (accessed on 10 July 2021), see Table 1 for Accession numbers.

Acknowledgments: Our gratitude goes to the staff of the NIWA Invertebrate Collection (Wellington), the National Museum New Zealand Te Papa Tongarewa (Wellington), the Tāmaki Paenga Hira Auckland Museum (Auckland) and the Muséum national d'Histoire naturelle (Paris) for access to collections and curatorial services. Thanks to sponge systematist Michelle Kelly, NIWA Auckland, for identifications of euplectellid and pheronematid host sponges. Thanks to Joe Goy (Harding University) and Laure Corbari (MNHN) for constructive comments on a draft of this manuscript and two anonymous reviewers for helpful suggestions and improvements. We acknowledge the following collection surveys: NORFANZ voyage TAN0308-a survey of the northern Tasman Sea sponsored by the National Oceans Office, CSIRO Marine Research, Australia, New Zealand Ministry of Fisheries and NIWA, New Zealand, project ZBD2002-16 (2003); TAN0803-“"MacRidge 2" Macquarie Ridge voyage, an interdisciplinary New Zealand-Australian voyage which also contributed to CSIRO's Division of Marine and Atmospheric Research project "Biodiversity Voyages of Discovery" funded by the CSIRO Wealth from Oceans Flagship and the 'Seamounts' project (2008); TAN1104-the Ocean Survey 20/20 Mapping the Mineral Resources of the Kermadec Arc Project, funded by Land Information New Zealand, Institute of Geological and Nuclear Science, NIWA, and Woods Hole Oceanographic Institution (2011); TAN1206 - the 'Impact of resource use on vulnerable deep-sea communities' project (CO1X0906), funded by the New Zealand Foundation for Research, Science and Technology (2012); TAN1612-the "Biodiversity of the Kermadec Islands and offshore waters of the Kermadec Ridge - a coastal, marine mammal and deep-sea survey", funded by the Marine Funding Advisory Research Group, NIWA, Ministry for the Environment, Te Papa Tongarewa, Auckland War Memorial Museum and The Pew Charitable Trust (2016); Project PoribacNewZ of the Institute for Chemistry and Biology of the Marine Environment (ICBM), Carl von Ossietzky University of Oldenburg, on the new German RV Sonne (voyage SO254), using the GEOMAR Helmholtz Centre for Ocean Research Kiel ROV KIEL 6000 [89]. The MNHN specimens were collected during the following surveys (i) Deep-sea cruises: KARUBENTHOS 2 (10.17600/15005400); NORFOLK2 (10.17600/3100030); BIOCAL (10.17600/85002911); MUSORSTOM 8 (10.17600/94100040), BATHUS 1 (10.17600/93000350); SEAMOUNT 2 (10.17600/93000020); MIRIKY; SMIB 4 (10.17600/89004911); CALSUB (10.17600/89009911); MUSORSOTOM 4 (10.17600/85009111); BORDAU 2 (10.17600/100060); GUYANE 2014 (ii) Shallow-water biodiversity surveys: PAPUA NIUGINI, SANTO 2006, PAKAIHI I TE MOANA, KARUBENTHOS 2012. Deep-sea cruises, PIs S. Samadi, L. Corbari, B. Richer de Forges and P. Bouchet, were operated by Muséum National d'Histoire Naturelle (MNHN) and Institut de Recherche pour le Développement (IRD) as part of the research program “Tropical Deep-Sea Benthos". Biodiversity surveys were operated by MNHN under the exploration program "Our planet reviewed" (https://www.mnhn.fr/en/research-expertise/lieux/our-planet-reviewed (accessed on 13 July 2021)), PI P. Bouchet (MNHN). Funders and sponsors include the French Ministry of Foreign Affairs, the Total Foundation, Prince Albert II of Monaco Foundation, Stavros Niarchos Foundation, and Richard Lounsbery Foundation.

Conflicts of Interest: The authors declare no conflict of interest.

\section{Abbreviations}

AWMM Tāmaki Paenga Hira Auckland War Memorial Museum, Auckland

CL total carapace length

COI mitochondrial cytochrome c oxidase I gene;

F female

ov. ovigerous

NIWA National Institute of Water \& Atmospheric Research, Wellington

NMNZ Museum of New Zealand Te Papa Tongarewa, Wellington

$\mathrm{M}$ male

Mxp1-3 maxillipeds 1-3

P1-5 pereiopods $1-5$

PCL Postrostral carapace length

TL total body length 


\section{References}

1. Bate, C.S. Report on the Crustacea Macrura Collected by the Challenger during the Years 1873-76; Neill and Company: Edinburgh, UK, 1888; Volume 24, pp. 1-942.

2. WoRMS Editorial Board. World Register of Marine Species. Available online: http://www.marinespecies.org (accessed on 18 May 2021).

3. Goy, J.W. Infraorder Stenopodidea Claus, 1872. In Treatise on Zoology—Anatomy, Taxonomy, Biology—The Crustacea Volume 9, Part A; Schram, F.R., von Vaupel Klein, J.C., Eds.; Koninklijke Brill NV: Leiden, The Netherlands, 2010.

4. Schwentner, M.; Richter, S.; Rogers, D.C.; Giribet, G. Tetraconatan phylogeny with special focus on Malacostraca and Branchiopoda: Highlighting the strength of taxon-specific matrices in phylogenomics. Proc. R. Soc. B Biol. Sci. 2018, 285, 20181524. [CrossRef]

5. Tan, M.H.; Gan, H.M.; Lee, Y.P.; Bracken-Grissom, H.; Chan, T.-Y.; Miller, A.D.; Austin, C.M. Comparative mitogenomics of the Decapoda reveals evolutionary heterogeneity in architecture and composition. Sci. Rep. 2019, 9, 10756. [CrossRef]

6. Wolfe, J.M.; Breinholt, J.W.; Crandall, K.A.; Lemmon, A.R.; Lemmon, E.M.; Timm, L.E.; Siddall, M.E.; Bracken-Grissom, H.D. A phylogenomic framework, evolutionary timeline and genomic resources for comparative studies of decapod crustaceans. Proc. R. Soc. B Biol. Sci. 2019, 286, 20190079. [CrossRef]

7. Alvarez, F.; Iliffe, T.M.; Villalobos, J.L. Macromaxillocarididae, a new family of stenopodidean shrimp from an anchialine cave in the Bahamas, with the description of Macromaxillocaris bahamaensis, n. gen., n. sp. J. Crustac. Biol. 2006, 26, 366-378. [CrossRef]

8. Komai, T.; Saito, T. A new genus and two new species of Spongicolidae (Crustacea, Decapoda, Stenopodidea) from the South-West Pacific. In Mémoires du Muséum National d'Histoire Naturelle; Editions du Muséum: Paris, France, 2006; Volume 193, pp. 265-284.

9. Goy, J.W. A review of the genus Engystenopus (Crustacea: Decapoda: Stenopodidea). Juxtastenopus, gen. nov., a new combination for E. spinulatus Holthuis, 1946, and transfer of E. palmipes Alcock \& Anderson, 1894 to the family Spongicolidae Schram, 1986. Zootaxa 2010, 2372, 263-277. [CrossRef]

10. Bochini, G.L.; Cunha, A.M.; Terossi, M.; Almeida, A.O. A new genus and species from Brazil of the resurrected family Macromaxillocarididae Alvarez, Iliffe \& Villalobos, 2006 and a worldwide list of Stenopodidea (Decapoda). J. Crustac. Biol. 2020, 40, 704-714. [CrossRef]

11. Komai, T.; de Grave, S.; Saito, T. Two new species of the stenopodidean shrimp genus Spongiocaris Bruce \& Baba, 1973 (Crustacea: Decapoda: Spongicolidae) from the Indo-West Pacific. Zootaxa 2016, 4111, 27. [CrossRef]

12. Saito, T.; Komai, T. A review of species of the genera Spongicola de Haan, 1844 and Paraspongicola de Saint Laurent \& Cleva, Crustacea, Decapoda, Stenopodidea, Spongicolidae). Zoosystema 2008, 30, 87-147.

13. Goy, J.W. Stenopodidean shrimps (Crustacea: Decapoda) from New Caledonian waters. Zootaxa 2015, 4044, 301-344. [CrossRef] [PubMed]

14. Saito, T.; Anker, A. Two new species and new records of Microprosthema Stimpson, 1860 (Crustacea: Decapoda: Stenopodidea: Spongicolidae) from the Indo-West Pacific. Zootaxa 2014, 3857, 24. [CrossRef]

15. Calado, R. Marine Ornamental Shrimp: Biology, Aquaculture and Conservation; Wiley-Blackwell: Hoboken, NJ, USA, 2008.

16. Saito, T.; Takeda, M. Phylogeny of the family Spongicolidae (Crustacea: Stenopodidea): Evolutionary trend from shallow-water free-living to deep-water sponge-associated habitat. J. Mar. Biol. Assoc. UK 2003, 83, 119-131. [CrossRef]

17. Chen, C.-L.; Goy, J.W.; Bracken-Grissom, H.D.; Felder, D.L.; Tsang, L.M.; Chan, T.-Y. Phylogeny of Stenopodidea (Crustacea : Decapoda) shrimps inferred from nuclear and mitochondrial genes reveals non-monophyly of the families Spongicolidae and Stenopididae and most of their composite genera. Invertebr. Syst. 2016, 30, 479-490. [CrossRef]

18. Hansen, H.J. Crustacea Malacostraca, I. Dan. Ingolf Exped. 1908, 3, 1-120.

19. Davie, P.J.F. Crustacea: Malacostraca: Phyllocarida, Hoplocarida, Eucarida (Part 1); CSIRO Publishing: Melbourne, Australia, 2002; Volume 19.3A, p. 551.

20. Baba, K. A new stenopodidean shrimp (Decapoda, Natantia) from the Chatham Rise, New Zealand. Pac. Sci. 1979, 33, $311-314$.

21. Bruce, A.J.; Baba, K. Spongiocaris, a new genus of stenopodidean shrimp from New Zealand and South African waters, with a description of two new species (Decapoda, Natantia, Stenopodidea). Crustaceana 1973, 25, 153-170. [CrossRef]

22. Yaldwyn, J.C. Records of, and observations on, the coral shrimp genus Stenopus in Australia, New Zealand and the south-west Pacific. Aust. Zool. 1968, 14, 277-289.

23. Olivier, A.G. Suite de l'Introduction à l'Histoire Naturelle des Insectes. Palèmon. In Encyclopédie Méthodique. Histoire Naturelle. Insectes, Volume 8; Olivier, A.G., Ed.; H. Agasse, Imprimeur-Libraire: Paris, France, 1811; pp. 656-670.

24. Charting Around New Zealand (CANZ) Group. New Zealand Region Bathymetry, 1:4 000 000, 2nd Edition. In NIWA Miscellaneous Chart Series No. 85; NIWA: Auckland, New Zealand, 2008.

25. Folmer, O.; Black, M.; Hoeh, W.; Lutz, R.; Vrijenhoek, R. DNA primers for amplification of mitochondrial cytochrome c oxidase subunit I from diverse metazoan invertebrates. Mol. Mar. Biol. Biotechnol. 1994, 3, 294-299.

26. Palumbi, S.R.; Benzie, J. Large mitochondrial DNA differences between morphologically similar Penaeid shrimp. Mol. Mar. Biol. Biotechnol. 1991, 1, 27-34. [PubMed]

27. Katoh, K.; Rozewicki, J.; Yamada, K.D. MAFFT online service: Multiple sequence alignment, interactive sequence choice and visualization. Brief. Bioinform. 2019, 20, 1160-1166. [CrossRef]

28. Tamura, K.; Stecher, G.; Peterson, D.; Filipski, A.; Kumar, S. MEGA6: Molecular evolutionary genetics analysis version 6.0. Mol. Biol. Evol. 2013, 30, 2725-2729. [CrossRef] [PubMed] 
29. Kalyaanamoorthy, S.; Minh, B.Q.; Wong, T.K.F.; von Haeseler, A.; Jermiin, L.S. ModelFinder: Fast model selection for accurate phylogenetic estimates. Nat. Methods 2017, 14, 587-589. [CrossRef]

30. Nguyen, L.T.; Schmidt, H.A.; von Haeseler, A.; Minh, B.Q. IQ-TREE: A fast and effective stochastic algorithm for estimating maximum likelihood phylogenies. Mol. Biol. Evol. 2015, 32, 268-274. [CrossRef]

31. Anisimova, M.; Gil, M.; Dufayard, J.F.; Dessimoz, C.; Gascuel, O. Survey of branch support methods demonstrates accuracy, power, and robustness of fast likelihood-based approximation schemes. Syst. Biol. 2011, 60, 685-699. [CrossRef]

32. Guindon, S.; Dufayard, J.F.; Lefort, V.; Anisimova, M.; Hordijk, W.; Gascuel, O. New Algorithms and Methods to Estimate Maximum-Likelihood Phylogenies: Assessing the Performance of PhyML 3.0. Syst. Biol. 2010, 59, 307-321. [CrossRef]

33. Hoang, D.T.; Chernomor, O.; von Haeseler, A.; Minh, B.Q.; Vinh, L.S. UFBoot2: Improving the ultrafast bootstrap approximation. Mol. Biol. Evol. 2018, 35, 518-522. [CrossRef] [PubMed]

34. Rambaut, A. FigTree 1.4.3. Available online: http://tree.bio.ed.ac.uk/software/figtree (accessed on 5 November 2020).

35. Kou, Q.; Gong, L.; Li, X. A new species of the deep-sea spongicolid genus Spongicoloides (Crustacea, Decapoda, Stenopodidea) and a new species of the glass sponge genus Corbitella (Hexactinellida, Lyssacinosida, Euplectellidae) from a seamount near the Mariana Trench, with a novel commensal relationship between the two genera. Deep Sea Res. Part I 2018, 135, 88-107. [CrossRef]

36. Xu, P.; Zhou, Y.; Wang, C. A new species of deep-sea sponge-associated shrimp from the North-West Pacific (Decapoda, Stenopodidea, Spongicolidae). ZooKeys 2017, 685. [CrossRef] [PubMed]

37. Sun, S.; Sha, Z.; Wang, Y. Complete mitochondrial genome of the first deep-sea spongicolid shrimp Spongiocaris panglao (Decapoda: Stenopodidea): Novel gene arrangement and the phylogenetic position and origin of Stenopodidea. Gene 2018, 676, 123-138. [CrossRef] [PubMed]

38. Mantelatto, F.L.; Terossi, M.; Negri, M.; Buranelli, R.C.; Robles, R.; Magalhaes, T.; Tamburus, A.F.; Rossi, N.; Miyazaki, M.J. DNA sequence database as a tool to identify decapod crustaceans on the São Paulo coastline. Mitochondrial DNA Part A 2018, 29, 805-815. [CrossRef] [PubMed]

39. Latreille, P.A. Histoire Naturelle, Générale et Particulière des Crustacés et des Insectes. Ouvrage Faisant Suite à L'histoire Naturelle Générale et Particulière, Composée par Leclerc de Buffon, et Rédigée par C.S. Sonnini, Membre de Plusieurs Sociétés Savantes; L'Imprimerie de F. Dufart: Paris, France, 1802; Volume 3, p. 476.

40. Schram, F.R. Crustacea; Oxford University Press: New York, NY, USA, 1986.

41. De Haan, W. Crustacea. In Fauna Japonica Sive Descriptio Animalium, Quae in Itinere per Japoniam, Jussu et Auspiciis Superiorum, Qui Summum in India Batava Imperium Tenent, Suspecto, Annis 1823-1830 Collegit, Notis, Observationibus et Adumbrationibus Illustravit; von Siebold, P.F., Ed.; Lugduni-Batavorum: Leiden, The Netherlands, 1833; pp. 1-243.

42. De Grave, S.; Fransen, C.H.J.M. Carideorum catalogus: The recent species of the dendrobranchiate, stenopodidean, procarididean and caridean shrimps (Crustacea: Decapoda). Zool. Meded. Leiden 2011, 89, 195-589.

43. Lévi, C.; Lévi, P. Spongiaires Hexactinellides du Pacifique Sud-Ouest (Nouvelle-Calédonie). Bull. Mus. Natl. D’histoire Nat. 1982, 4, 283-317.

44. Schulze, F.E. Über den Bau und das System der Hexactinelliden. Abh. Königlichen Akad. Wiss. Berl. Phys. Math. Cl. 1886, 1-97.

45. Alcock, A. A Descriptive Catalogue of the Indian Deep-Sea Crustacea Decapoda Macrura and Anomala, in the Indian Museum. Being a Revised Account of the Deep-Sea Species Collected by the Royal Indian Marine Survey Ship Investigator; Trustees of the Indian Museum: Calcutta, India, 1901; p. 286.

46. Ijima, I. Notice of New Hexactinellida from Sagami Bay. Zool. Anz. 1896, 19, 249-254.

47. Reiswig, H.M.; Kelly, M. The marine fauna of New Zealand: Euplectellid glass sponges (Hexactinellida, Lyssacinosida, Euplectellidae). NIWA Biodivers. Mem. 2018, 130, 1-170.

48. Saito, T.; Tsuchida, S.; Yamamoto, T. Spongicoloides iheyaensis, a new species of deep-sea sponge-associated shrimp from the Iheya Ridge, Ryukyu Islands, Southern Japan (Decapoda: Stenopodidea: Spongicolidae). J. Crustac. Biol. 2006, 26, 224-233. [CrossRef]

49. Goy, J.W. Spongicoloides galapagensis, a new shrimp representing the first record of the genus from the Pacific Ocean (Crustacea: Decapoda: Stenopodidea). Proc. Biol. Soc. Wash. 1980, 93, 760-770.

50. Baba, K. Spongicoloides hawaiiensis, a new species of shrimp (Decapoda: Stenopodidea) from the Hawaiian Islands. J. Crustac. Biol. 1983, 3, 477-481. [CrossRef]

51. Burukosvsky, R.N. A description of the shrimp Spongicoloides tabachnicki (Decapoda, Spongicolidae) from the glass sponge Euplectella jovis. Zool. Zhurnal 2009, 88, 498-503. (In Russian)

52. Saito, T.; Okuno, J.; Chan, T. A new species of Stenopus (Crustacea: Decapoda: Stenopodidae) from the Indo-west Pacific, with a redefinition of the genus. Raffles Bull. Zool. Suppl. 2009, 20, 109-120.

53. Ahyong, S.T. Decapod crustacea of the Kermadec Biodiscovery Expedition 2011. In Kermadec Biodiscovery Expedition 2011; Trnski, T., Schlumpf, A., Eds.; Auckland Museum: Auckland, New Zealand, 2015; Volume 20, pp. 406-442.

54. Schnabel, K.E. The Marine Fauna of New Zealand. Squat lobsters (Crustacea: Decapoda: Chirostyloidea). NIWA Biodivers. Mem. 2020, 132, 1-351.

55. Claus, C. Grundzüge der Zoologie. Zum Gebrauche an Universitäten und Höheren Lehranstalten sowie zum Selbststudium (Zweite Vermehrte Auflage); N.G. Elwert'sche Universitäts-Buchshandlung: Marburg/Leipzig, Germany, 1872; p. 1170.

56. Latreille, P.A. Salicoques, Carides, Latr. Nouv. Dict. D'histoire Nat. 1819, 30, 68-73.

57. Holthuis, L.B. Biological results of the Snellius expedition. XIV. The Stenopodidae, Nephropsidae, Scyllaridae and Palinuridae. Temminckia 1946, 7, 1-178. 
58. Doak, W.T. Beneath New Zealand Seas; Reed: Wellington, New Zealand, 1971; p. 112.

59. Yaldwyn, J.C. Shrimps and prawns. N. Z. Nat. Herit. 1974, 38, 1041-1046.

60. De Saint Laurent, M.; Cleva, R. Crustacés Décapodes: Stenopodidea. In Résultats des Campagnes MUSORSTOM: I. Philippines (18-28 Mars 1976). Série A, Zoologie; Forest, J., Ed.; Mémoires du Muséum National d’Histoire Naturelle: Paris, France, 1981; Volume 91, pp. 151-188.

61. Goy, J.W. A new species of Stenopus from Australia, with a redescription of Stenopus cyanoscelis (Crustacea: Decapoda: Stenopodidae). J. Nat. Hist. Lond. 1992, 26, 79-102. [CrossRef]

62. Poore, G.C.B. Marine Decapod Crustacea of Southern Australia. A Guide to Identification (with Chapter on Stomatopoda by Shane Ahyong); CSIRO Publishing: Melbourne, Australia, 2004; p. 574.

63. Yaldwyn, J.C.; Webber, R. Annotated checklist of New Zealand Decapoda (Arthropoda: Crustacea). Tuhinga 2011, 22, 171-272.

64. Webber, W.R.; Fenwick, G.D.; Bradford-Grieve, J.M.; Eagar, S.H.; Buckeridge, J.S.; Poore, G.C.B.; Dawson, E.W.; Watling, L.; Jones, B.; Wells, J.B.J.; et al. Subphylum Crustacea-Shrimps, crabs, lobsters, barnacles, slaters, and kin. In New Zealand Inventory of Biodiversity Volume 2. Chaetognatha, Ecdysozoa, Ichnofossils; Gordon, D.P., Ed.; Canterbury University Press: Christchurch, New Zealand, 2010; Volume 2, pp. 98-232.

65. Williams, A.B. Shrimps, Lobsters, and Crabs of the Atlantic Coast of the Eastern United States, Maine to Florida; Smithsonian Institution Press: Wasington, DC, USA, 1984; p. 550.

66. Manning, R.B.; Chace, F.A.J. Decapod and Stomatopod Crustacea from Ascension Island, South Atlantic Ocean. Smithson. Contrib. Zool. 1990, 503, 1-91. [CrossRef]

67. Goy, J.W. Microprosthema emmiltum, new species, and other records of stenopodidean shrimps from the Eastern Pacific (Crustacea: Decapoda). Proc. Biol. Soc. Wash. 1987, 100, 717-725.

68. Risso, A. Histoire Naturelle des Principales Productions de l'Europe Méridionale et Particulièrement de Celles des Environs de Nice et des Alpes Maritimes; F.G. Levrault: Paris, France, 1826. [CrossRef]

69. De Man, J.G. Bericht ueber die von Herrn Dr. J. Brock im indischen Archipel gesammelten Decapoden und Stomatopoden. Arch. Naturges 1888, 53, 215-600. [CrossRef]

70. Goy, J.W. Diagnosis of three new Stenopus species. In Armoured Knights of the Sea; Debelius, H., Ed.; Alfred Kernen Verlag: Essen, Germany, 1984; pp. 116-117.

71. Wainwright, B.J.; Arlyza, I.S.; Karl, S.A. Population genetics of the banded coral shrimp, Stenopus hispidus (Olivier, 1811), in the Indonesian archipelago. J. Exp. Mar. Biol. Ecol. 2020, 525, 151325. [CrossRef]

72. Dudoit, A.A.; Iacchei, M.; Coleman, R.R.; Gaither, M.R.; Browne, W.E.; Bowen, B.W.; Toonen, R.J. The little shrimp that could: Phylogeography of the circumtropical Stenopus hispidus (Crustacea: Decapoda), reveals divergent Atlantic and Pacific lineages. PeerJ 2018, 6, e4409. [CrossRef]

73. Bracken-Grissom, H.D.; Felder, D.L.; Vollmer, N.L.; Martin, J.W.; Crandall, K.A. Phylogenetics links monster larva to deep-sea shrimp. Ecol. Evol. 2012, 2, 2367-2373. [CrossRef] [PubMed]

74. Alcock, A.; Anderson, A.R.S. Natural history notes from H.M. Royal Indian Marine Survey Steamer "Investigator", commander C.F. Oldham, R.N., commanding.-Series II, No. 14. An account of a recent collection of deep-sea Crustacea from the Bay of Bengal and Laccadive Sea. J. Asiat. Soc. Bengal Nat. Hist. 1894, 63, 141-185.

75. Holthuis, L.B. The Decapoda of the Siboga Expedition. Part XI. The Palaemonidae collected by the Siboga and Snellius Expeditions, with remarks on other Species. II. Subfamily Pontoniinae. Siboga Exped. 1952, 39, 1-253.

76. Oken, L. Lehrbuch der Naturgeschichte. Dritter Theil: Zoologie. Erste Abtheilung: Fleischlose Thiere; C.H. Reclam \& Jena: A. Schmid: Leipzig, Germany, 1815; p. 842.

77. Bruce, A.J. Notes on some Indo-West Pacific Pontoniinae. XL. The rediscovery of Periclimenes lifuensis Borradaile, 1898 (Decapoda, Pontoniine) and the establishment of its systematic position. Crustaceana 1982, 42, 158-173. [CrossRef]

78. Marin, I.; Anker, A. A partial revision of the Philarius gerlachei (Nobili, 1905) species complex, with description of four new species from the Indo-West Pacific. Zootaxa 2011, 2781, 1-28. [CrossRef]

79. Mitsuhashi, M. A new species of the genus Philarius (Crustacea: Decapoda: Palaemonidae) from Ryukyu Islands, Japan. Zootaxa 2012, 3481, 82-88. [CrossRef]

80. Kou, Q.; Li, X. A new palaemonid shrimp of the "Philarius gerlachei (Nobili, 1905) species complex" (Crustacea: Decapoda: Palaemonidae) from Hainan Island, South China Sea. Raffles Bull. Zool. 2016, 64, 269-277.

81. Rathbun, M.J. Investigations of the Aquatic Resources and Fisheries of Porto Rico by the United States Fish Commission Steamer Fish Hawk in 1899. The Brachyura and Macrura of Porto Rico. Bull. U. S. Fish Comm. 1901, 20, 1-127.

82. Hurt, C.; Silliman, K.; Anker, A.; Knowlton, N. Ecological speciation in anemone-associated snapping shrimps (Alpheus armatus species complex). Mol. Ecol. 2013, 22, 4532-4548. [CrossRef]

83. Bruce, A.J.; Chace, F.A.J. Paralebbeus zotheculatus, n. gen, n sp., a new hippolytid shrimp from the Australian northwest shelf. Proc. Biol. Soc. Wash. 1986, 99, 237-247.

84. Gray, J.E. Notes on the Arrangement of Sponges, with the Descriptions of some New Genera. Proc. Zool. Soc. Lond. 1867, 1867, 492-558.

85. Gray, J.E. Notes on the Classification of the Sponges. Ann. Mag. Nat. Hist. 1872, 9, 442-461. [CrossRef] 
86. Chace, F.A.J. The caridean shrimps (Crustacea: Decapoda) of the Albatross Philippine expedition, 1907-1910, Part 7: Families Atyidae, Eugonatonotidae, Rhynchocinetidae, Bathypalaemonellidae, Processidae and Hippolytidae. Smithson. Contrib. Zool. 1997, 587, 1-106.

87. Xu, P.; Liu, F.; Ding, Z.; Wang, C. A new species of the thorid genus Paralebbeus Bruce \& Chace, 1986 (Crustacea: Decapoda: Caridea) from the deep sea of the Northwestern Pacific Ocean. Zootaxa 2016, 4085, 119-126. [CrossRef] [PubMed]

88. Kou, Q.; Xu, P.; Poore, G.C.B.; Li, X.; Wang, C. A New Species of the Deep-Sea Sponge-Associated Genus Eiconaxius (Crustacea: Decapoda: Axiidae), With New Insights Into the Distribution, Speciation, and Mitogenomic Phylogeny of Axiidean Shrimps. Front. Mar. Sci. 2020, 7, 469. [CrossRef]

89. Schupp, P.J.; Rohde, S.; Versluis, D.; Petersen, L.-E.; Clemens, T.; Conrad, K.P.; Mills, S.; Kelly, M. Section 7.14. Investigations on the biodiversity of benthic sponge and invertebrate communities and their associated microbiome. In Functional Diversity of Bacterial Communities and the Metabolome in the Water Column, Sediment and in Sponges in the Southwest Pacific around New Zealand RV SONNE SO254 Cruise Report/Fahrtbericht; Simon, M., Ed.; University of Oldenburg: Oldenburg, Germany, 2017 ; pp. 57-59. 